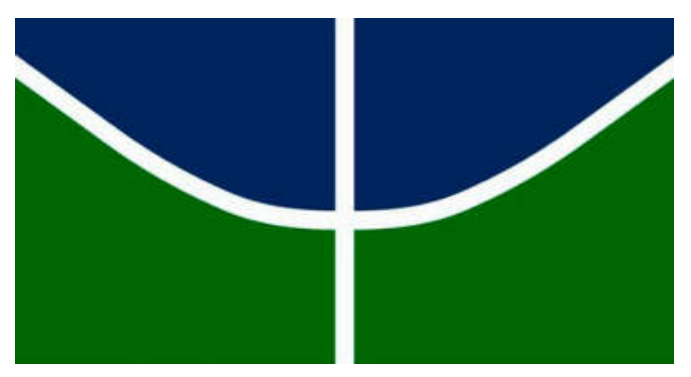

Programa de Pós-Graduação em Zoologia

Departamento de Zoologia

Instituto de Ciências Biológicas

Universidade de Brasília

SISTEMÁTICA DO GÊNERO LANTHANOMELISSA HOLMBERG

(HYMENOPTERA, APIDAE: TAPINOTASPIDINI)

HANNA HEID SOARES DE SOUZA

Brasília, 2017 


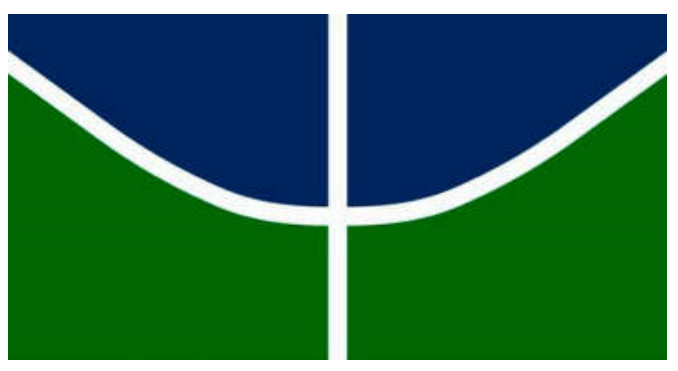

Programa de Pós-Graduação em Zoologia

Departamento de Zoologia

Instituto de Ciências Biológicas

Universidade de Brasília

\section{SISTEMÁTICA DO GÊNERO LANTHANOMELISSA HOLMBERG (HYMENOPTERA, APIDAE: TAPINOTASPIDINI)}

HANNA HEID SOARES DE SOUZA

Dissertação de Mestrado apresentada ao Programa de Pós-Graduação em Zoologia da Universidade de Brasília, como requisito para obtenção do título de Mestre em Zoologia.

Orientador: Prof. Dr. Antonio J. C. de Aguiar 
Dedico essa dissertação à minha filha Savannah Soares Manigat. 


\section{AGRADECIMENTOS}

Ao meu orientador Prof. Dr. Antonio José Camillo de Aguiar pela orientação oferecida e disponibilidade no desenvolvimento do trabalho.

À Universidade de Brasília (UnB) e ao programa de pós-graduação em Zoologia pela oportunidade oferecida.

À FAPDF pela bolsa concedida e auxílio financeiro (Projeto Demanda Espontânea 2015, processo: 193.000.893/2015).

Aos curadores das coleções listadas no "Material e Métodos" pelo empréstimo do material para estudo. Um agradecimento em especial à Dra. Betina Blochtein da Pontifícia Universidade Católica do Rio Grande do Sul, à Dra. Aline Barcellos da Fundação Zoobotânica do Rio Grande do Sul, à Dra. Birgit Harter Marques da Universidade do Extremo Sul Catarinense e aos professores Doutores Gabriel Melo e Danúncia Urban da Universidade Federal do Paraná pela cordialidade ao cederem seus materiais para estudo. Obrigada!

Ao meu namorado Donald Manigat por todo o apoio, incentivo e carinho. Te amo.

À minha filha Savannah por sempre ter me possibilitado enxergar a luz no final do túnel.

Agradeço à minha família pela paciência, apoio e ajuda financeira nas viagens e no primeiro ano sem bolsa.

Um grande obrigada a minha amiga e companheira de laboratório Taís Ribeiro pela amizade, pelos momentos de alegria, pelos bolos gostosos, pelo "coffee break", e principalmente pela disposição em sempre querer ajudar e criticar construtivamente. Obrigada pela imensa ajuda ao longo desses dois anos! Com certeza esse mestrado colocou uma grande amiga em minha vida!

Um obrigada em especial a Dra. Aline Martins por ter se oferecido para me ajudar na organização e formatação do texto, assim como na leitura da dissertação.

Ao colega Msc. André Martins da Universidade Federal do Paraná por ter se prontificado à tirar as fotos dos holótipos de Lanthanomelissa. 
E por final, agradeço a todos aqueles de alguma forma auxiliaram ou me acompanharam durante esses dois anos de caminhada.

\section{Obrigada!}




\section{SUMÁRIO}

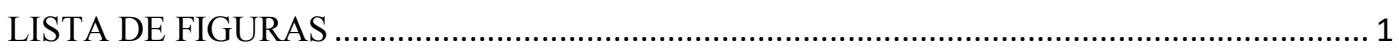

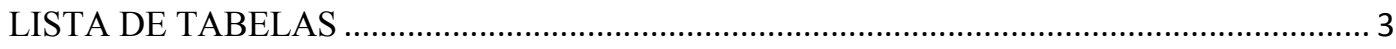

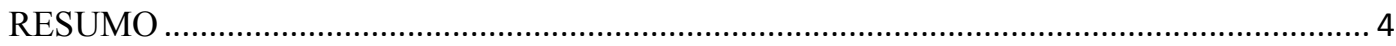

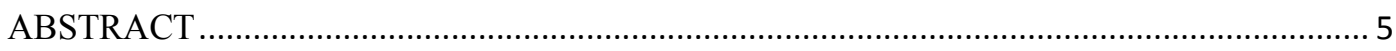

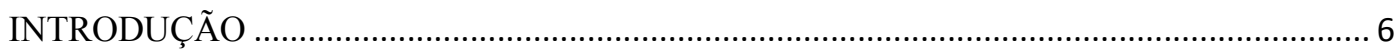

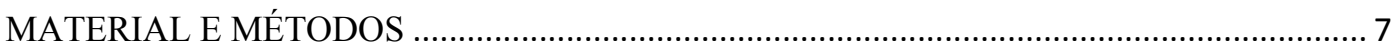

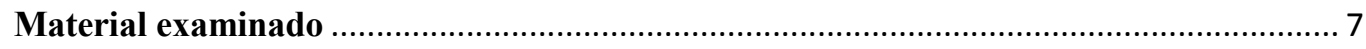

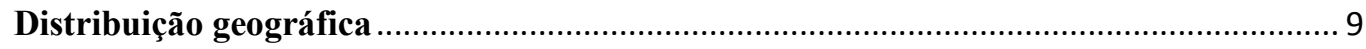

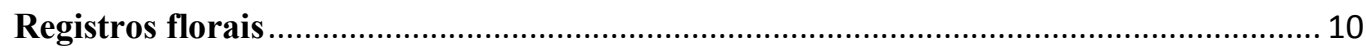

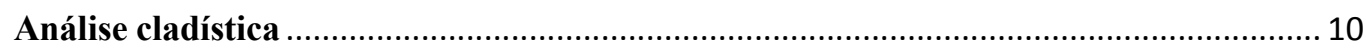

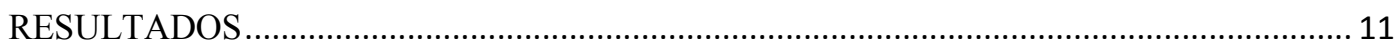

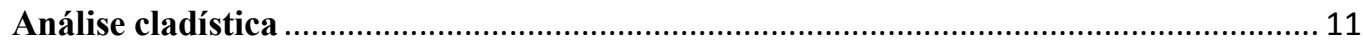

Grupo Chalepogenus goeldianus + [ Lanthanomelissa + Chalepogenus parvus] $] \ldots \ldots \ldots \ldots . . . .19$

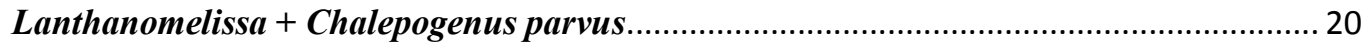

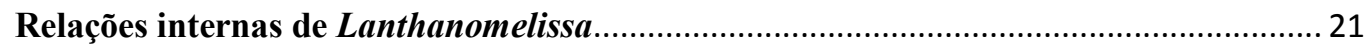

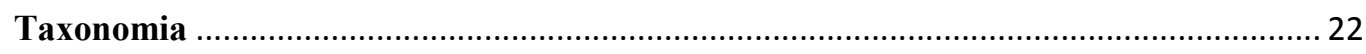

Chave para as espécies de Lanthanomelissa (machos) ................................................... 27

Chave para as espécies de Lanthanomelissa (fêmeas) ……………………………......... 28

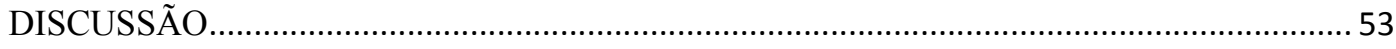

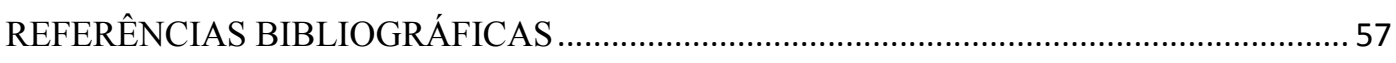

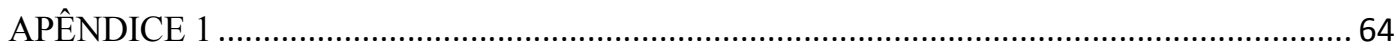

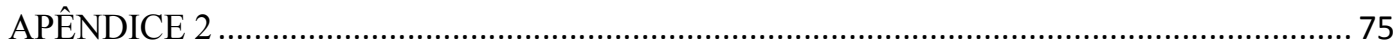




\section{LISTA DE FIGURAS}

Figura 1. Única árvore obtida através da busca exaustiva para as relações filogenéticas entre as espécies do gênero Lanthanomelissa e seus grupos externos, com otimização acelerada (L.123, IC.70, IR 70). Legenda: círculos pretos = mudanças sinapomórficas, círculos brancos $=$ mudanças homoplásticas.

Figura 2. Lanthanomelissa, hábito lateral: a. Lanthanomelissa betinae Urban (holótipo); b. Lanthanomelissa pampicola Urban (holótipo); c. Lanthanomelissa discrepans (fêmea; DZUP; Argentina, Corrientes, Ituzaingo, Fritz col.; A. Roig-Alsina det., comparado com o lectótipo); d. $\begin{array}{lllll}\text { Lanthanomelissa } & \text { clementis } & \text { Urban } & \text { (holótipo); } & \text { escala }\end{array}$ $\mathrm{mm}$

Figura 3. Esternos, machos: a. Lanthanomelissa betinae Urban (DZUP, Brasil, Paraná, Araucária); b. Lanthanomelissa pampicola Urban (holótipo); c. Lanthanomelissa clementis Urban (holótipo); d. Lanthanomelissa magaliae Urban (holótipo); e. Lanthanomelissa discrepans Holmberg (DZUP, Brasil, Rio Grande do Sul, Canguçu); f. Lanthanomelissa parva (Roig-Alsina) (Argentina, Córdoba, Dean Funes). 26

Figura 4. Lanthanomelissa betinae Urban; a. face, macho (holótipo); b. face, fêmea (parátipo, Brasil, Rio Grande do Sul, Gramado); c. cabeça e metassoma lateral (holótipo); d. metassoma dorsal (holótipo) 32

Figura 5. Terminália interna do macho de Lanthanomelissa betinae; a. visão dorsal da cápsula genital; b.visão ventral da cápsula genital; c. visão dorsal de E7; d. visão dorsal de E8 .33

Figura 6. Lanthanomelissa clementis Urban; a. face, macho (holótipo); b. face, fêmea (parátipo, Brasil, Rio Grande do Sul, Guaíba); c. cabeça e metassoma lateral (holótipo); d. metassoma dorsal (holótipo)

Figura 7. Terminália interna do macho de Lanthanomelissa clementis; a. visão dorsal da cápsula genital; b. visão ventral da cápsula genital; c. visão dorsal de E7; d. visão dorsal de E8. .37

Figura 8. Lanthanomelissa discrepans Holmberg; a. face, macho (DZUP; Argentina, Corrientes, Ituzaingo); b. face, fêmea (DZUP; Argentina, Corrientes, Ituzaingo, Fritz col.; A. Roig-Alsina det., comparado com o lectótipo); c. metassoma, macho (DZUP; Brasil, Rio Grande do Sul, Bagé, Casa de Pedra, C. Schlindwein col., D. Urban det.); c. metassoma, macho 


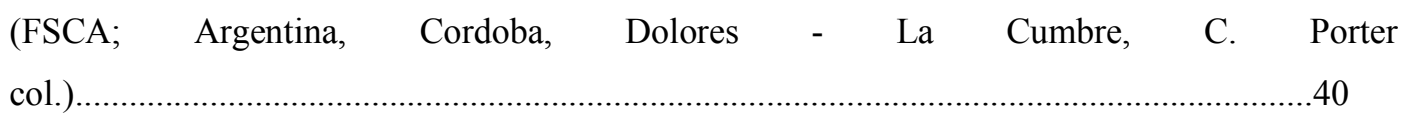

Figura 9. Terminália interna do macho de Lanthanomelissa discrepans; a. visão dorsal da cápsula genital; b. visão ventral da cápsula genital; c. visão dorsal de E7; d. visão dorsal de E8

Figura 10. Lanthanomelissa magaliae Urban; a. face, macho (holótipo); b. face, fêmea (DZUP, Brasil, Rio Grande do Sul, Viamão, Morro do Coco); c. cabeça e metassoma lateral (holótipo); d. metassoma dorsal (holótipo).

Figura 11. Terminália interna do macho de Lanthanomelissa magaliae; a. visão dorsal da cápsula genital; b. visão ventral da cápsula genital; c. visão dorsal de E7; d. visão dorsal de E8 .45

Figura 12. Lanthanomelissa pampicola Urban; a. face, macho (holótipo); b. face, fêmea (parátipo, Brasil, Rio Grande do Sul, Guaritas); c. cabeça e mesossoma lateral (holótipo); d. metassoma dorsal (holótipo)

Figura 13. Terminália interna do macho de Lanthanomelissa pampicola; a. visão dorsal da cápsula genital; b. visão ventral da cápsula genital; c. visão dorsal de E7; d. visão dorsal de E8. .48

Figura 14. Lanthanomelissa parva (Roig-Alsina); a. face, macho; b. face, fêmea; c. macho, lateral; d. fêmea, lateral (Argentina, Córdoba, Dean Funes).

Figura 15. Mapa de distribuição biogeográfica das espécies L. betinae, L. magaliae e L. parva de acordo com o gradiente de altitude

Figura 16. Mapa de distribuição biogeográfica das espécies L. clementis, $L$. discrepans e $L$. pampicola de acordo com o gradiente de altitude.

Figura 17. Mapa de distribuição das espécies L. betinae, L. magaliae e L. parva de acordo com a regionalização biogeográfica de Morrone (2014).

Figura 18. Mapa de distribuição das espécies L. clementis, L. discrepans e L. pampicola de acordo com a regionalização biogeográfica de Morrone (2014). .52 


\section{LISTA DE TABELAS}

Tabela 1. Matriz de estados de caracteres para análise cladística de Lanthanomelissa e espécies

do grupo externo. Legenda: "?" = condição variável ou

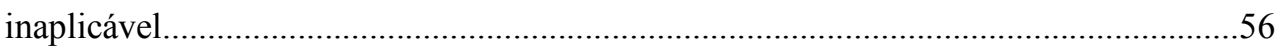




\section{RESUMO}

O gênero Lanthanomelissa Holmberg, 1903 é representado por abelhas pequenas com distribuição restrita as áreas de campos do sul e sudeste do Brasil, do Paraguai e da Argentina. Descrito por Holmberg em 1903, o grupo apresenta diferentes propostas de classificação e a taxonomia de suas espécies foi estabelecida com base em um pequeno número de espécimes com distribuição restrita. O presente trabalho teve como objetivos revisar as espécies de Lanthanomelissa, testar o monofiletismo do gênero, avaliar as relações com outros gêneros da tribo Tapinotaspidini e avaliar sua distribuição geográfica. Para o estudo foram visitadas coleções no Brasil, Argentina e Estados Unidos, assim como adquirido material via empréstimo. Foram examinados 381 espécimes do gênero Lanthanomelissa, incluindo holótipos e parátipos. Foram utilizados 12 táxons terminais, com sete espécies pertencendo aos grupos externos e cinco ao grupo interno. Setenta e um caracteres foram gerados para a análise filogenética com base na morfologia externa e terminália interna dos machos. Através da busca exaustiva no programa TNT foi obtida uma única árvore em que o monofiletismo do gênero Lanthanomelissa é bem suportado formando um clado diretamente relacionado à espécie Chalepogenus parvus (Roig-Alsina, 1997), e este clado diretamente relacionado à Chalepogenus goeldianus (Friese, 1899). Foram observadas como relações entre as espécies de Lanthanomelissa dois clados, um contendo as espécies $L$. betinae e L. clementis e outro com a espécie L. pampicola diretamente relacionada com às espécies L. discrepans e L. magaliae. Com base neste resultado sugerimos a aloação de $C$. parvus para Lanthanomelissa e a revalidação do gênero Lanthanella Michener e Moure 1957 formando as seguintes novas combinações: Lanthanomelissa parva comb.nov., Lanthanella goeldiana, Lanthanella neffi comb.nov. e Lanthanella luciane. A interpretação dos mapas das espécies sugere que a distribuição do gênero esteja concentrada dentro da subregião Chacoana, entre altitudes de 0 a 1000 metros. Aparentemente algumas espécies tem distribuição preferencial nas áreas de altitude acima de 400 metros na Floresta de Araucárias e em áreas de transição, enquanto outras apresentam distribuição preferencial na Província dos Pampas em áreas baixas.

Palavras-chaves: Óleo floral, Morfologia, Regiao Neotropical, Taxonomia, Filogenia. 


\section{ABSTRACT}

The genus Lanthanomelissa Holmberg, 1903 is represented by small-sized bees with restricted distribution in areas of grassland vegetation of the Southeast and South of Brazil, Paraguay and Argentina. Described by Holmberg in 1903, the group presents different proposals of classification and the taxonomy of its species was established based on a small number of specimens with restricted distribution. The present paper objectives were to review Lanthanomelissa species, to test the monophyletism of the genus, to evaluate the relations with other genus of the Tapinotaspidini tribe and to evaluate its geographical distribution. For the study some collections in Brazil, Argentina and United States of America were visited and some materials borrowed. A total of 381 specimens of all Lanthanomelissa species were studied including the holotypes and the paratypes. Twelve terminal taxa were used with 7 species belonging to the outgroups and 5 to the ingroup. Seventy-one characters were used for the

phylogenetic analysis based on the external morphology and male terminalia.Through an exhaustive search in the TNT program a single tree was obtained and it shows that the monophyletism of the genus Lanthanomelissa is well supported, forming a clade as the sister group of the species Chalepogenus parvus (Roig-Alsina, 1997) and this clade directly related to Chalepogenus goeldianus (Friese, 1899). Between the internal Lanthanomelissa relations it can be observed that the genus have two clades, one with the species L. betinae and L. clementis and another one with the species L. pampicola directly related to the species $L$. discrepans and L. magaliae. Based on this result we suggest here the allocation of the species Chalepogenus parvus to the genus Lanthanomelissa and the revalidation of the genus Lanthanella Michener \& Moure 1957 in order to form the following new combinations: Lanthanomelissa parva comb. nov., Lanthanella goeldiana, Lanthanella neffi comb.nov and Lanthanella luciane. The interpretation of the maps suggests that the genus distribution is concentrated inside the Chacoan subregion, bellow 1000 altitude meters high. Apparently some species have preferential distribution in areas of 400 meters high in Araucaria Forest and in transitional areas and others show preferential distribution in the Pampas Province in lowland areas.

Keywords: Floral Oil, Morphology, Neotropical Region, Taxonomy, Phylogeny. 


\section{INTRODUÇÃO}

As espécies de abelhas do gênero Lanthanomelissa Holmberg, 1903 (Hymenoptera, Apidae) apresentam distribuição restrita as regiões Sudeste e Sul do Brasil, abrangendo desde o estado de São Paulo até o Rio Grande do Sul, e regiões do Paraguai e da Argentina (Michener \& Moure 1957, Urban 1995, Michener 2007). Todas espécies do gênero dependem da coleta de óleo em flores de Sisyrinchium L., Iridaceae (Cocucci et al. 2000, Cocucci \& Vogel 2001, Rozen et. al. 2006, Alves-dos-Santos et al. 2007). Os ninhos de Lanthanomelissa são solitários no solo, em áreas planas ou em barrancos de leve declive, e são parasitados por abelhas do gênero Paraepeolus (Sakagami \& Laroca 1988, Rozen et al. 2006).

O gênero Lanthanomelissa foi descrito por Holmberg (1903) com base em espécimes coletados na Argentina (província de Buenos Aires, Chacabuco). Em sua descrição, o autor enfatizou a cor amarela presente no escapo, labro, clípeo e nos tergos metassomais. Somente muito posteriormente, Michener e Moure (1957) apresentaram uma diagnose para o gênero juntamente com a proposta da divisão do mesmo em dois subgêneros: Lanthanomelissa (Lanthanomelissa) e Lanthanomelissa (Lanthanella) Michener e Moure, 1957. Os dois subgêneros diferenciavam-se entre si principalmente pela presença de apenas duas células submarginais em Lanthanomelissa sensu stricto e três células submarginais em Lanthanomelissa (Lanthanella) e pelo formato do basitarso anterior, este plano a levemente côncavo no primeiro subgênero e convexo no segundo. Apesar desta divisão, Moure expõe no trabalho sua preferência pelo tratamento em nível de gênero para esses grupos tratados como subgêneros, opinião que é formalmente exposta em Moure (1993).

O trabalho taxonômico mais relevante para Lanthanomelissa foi o publicado por Urban (1995), em que são descritas quatro novas espécies de Lanthanomelissa e uma nova espécie de Lanthanella, a partir de material coletado principalmente no Rio Grande do Sul nas localidades de Porto Alegre, Viamão e Caçapava do Sul.

$\mathrm{Na}$ análise filogenética para a tribo Tapinotaspidini (Roig-Alsina 1997) foram incluídas as espécies Lanthanomelissa discrepans Holmberg, 1903 e Chalepogenus goeldianus Friese, 1899. Neste trabalho é designado o lectótipo de L. discrepans, apesar da condição extremamente precária do mesmo em que faltava a maior parte do corpo. 
$\mathrm{Na}$ análise de Roig-Alsina (1997), Lanthanomelissa discrepans aparece relacionada às espécies Caenonomada bruneri Ashmead, 1899, Tapinotaspis chalybaea Friese, 1899, Tapinotaspis latitarsis Friese, 1899, Tapinotaspoides nigerrima Schrottky, 1909 e Tapinotaspoides tucumana Vachal, 1904.

A partir deste trabalho, Roig-Alsina (1999) apresenta a revisão do gênero Chalepogenus Holmberg, 1903 onde reloca as espécies Lanthanella goeldiana e Lanthanella luciane para Chalepogenus, formando o grupo goeldianus. Duas espécies de Chalepogenus apresentam somente duas células submarginais nas asas anteriores semelhantes a Lanthanomelissa, sendo elas: Chalepogenus bicelluaris Roig-Alsina, 1999 e Chalepogenus parvus Roig-Alsina, 1997. No entanto, apesar dessa condição similar, a espécie C. bicellularis encontra-se inserida dentro do grupo vogeli, enquanto C. parvus não se encontra inserida dentro de nenhum grupo.

Michener $(2000,2007)$ apresenta uma proposta totalmente distinta as anteriores, onde considera que o gênero Chalepogenus seja composto por dois subgêneros: Chalepogenus (Chalepogenus) e Chalepogenus (Lanthanomelissa). De acordo com o autor uma das únicas estruturas para que o gênero Chalepogenus possa ser diferenciado de Lanthanomelissa continua sendo o formato do basitarso anterior e a quantidade de células submarginais nas asas anteriores.

O presente trabalho teve como objetivo revisar as espécies do gênero Lanthanomelissa, testar o monofiletismo do grupo e avaliar suas relações com outros gêneros de Tapinotaspidini.

\section{MATERIAL E MÉTODOS}

\section{Material examinado}

Um total de 381 espécimes de Lanthanomelissa foram estudados. O material examinado é proveniente das instituições e museus listados abaixo, seguido do nome do (a) pesquisador (a) responsável:

AMNH: American Museum of Natural History, Nova Iorque, Nova Iorque, Estados Unidos da América (Dr. Jerome Rozen Jr);

CCS: Coleção Cocucci/ Sersic, Universidade de Córdoba, Córdoba, Argentina (Dr. Andrea Cocucci e Dra. Alicia Sersic); 
DZUP: Coleção de Entomologia Pe. J. S. Moure, Departamento de Zoologia da Universidade Federal do Paraná, Curitiba, Paraná, Brasil (Dr. Gabriel A. R. Melo);

JTP: Coleção Juan Pablo Torretta, Universidade de Agronomia de Buenos Aires, Buenos Aires, Argentina (Dr. Juan Pablo Toretta);

LANUFSC: Laboratório de Abelhas Nativas da Universidade Federal de Santa Catarina, Florianópolis, Santa Catarina, Brasil (Dra. Josefina Steiner);

MCNZ: Museu de Ciências Naturais, Fundação Zoobotânica do Rio Grande do Sul, Porto Alegre, Rio Grande do Sul, Brasil (Dra. Aline Barcellos Prates dos Santos);

MCTP: Museu de Ciências e Tecnologia da Pontifícia Universidade Católica do Rio Grande do Sul, Porto Alegre, Rio Grande do Sul, Brasil (Dra. Betina Blochtein e Dr. Elio Corseuil);

MLP: Museu de La Plata, capital da Província de Buenos Aires, Argentina (Dr. Alberto Abramovich/ Dr. Leopoldo Alvares);

RPSP: Coleção João Maria Franco de Camargo, Departamento de Biologia da Universidade de São Paulo, Ribeirão Preto, São Paulo, Brasil (Dr. Eduardo Almeida);

UNB: Universidade de Brasília, Brasília, Distrito Federal (Dr. Antonio José Camillo de Aguiar);

UFFS: Universidade Federal da Fronteira Sul, Chapecó, Santa Catarina, Brasil (Dra. Mardiore Pinheiro);

UNESC: Coleção Entomológica da Universidade Estadual do Sul Catarinense, Criciúma, Santa Catarina, Brasil (Dra. Birgit Harter-Marques).

As informações contidas nas etiquetas de todos os espécimes estudados foram transcritas na seção "Material tipo" e "Material examinado" (Apêndice 1). O símbolo de barra invertida $(\)$ indica linhas diferentes dentro de uma mesma etiqueta e apóstrofe (') se refere à quebra de linha indicando o final da informação contida na etiqueta. Todo o material examinado foi transferido para uma planilha de dados no programa Excel. Os símbolos de macho e fêmea presentes nas etiquetas foram representados pelas iniciais $\mathrm{M}$ e F respectivamente. 
A morfologia externa foi estudada com uma lupa Leica M125C. A cápsula genital e esternos metassomais (E7 e E8) do macho foram separados do metassoma para o estudo da terminália e inseridos em um tubo tipo eppendorf contendo solução de $\mathrm{KOH}$ $10 \%$ onde ficaram incubados por 24 horas. Após esse período, a genitália e os esternos foram neutralizados com ácido acético diluído em água e transferidos para um recipiente contendo glicerina.

A mensuração dos espécimes foi realizada com a régua micrométrica acoplada na ocular de uma lupa Leica M125C. Todas as mensurações foram dadas em milímetros ou relativas ao diâmetro do segundo flagelômero.

A terminologia segue a proposta por Michener e Moure (1957), Urban (1967), e Michener (2000, 2007), exceto pelo triângulo propodeal que é tratado por metaposnoto (Brothers 1976). A terminologia referente à terminália segue Michener e Moure (1957), Roig-Alsina (1997) e Michener (2000, 2007). São utilizadas as seguintes abreviações: F1 a F11 para indicar os flagelômeros antenais e E1-E8 e T1-T8 para se referir aos esternos e tergos metassomais respectivamente.

A lista catalográfica das espécies de Lanthanomelissa foi atualizada a partir de dados de Aguiar e Melo (2007), englobando os anos de 2007 até o ano final da conclusão desse trabalho, 2017.

A captura das imagens referentes à morfologia externa e terminália interna do macho foi feita por meio de câmera acoplada à lupa Leica M125C, e as fotomontagens foram geradas no software Combine $\mathrm{Z}$ e editadas no Photoshop.

\section{Distribuição geográfica}

A distribuição geográfica das espécies de Lanthanomelissa foi compilada das próprias etiquetas de coleta dos espécimes. Quando não inferidas na etiqueta original, o município foi utilizado como referência para se obter as coordenadas por meio do Google Maps (Google 2016). A conversão das mesmas de GMS para decimais foi feita através de ferramenta online de conversão da Federal Communications Commission (FCC 2016). Os pontos geográficos amostrados e as respectivas coordenadas encontram-se no Apêndice 2. Os mapas de distribuição das espécies foram gerados no programa $\mathrm{R}$ versão 3.3.1(R Core Team 2016), implementado no RStudio versão 0.99.902 (RStudio Team 2015), utilizando-se como base os shapefiles da América do Sul e o mapa altitudinal da América do Sul (US Geological Survey 2017). A distribuição das espécies de Lanthanomelissa também foram sobrepostas a regiões 
biogeográficas propostas por Morrone (2014) utilizando-se dos shapefiles produzidos por Löwenberg-Neto (2014). Os dados geográficos foram manipulados nos pacotes Raster (Hijmans 2014), Sp (Pebesma \& Bivand 2005) e Rgdal (Deckmyn 2016), que foram necessários para ler o arquivo dos shapefiles e as coordenadas inseridas. Também foram utilizados os pacotes Gplot2 (Wickham 2009) para editar parâmetros gráficos gerais e Maps (Richard \& Wilks 2016) para plotar os eixos, além do Rdevices (Bengtsson 2016) para exportar imagens em alta resolução. Dados adicionais de distribuição geográfica das espécies de Lanthanomelissa e Chalepogenus parvus foram obtidos da literatura.

\section{Registros florais}

As informações acerca do registro das plantas visitadas por Lanthanomelissa foram obtidas das etiquetas do material estudado e da literatura.

\section{Análise cladística}

A análise cladística foi realizada com o objetivo de construir as relações filogenéticas existentes entre as espécies e testar o monofiletismo do gênero. A topologia gerada pela análise foi enraizada de acordo com o método de grupo externo (Farris 1982, Nixon \& Carpenter 1993). Para compor o grupo interno foram utilizadas as cinco espécies conhecidas de Lanthanomelissa: L. betinae, L. clementis, L. discrepans, L. magaliae e L. pampicola. Para os grupos externos foram escolhidas espécies de gêneros próximos: Arhysoceble huberi Ducke, 1908, Arhysoceble picta Friese, 1899, Chalepogenus goeldianus Friese, 1899, Chalepogenus muelleri Friese, 1899, Chalepogenus parvus Roig-Alsina, 1997, Trigonopedia ferruginea Friese, 1899 e Trigonopedia sp.

A matriz foi editada no programa Winclada (Nixon 2002) e foi realizada uma busca exaustiva de árvores no programa TNT (Goloboff et al. 2003). Foi selecionada a otimização acelerada ACCTRAN que privilegia as reversões em relação as convergências. A forma de codificação e apresentação dos caracteres segue como apresentado por Sereno (2007). Os caracteres foram propostos com base no estudo da morfologia externa e da terminália do macho sendo todos tratados como não ordenados. 


\section{RESULTADOS}

\section{Análise cladística}

Através do estudo de séries dos espécimes pertencentes aos 12 táxons terminais foram propostos os seguintes 71 caracteres, sendo 55 referentes à morfologia externa e 16 à terminália interna dos machos:

1. Palpômeros labiais, número: (0) 4 - 5; (1) 6.

2. Mandíbula, articulação (Michener \& Moure 1957): (0) na mesma distância do olho; (1) abaixo da margem posterior do olho; (2) atrás da porção média do olho.

3. Labro, cor (fêmeas): (0) preto; (1) amarelo.

Comentário: A espécie T. ferruginea, com labro alaranjado foi codificada como inaplicável (?) entre o que seria o amarelo e o marrom escuro alaranjado quase preto.

4. Labro, disco, pilosidade: (0) plumosa; (1) simples.

5. Clípeo, cor (fêmeas): (0) predominantemente preto; (1) predominantemente amarelo à alaranjado.

Comentário: A espécie L. betinae apresenta a maior parte de seus espécimes com clípeo predominantemente preto, porém foi codificada como variável (?) devido ao fato de ocorrerem alguns espécimes com clípeo predominantemente amarelo. Os espécimes de L. pampicola apresentaram a condição bicolor, geralmente com mancha amarela na forma de letra $\mathrm{W}$, e desta forma essa espécie foi codificada como variável (?).

6. Clípeo, margem superior: (0) convexa; (1) côncava.

7. Área supraclipeal (machos): (0) com nódoa amarela; (1) preta; (2) laranja.

Comentário: As espécies L. clementis e L. pampicola foram codificadas como variáveis (?) por existir variação na cor dessa estrutura.

8. Área supraclipeal (fêmeas): (0) com nódoa amarela; (1) preta; (2) laranja.

Comentário: Por haver variação nessa estrutura entre os espécimes já observados de A. picta, a espécie foi codificada como variável (?). Nas espécies $L$. 
discrepans e L. magaliae também existe variação com relação à coloração dessa estrutura.

9. Área parocular inferior, superfície (machos): (0) encoberta por cerdas plumosas; (1) predominantemente glabra.

Comentário: Em Arhysoceble os pelos estão distribuídos de maneira mais esparsa na superfície do que nas espécies de Lanthanomelissa e Chalepogenus.

10. Área parocular inferior, mancha amarela (fêmeas): (0) ausente; (1) presente.

11. Área parocular inferior, mancha amarela (machos): (0) presente; (1) ausente. Comentário: As espécies L. betinae e L. clementis foram codificadas como estado variável (?) devido ao fato de apresentarem na maior parte dos seus espécimes a condição ausente. Porém três espécimes de L. clementis da coleção DZUP (Itambé, PR) apresentam a parocular amarela, e três espécimes de L. betinae da cidade da coleção UNB (Cascavel, PR) também apresentam mancha amarela na região parocular.

12. Olho, órbita interna: (0) levemente sinuada na parocular superior, quase reta; (1) côncava.

13. Vértice, área pós-ocelar (Roig-Alsina 1997; caráter 4): (0) arredondado, não carenado; (1) carenado.

14. Fronte, pilosidade: (0) plumosa e decumbente; (1) simples e eriçada.

Comentário: As duas espécies de Trigonopedia foram codificadas como inaplicáveis (?) pelo fato da superfície da fronte ser praticamente glabra.

15. Pedicelo, porção anterior (machos): (0) predominantemente preta: (1) predominantemente amarela; (2) laranja.

16. Escapo, cor (machos; Urban 1995): (0) predominantemente preto; (1) predominantemente amarelo.

Comentário: As espécies T. ferruginea e $T$. sp. foram codificadas como inaplicáveis (?) por possuírem escapo alaranjado e bicolor respectivamente.

17. Escapo, cerdas longas eretas: (0) presentes apenas na superfície da face interna; (1) presentes em ambas as superfícies das faces interna e externa.

Comentário: A posição dos escapos, assim como definição de suas faces se baseiam na posição do escapo quando a face posterior está encostada sobre a 
fronte, a face anterior oposta à posterior, e as faces internas e externas são aquelas direcionadas para cada lado dos escapos.

18. Escapo, superfície lateral interna, cerdas grossas, comprimento (fêmeas): (0) curtas (ca. < F2); (1) longas (ca. > F2).

19. Flagelômeros, lateral externa, superfície (machos; Urban 1995): (0) lisa; (1) crenulada.

20. Flagelômeros, face ventral, conjunto de 2 a 3 cerdas eretas longas (machos): (0) ausentes; (1) presentes.

21. Flagelômeros, face ventral, conjunto de 2 a 3 cerdas eretas longas (machos): (0) distribuídas ao longo de todo o segmento antenal; (1) restrita aos flagelômeros F1 e F2.

22. Pró-pleura, carena lateral (Roig-Alsina \& Michener 1993; caráter 63; figura 19): (0) presente; (1) ausente.

Comentário: Os estados dos caracteres foram definidos pela forma codificada por Roig-Alsina (1997).

23. Crista dorsal do colar e lobos pronotais, cor: (0) predominantemente preto; (1) predominantemente amarelo.

Comentário: Na espécie $A$. picta os machos possuem colar pronotal de coloração amarela enquanto as fêmeas, preta. Dessa forma, decidiu-se codificar essa espécie como variável (?). Em T. ferruginea, devido a presença de coloração alaranjada a mesma também recebeu codificação (?).

24. Mesoscuto, pilosidade (machos; Roig-Alsina 1997; caráter 19 modificado): (0) densa e predominantemente longa e composta em sua maioria de pelos longos entremeada a poucos pelos curtos; (1) com pelos muito curtos formando um fino tapete sobre a superfície. (Michener \& Moure 1957; Roig-Alsina 1997; RoigAlsina 1999).

25. Escutelo, estrutura: (0) margem posterior do escutelo truncada formando entre a superfície dorsal e posterior um ângulo levemente arredondado; (1) margem posterior do escutelo em declive suave contínuo com o metanoto.

26. Escutelo, superfície dorsal, cerdas plumosas (machos): (0) ao longo de toda a margem; (1) concentradas em tufos de pelos curtos apenas nas porções laterais. Comentário: Devido a ausência de pilosidade no escutelo, a espécie $T$. sp. foi codificada como inaplicável (?). 
27. Escutelo, cor (fêmeas): (0) preto; (1) amarelo.

28. Metanoto (machos): (0) completamente preto; (1) com estria amarela central dorsal.

Comentário: A espécie T. ferruginea, por apresentar integumento inteiramente de coloração alaranjada foi codificada como inaplicável (?).

29. Metaposnoto, disco, pilosidade (machos): (0) pelos curtos decumbentes que cobrem a superfície como um tapete; (1) pelos longos e eriçados; (2) pelos muito curtos e eriçados.

30. Células submarginais, quantidade (Michener \& Moure 1957): (0) 3 células; (1) 2 células.

Comentário: A perda do segmento alar da veia cubital fez com que a segunda célula submarginal se tornasse muito longa comparada com a primeira submarginal.

31. Perna anterior, tarsômeros distais, porção interna, superfície (fêmeas): (0) com uma ampla área lisa; (1) predominantemente coberta por cerdas.

32. Perna anterior, tarsômeros distais, margem lateral externa, cerdas foliáceas (fêmeas): (0) poucas e esparsas (1 a 8 cerdas) (0); (1) numerosas (acima de 10 cerdas).

33. Perna anterior, tarsômeros distais, margem apical, cerdas (fêmeas): (0) em uma fileira única; (1) sobrepostas.

Comentário: $\mathrm{O}$ formato das cerdas varia em um contínuo que se torna difícil de separar entre as formas tubulares setáceas das achatadas foliáceas.

34. Basitarso anterior, superfície anterior, cerdas (fêmeas; Figs. 7-9 de Roig-Alsina 1997): (0) foliáceas curtas; (1) tubulares longas.

35. Basitarso anterior, superfície externa (fêmeas; Michener \& Moure 1957): (0) convexa; (1) levemente convexa na metade próximal, com metade apical levemente côncava à plana.

Comentário: Em C. parvus, a superfície é levemente convexa na metade proximal, porém a metade distal é plana.

36. Basitarso anterior, margem externa, pilosidade: (0) composta por cerdas intercaladas que não formam uma fileira única; (1) composta por uma fileira única de cerdas similares e contíguas. 
Comentário: C. parvus apresenta cerdas semelhantes na margem externa porém não formando uma fileira de cerdas contíguas justapostas e nem uma estrutura em forma de pente.

37. Basitarso posterior, ápice do bordo posterior: (0) com expansão; (1) sem expansão.

Comentário: É considerado a área de expansão do basitarso somente a região sem microtriquias vista pela face interna.

38. Basitarso posterior, ápice da expansão no bordo: (0) deslocado para o ápice do bordo; (1) deslocado para a porção média do bordo.

39. Basitarso posterior, forma da expansão do bordo (machos): (0) triangular agudo, porém levemente arredondado; (1) retangular; (2) ovalada.

40. Mediotarso, face posterior (fêmeas): (0) sem cerdas plumosas; (1) com cerdas plumosas.

41. Placa basitibial, cor (machos): (0) marrom a preta; (1) amarela com porção apical mais escura; (2) amarela pálida.

42. Tergos, nódoas ou faixas amarelas: (0) presentes; (1) ausentes.

43. T1, disco, superfície (fêmeas): (0) predominantemente glabra; (1) com poucas cerdas esparsas.

44. T1, faixa de cerdas pré-marginais: (0) ausentes; (1) presentes e restrita as extremidades laterais.

45. T1, margem, área côncava (machos): (0) ausente; (1) presente.

46. T3, margem, faixa de pelos (fêmeas): (0) incompleta; (1) completa.

47. Esternos, tegumento, cor (machos): (0) castanhos a pretos; (1) amarelos a alaranjados.

48. Esternos, tegumento, cor (fêmeas): (0) castanhos a pretos; (1) amarelos a alaranjados.

49. E2, franja (machos; Urban 1995): (0) completa; (1) incompleta e com uma falha na região mediana.

50. E5, franja, pilosidade (machos; Urban 1995; modificado): (0) uniforme, com pelos de mesmo comprimento; (1) irregular, com pelos mais longos nas laterais e mais curtos no centro, deixando o tegumento exposto.

51. E6, pilosidade (machos; Urban 1995; modificado): (0) presente; (1) ausente. 
Comentário: Nas espécies L. betinae e L. clementis a pilosidade do disco é fina, enquanto na espécie L. magaliae é mais densa.

52. E6, tufo piloso (fêmeas; Urban 1995; modificado): (0) sem áreas subapicais glabras; (1) com duas áreas subapicais glabras arredondadas.

53. Placa pigidial (machos; Michener \& Moure 1957; modificado): (0) indistinta, com margens laterais e apicais reduzidas; (1) elevada em relação a superfície do tegumento, com margens laterais e apical distintas.

54. T7, superfície do processo apical, pilosidade (machos; Roig-Alsina 1997; caráter 39 modificado): (0) grande parte do tegumento exposto, delimitado por cerdas nas margens laterais; (1) coberta por pelos decumbentes.

55. Gonóstilo, superfície dorsal, pilosidade (machos): (0) com cerdas esparsas; (1) com cerdas abundantes.

56. Gonóstilo, porção proximal dorsal, superfície, cerdas: (0) curtas, menos da metade do diâmetro do lobo final do gonóstilo; (1) longas, referentes ao diâmetro do lobo final do gonóstilo; (2) muito longas, cerca de 2 a 3 vezes o diâmetro do lobo final do gonóstilo.

Comentário: Em L. discrepans, as cerdas são um pouco mais longas do que a observada nas espécies C. parvus, L. betinae e L. clementis.

57. Gonóstilo, superfície ventral, pilosidade (machos): (0) distribuída em toda a superfície; (1) concentrada predominantemente na porção distal.

Comentário: As cerdas em Trigonopedia estão distribuídas esparsamente sobre a superfície, porém a grande maioria está concentrada na porção distal. Em Lanthanomelissa as cerdas se distribuem ao longo de toda a superfície esparsamente e em pouca quantidade, exceto nas espécies $L$. clementis e $L$. pampicola que apresentam uma densidade de cerdas maior do que a observada nas outras espécies.

58. Lobo parapenial (machos): (0) ausente; (1) presente.

59. Lobo parapenial (machos): (0) curto, de tamanho igual ou inferior ao comprimento do gonóstilo; (1) longo, quase tão longo quanto o comprimento do gonóstilo.

60. Valvas, região proximal dorsal, cerdas grossas (machos): (0) muito longas (de 2 a 3 vezes o diâmetro do lobo do gonóstilo); (1) curtas (cerca de 0.5 o diâmetro do 
lobo do gonóstilo); (2) longas ( iguais ou levemente maiores do que o diâmetro do lobo do gonóstilo).

Comentário: As cerdas presentes nas valvas da espécie $L$. discrepans são mais longas do que aquelas observadas nas outras espécies, além de mais numerosas.

61. Gonocoxito, lobo apical interno (machos): (0) presente; (1) ausente.

62. Gonocoxito, lobo interno ventral, projeção (machos): (0) aguda; (1) obtusa.

Comentário: A espécie C. muelleri apresenta o bordo obtuso quase agudo, com uma segunda crenulação na margem muito distinta da observada em todas as demais espécies. O padrão do bordo de C. muelleri é comum as demais espécies do grupo muelleri de Chalepogenus.

63. Gonocoxito, bordo interno ventral (machos): (0) reto, sem cavidade côncava; (1) expandido, com uma cavidade côncava distinta.

64. Gonocoxito, bordo interno ventral, expansão (machos) (0) aguda; (1) obtusa.

Comentário: Aplicável somente as espécies codificadas com estado expandido no caráter anterior $(63)$.

65. E7, lâmina posterior (machos): (0) única, sem divisão; (1) com lobo ventral.

66. E7, lâmina interna, lobo (machos): (0) indistinto; (1) distinto.

67. E7, lobo interno ventral (machos): (0) pouco desenvolvido e sem cerdas; (1) muito desenvolvido e com cerdas.

68. E7, apódemas (machos): (0) retos e não divergentes; (1) divergentes.

69. E8, lobo apical ventral, pilosidade (machos): (0) presente em toda a superfície; (1) presente apenas na margem anterior; (2) presente nas margens anterior e laterais.

70. E8, ápice da lâmina posterior (machos): (0) único, sem divisão; (1) com um recorte formando um lobo lateral digitiforme.

71. E8, lâmina, margem lateral (machos): (0) sem recorte mediano; (1) com recorte mediano.

\section{Filogenia}

Através da busca exaustiva foi obtida uma única árvore (Fig. 1, L 123, IC 70, IR 70). Dentre as opções de enraizamento avaliadas aplicadas aos nós dos grupos externos, a posição de Chalepogenus muelleri varia, podendo ser mais próxima ao clado 
composto por Arhysoceble e Trigonopedia, ou mais próxima ao clado com as demais espécies de Chalepogenus (Chalepogenus goeldianus e Chalepogenus parvus) e Lanthanomelissa. As relações do grupo interno se mantiveram estáveis independente da topologia nos diferentes nós do grupo externo.

Quando a árvore é enraizada na espécie Chalepogenus muelleri (espécie tipo do gênero Chalepogenus), percebe-se que a mesma não está diretamente relacionada as demais espécies de Chalepogenus. Quando enraizada no ancestral comum de Arhysoceble e Trigonopedia, Chalepogenus muelleri passa a ser relacionada as demais espécies de Chalepogenus e Lanthanomelissa. A primeira opção de enraizamento sugere a formação do clado Lanthanomelissa com C. goeldianus como proposto por Michener \& Moure (1957). A segunda opção, onde C. muelleri forma um grado de transformação no clado que compõem também $C$. goeldianus, C. parvus e Lanthanomelissa sugere uma classificação ainda não reconhecida por nenhum autor, onde Chalepogenus é parafilético e inclui as espécies de Lanthanomelissa. A condição aqui observada aproxima a proposta de Michener (2000, 2007) que sugere que Chalepogenus tenha duas linhagens: uma composta por Chalepogenus s.s. e Chalepogenus (Lanthanomelissa). 


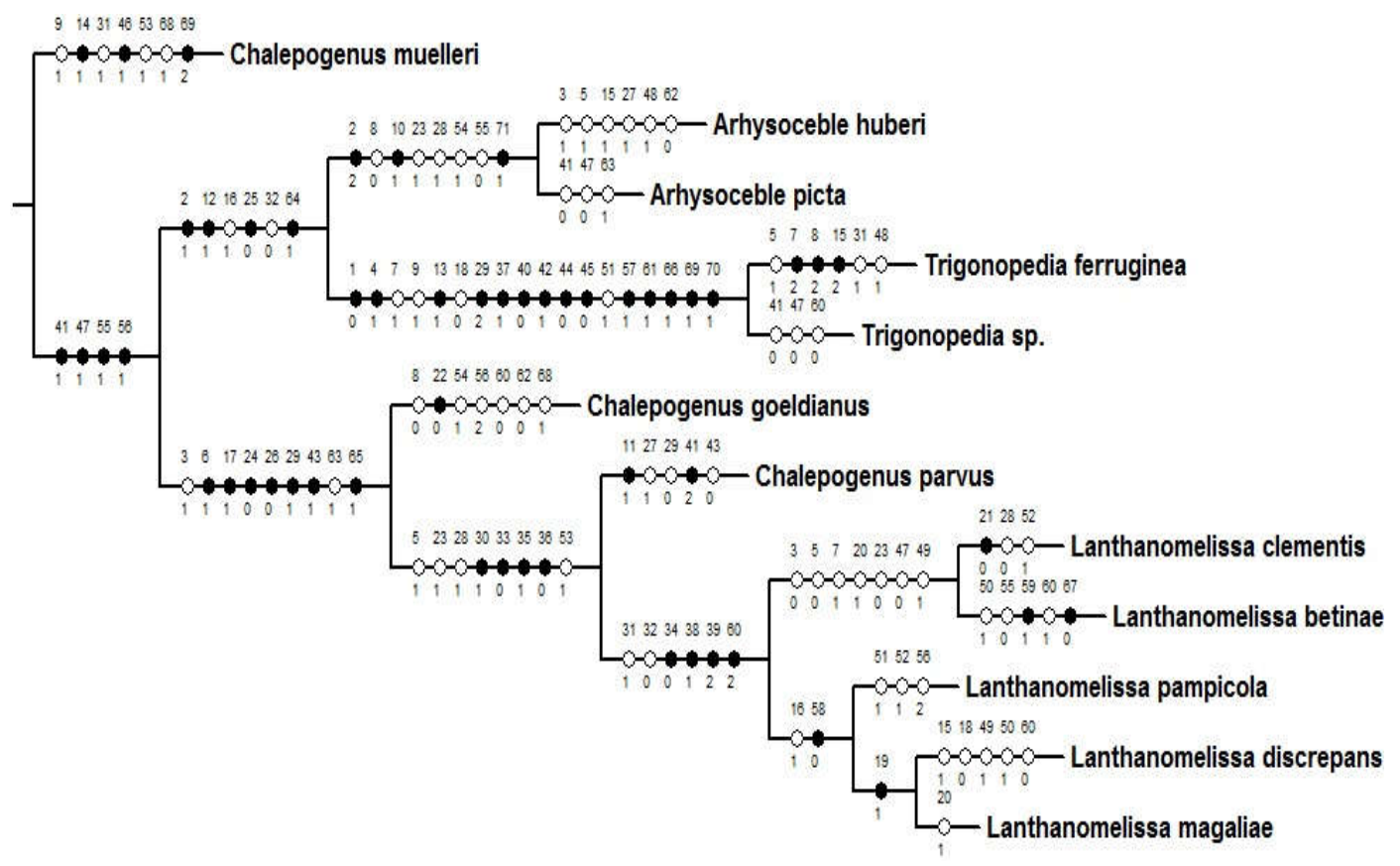

Figura 1. Única árvore obtida através da busca exaustiva para as relações filogenéticas entre as espécies do gênero Lanthanomelissa e seus grupos externos. Legenda: círculos pretos = mudanças sinapomórficas, círculos brancos = mudanças homoplásticas.

\section{Grupo Chalepogenus goeldianus + [ Lanthanomelissa + Chalepogenus parvus]}

Nove caracteres suportam a relação entre C. goeldianus, C. parvus e Lanthanomelissa. Dentre estas, sete são transformações únicas (sinapomorfias): margem superior do clípeo côncava (C6:1), cerdas longas eretas no escapo presente em ambas as laterais (C17:1), pilosidade no mesoscuto do macho densa e predominantemente longa, composta em sua maioria por pelos longos entremeados a pelos curtos (C24:0), cerdas plumosas na superfície dorsal do escutelo do macho presentes ao longo de toda a margem (C26:0), pilosidade no disco do metaposnoto do macho composta por pelos longos e eriçados (C29:1), superfície do disco de T1 da fêmea com poucas cerdas esparsas (C43:1) e lâmina posterior de E7 do macho composta por lobo ventral (C65:1). Apenas duas homoplasias estão presentes neste grupo: cor do labro da fêmea amarelo (C3:1) e bordo interno ventral do gonocoxito do macho expandido e com uma cavidade côncava distinta (C63:1).

C. goeldianus é a espécie tipo de Lanthanella e compõe um grupo juntamente com as espécies Chalepogenus neffi e Chalepogenus luciane. As três espécies estão 
diretamente relacionadas pela semelhança da cápsula genital, esternos 7 e 8 , e sétimo esterno do macho com lobos médios cobertos por cerdas baciliformes, por uma carena lateral da pró-pleura bem definida, espiráculo propodeal com abertura estreita e curvada e basitarso posterior da fêmea com ângulo apical dorsal, como exposto no trabalho de Roig-Alsina (1999). Devido à proximidade de Chalepogenus goeldianus com Lanthanomelissa e ao fato de Chalepogenus muelleri encontrar-se distante de $C$. goeldianus, propõe-se aqui que essas três espécies que formam o grupo goeldianus sensu Roig-Alsina (1999) sejam relocadas para o gênero Lanthanella como inicialmente proposto por Michener \& Moure (1957) e sejam desagregadas do gênero onde encontram-se inseridas, Chalepogenus. Neste trabalho (Michener \& Moure, 1957) em Lanthanella estava incluso apenas a espécie Chalepogenus goeldianus sob o nome de Lanthanella goeldiana.

\section{Lanthanomelissa + Chalepogenus parvus}

Segundo a árvore encontrada, a espécie Chalepogenus parvus é espécie irmã de Lanthanomelissa, sendo sugerida sua alocação para este gênero, sob o nome Lanthanomelissa parva (Roig-Alsina). Desta forma, o gênero Lanthanomelissa passa a ser composto por seis espécies. Oito caracteres suportam a monofilia do gênero, destes, quatro sinapomorfias: duas células submarginais nas asas anteriores (C30:1), cerdas da margem apical dos tarsômeros distais da perna anterior da fêmea dispostas em uma fileira única (C33:0), superfície externa do basitarso anterior da fêmea levemente convexa na metade proximal e com metade apical levemente côncava a plana (C35:1) e pilosidade na margem do basitarso anterior composta por cerdas intercaladas que não formam uma fileira única (C36:0). Os caracteres homoplásticos compartilhados por este grupo são: clípeo da fêmea predominantemente amarelo (C5:1), crista dorsal do colar e lobos pronotais também predominantemente amarelos (C23:1), metanoto do macho com estria amarela central dorsal (C28:1) e placa pigidial no macho elevada em relação a superfície do tegumento, com margens laterais e apical distintas (C53:1). 


\section{Relações internas de Lanthanomelissa}

As espécies $L$. betinae, L. clementis, L. discrepans, L. pampicola e L. magaliae formam um grupo fortemente sustentado por seis caracteres, com quatro sinapomorfias: cerdas foliáceas curtas na superfície anterior do basitarso anterior da fêmea (C34:0), ápice da expansão no bordo do basitarso posterior deslocado para a porção média do bordo (C38:1), forma da expansão do bordo do basitarso posterior do macho ovalada (C39:2) e cerdas grossas da região proximal dorsal das valvas do macho longas, de comprimento igual ou levemente maior do que o diâmetro do lobo do gonóstilo (C60:2). As duas homoplasias são: superfície da porção interna dos tarsômeros distais da perna anterior da fêmea predominantemente coberta por cerdas (C31:1) e poucas cerdas foliáceas esparsas na margem lateral externa dos tarsômeros distais da perna anterior da fềmea (C32:0).

As espécies L. betinae e L. clementis são quase idênticas morfologicamente, detendo o status de espécies irmãs, sendo distintas apenas por algumas características principalmente nos machos. Os seguintes caracteres estão presentes na espécie $L$. clementis: pilosidade uniforme na superfície posterior do fêmur posterior, franja de E5 composta por pelos de tamanhos uniformes (C50:0; Urban, 1995), superfície dorsal do gonóstilo com cerdas abundantes (C55:1), lobo parapenial curto (C59:0), cerdas longas e grossas na região proximal dorsal das valvas (C60:2) e lobo interno ventral de E7 muito desenvolvido (C67:1). Presença de estria amarela central dorsal no metanoto em L. betinae (C:28:1) e ausente em L. clementis. As fêmeas se distinguem basicamente pela pilosidade no E6, que pode ocupar o disco da superfície, como observado em $L$. betinae (C52:0) ou com duas áreas subapicais glabras que ocorre em L. clementis (C52:1). Sete caracteres homoplásticos suportam as semelhanças entre essas duas espécies: cor do labro da fêmea preto (C3:0), clípeo predominantemente preto na fêmea (C5:0), área supraclipeal do macho preta (C7:1), conjunto de 2 a 3 cerdas eretas longas na face ventral dos flagelômeros do macho (C20:1), crista dorsal do colar e lobos pronotais predominantemente pretos (C23:0), tegumento dos esternos do macho castanhos a pretos (C47:0), e franja de E2 do macho incompleta e apresentando uma falha na região mediana (C49:1). Na espécie L. betinae são observadas duas autapomorfias: lobo parapenial do macho longo, sendo quase tão longo quanto o comprimento do gonóstilo (C59:1) e lobo interno ventral de E7 do macho pouco 
desenvolvido e sem cerdas (C67:0), enquanto na sua espécie irmã L. clementis apresenta como característica única um conjunto de 2 a 3 cerdas eretas longas na face ventral dos flagelômeros do macho, estando distribuídas ao longo de todo o segmento antenal (C21:0).

L. pampicola é espécie irmã do clado formado pelas espécies $L$. discrepans e $L$. magaliae. As espécies L. magaliae e L. discrepans são unidas pela crenulação na superfície externa dos flagelômeros do macho (C19:1), compartilhando com $L$. pampicola a ausência do lobo parapenial no macho (C58:0) e escapo de coloração predominantemente amarela no macho (C16:1).

\section{Taxonomia}

\section{Lanthanomelissa Holmberg, 1903}

(Figs 2, 3)

Lanthanomelissa Holmberg (1903): 418; espécie-tipo: Lanthanomelissa discrepans Holmberg, 1903.

Lanthanomelissa; Urban (1995): 767 (novas espécies, diagnose e chave de identificação). Michener (1963): 156 (cit.). Michener (1997): 32 (cit.). Roig-Alsina (1997): 17 (diagnose do gênero). Cocucci et al. (2000): 62 (estruturas relacionadas a coleta de óleo). Aguiar \& Melo (2007): 512 (cit.). Vilhena \& Augusto (2007): 14 (cit.). Alves-dos-Santos et al. (2007): 545 (cit.), 546: (Fig. 1; D-F. Lanthanomelissa. D. basitarso da fêmea, E-F. cerdas do basitarso anterior). Straka \& Bogusch (2007): 702 (Tabela 1, cit., filogenia morfológica de estados larvais). Hinojosa-Díaz \& Engel (2008): 103 (estruturas justo-ocelares). Aguiar \& Melo (2009): 154 (cit.). Gonçalves et al. (2009): 171 (cit.), 176 (inventário de abelhas). Alves-dos-Santos (2009): 110 (cit.). Alves-dos-Santos et al (2009): 519 (cit). Renner \& Schaefer (2010): 425, (cit.), 429 (cit.). Torretta et al. (2011): 21 (cit.). Chaveau et al. (2011): 20 (cit.).Torretta \& Roig-Alsina (2016): 1 (cit.).

Lanthanomelissa (Lanthanomelissa); Michener \& Moure (1957): 416 (diagnose e chave taxonômica).

Lanthanomelisa [sic]; Vogel (1974): 228 (cit.).

Chalepogenus (Lanthanomelissa); Michener (2000): 670. Michener (2007): 689, 690 (diagnose e chave taxonômica). Silvério et al (2012): 275 (cit.). 
Comentários e Diagnose

As abelhas deste gênero apresentam tegumento bicolor (preto e amarelo), podendo possuir algumas estruturas como o clípeo, labro e áreas paroculares inteiramente amarelas (Michener \& Moure 1957; Urban 1995; Roig-Alsina 1997). O grupo é facilmente distinto dos outros gêneros da tribo Tapinotaspidini pela presença de apenas duas células submarginais nas asas anteriores e por um aparato coletor de óleo floral único e especializado composto por cerdas foliáceas (Michener \& Moure 1957, Urban 1995; Roig-Alsina 1997; Cocucci et al. 2000; Michener 2007).

As espécies de Lanthanomelissa se assemelham à Lanthanella pela margem superior do clípeo côncava (C6:1), pela presença de cerdas longas e eretas no escapo em ambas as superfícies das faces laterais (C17:1), pilosidade no mesoscuto do macho densa e predominantemente longa, composta em sua maioria por pelos longos entremeados a poucos pelos curtos $(\mathrm{C} 24: 0)$, pela presença de cerdas plumosas na superfície dorsal do escutelo do macho ao longo de toda a margem (C26:0), pilosidade no disco do metaposnoto do macho composta por pelos longos e eriçados, superfície do disco de T1 da fêmea predominantemente glabra (C43:0) e lâmina posterior de E7 no macho com um lobo ventral (C65:1). Poucas características distinguem Lanthanella de Lanthanomelissa, as principais são: 3 células submarginais (C30:0) em Lanthanella, cerdas tubulares longas na superfície anterior do basitarso anterior da fêmea (34:1), pilosidade na margem externa do basitarso anterior composta por uma fileira única de cerdas similares e contíguas (C36:1) e placa pigidial do macho indistinta, com margens laterais e apicais reduzidas (C53:0).

Separa-se de Trigonopedia e Arhysoceble pela órbita levemente sinuada na parocular superior, sendo quase reta (C12:0), enquanto estes dois gêneros compartilham a condição da órbita interna do olho ser côncava (C12:1). Margem posterior do escutelo em Lanthanomelissa em declive suave contínuo com o metanoto (C25:1), presença de área côncava na margem de $\mathrm{T} 1$ do macho (C45:1), diferentemente da condição observada nas espécies de Trigonopedia e Arhysoceble. Placa pigidial elevada em relação a superfície do tegumento, com margens laterais e apical distintas.(C53:1) de Lanthanomelissa. Trigonopedia, Arhysoceble e Lanthanella apresentam placa pigidial indistinta e com margens laterais e apicais reduzidas (C53:0). 
Tamanho corporal de 4 a $7 \mathrm{~mm}$; tegumento predominantemente preto com máculas amarelas nas pernas e tergos metassomais, machos com clípeo, labro e eventualmente região parocular inferior amarelas; asas predominantemente hialinas, com pteroestigma e venação alar alaranjados. Cor da pilosidade: predominantemente amarela pálida, com regiões como escapo, fronte, mesepisterno e metaposnoto mais esbranquiçados. Pilosidade densa na face, principalmente na região parocular inferior composta por pelos plumosos; nos machos, pilosidade da fronte e mesoscuto mais densa e com pelos mais longos, clípeo com cerdas longas na porção mediana e pouco mais curtas nas laterais, ambas plumosas; labro inteiramente envolvido por uma pilosidade bastante densa e abundante, sendo esta composta por pelos predominantemente longos e plumosos; escapo com cerdas ramificadas concentradas nas laterais; mesoscuto com pelos longos intercalados com alguns mais curtos distribuídos em toda a superfície, porém expondo parte do integumento; no mesepisterno cerdas bastante longas e plumosas; no metaposnoto pelos finos e curtos cobrem a superfície; tergos com pilosidade completa apenas de T3-T6; franjas metassomais com pelos muito longos e simples ao longo de toda a superfície da estrutura; basitarso anterior com cerdas grossas foliáceas e na porção mediana quase sem pelos ou glabro; pilosidade do basitarso posterior extremamente densa com pelos longos e plumosos entremeados entre si. Pontuação predominantemente fina; fina e densa na região parocular inferior e no mesoscuto, com pontos muito próximos uns dos outros; um pouco mais grossa na porção mediana do clípeo. Face convexa; vértice atrás dos ocelos arredondado, não formando uma carena; órbita interna do olho levemente sinuada na parocular superior, quase reta; fóveas antenais evidentes e localizadas abaixo da metade do olho; clípeo aproximadamente duas vezes mais largo do que longo; placa labral cerca de duas vezes mais larga do que longa; articulação da mandíbula localizada na mesma distância do olho; palpômero labial composto por seis segmentos; carena lateral da propleura presente; margem posterior do escutelo em declive suave contínuo com o metanoto; asas anteriores com duas células submarginais; esporão mesotibial serrilhado; basitarso anterior com superfície plana; garras tarsais bífidas e com unhas de comprimentos semelhantes; nos machos placa pigidial bem evidente, com superfície lisa e cercada por pelos decumbentes e plumosos; franjas esternais muito densas e plumosas na região do disco do esterno; E6 composto por um tufo de cerdas grossas nas margens laterais direcionadas para fora; apódemas de E7 não convergentes; lâmina posterior de E8 única, sem divisão e sem recorte. Tamanho da cabeça 2,10 - 2,50 mm. 

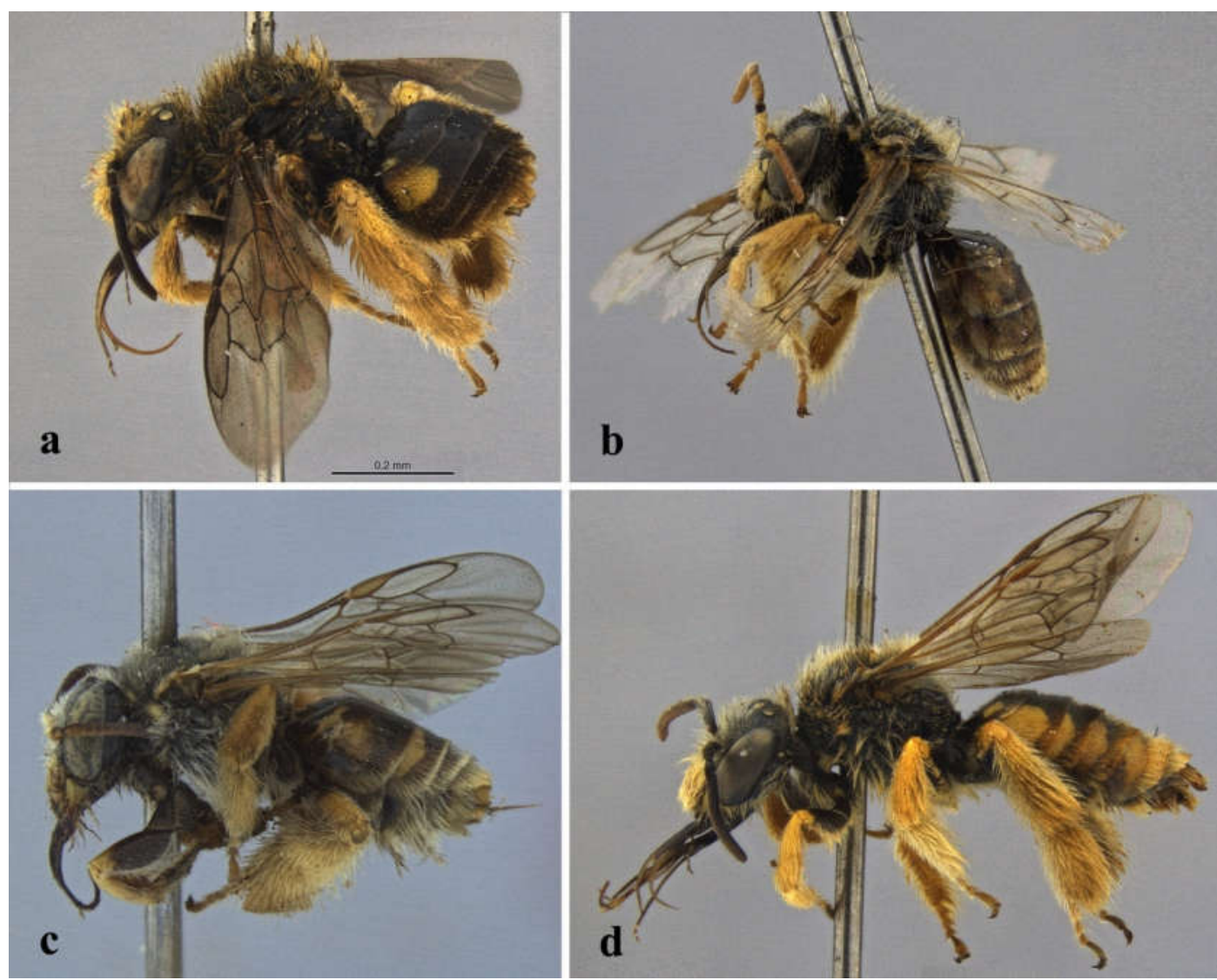

Figura 2. Lanthanomelissa, hábito lateral: a. Lanthanomelissa betinae Urban (holótipo); b. Lanthanomelissa pampicola Urban (holótipo); c. Lanthanomelissa discrepans (fêmea; DZUP; Argentina, Corrientes, Ituzaingo, Fritz col.; A. Roig-Alsina det., comparado com o lectótipo); d. Lanthanomelissa clementis Urban (holótipo); escala $=0.2 \mathrm{~mm}$. 

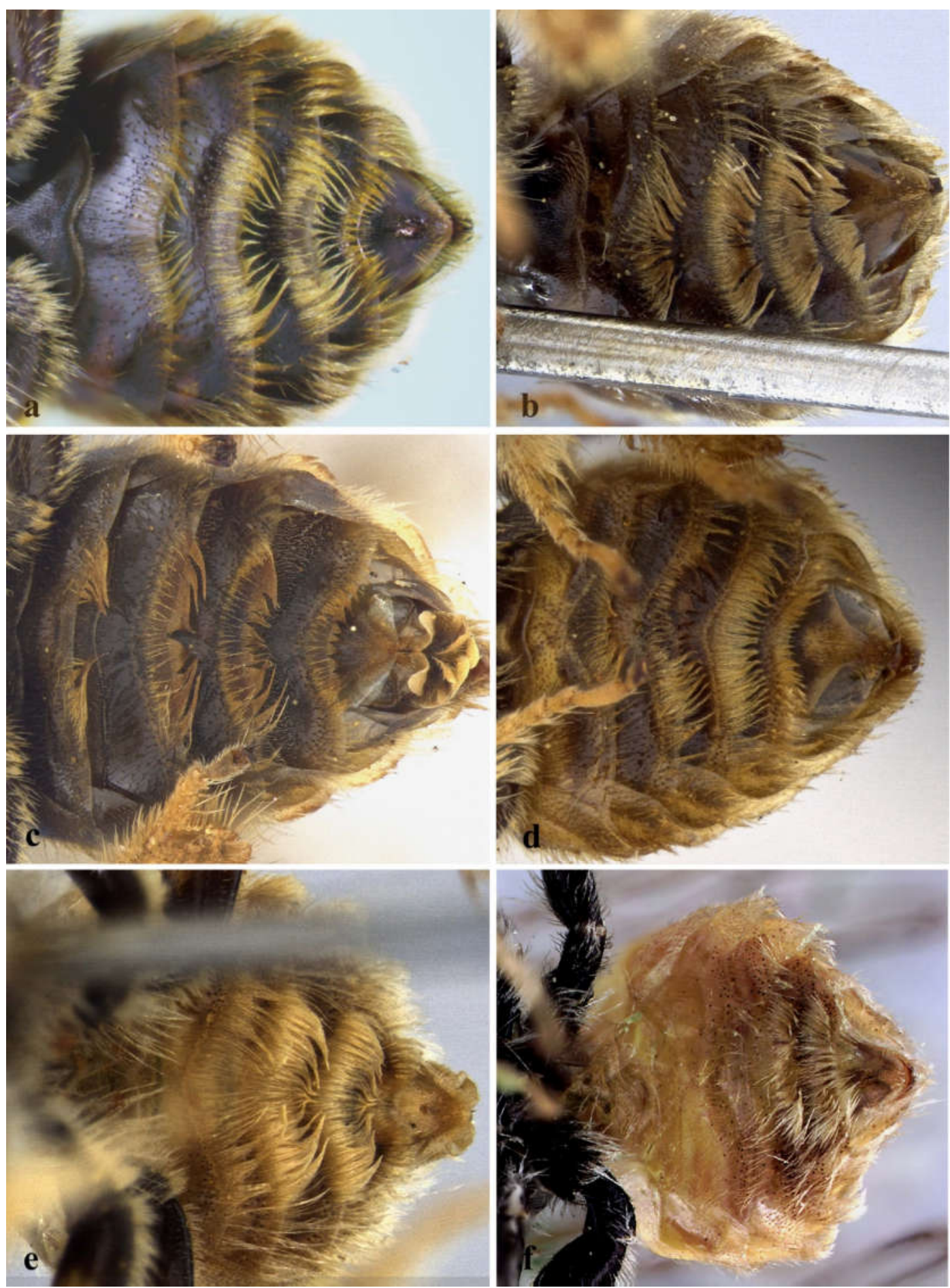

Figura 3. Esternos, machos: a. Lanthanomelissa betinae Urban (DZUP, Brasil, Paraná, Araucária); b. Lanthanomelissa pampicola Urban (holótipo); c. Lanthanomelissa clementis Urban (holótipo); d. Lanthanomelissa magaliae Urban (holótipo); e. Lanthanomelissa discrepans Holmberg (DZUP, Brasil, Rio Grande do Sul, Canguçu); f. Lanthanomelissa parva (Roig-Alsina) (Argentina, Córdoba, Dean Funes). 


\section{Chave para as espécies de Lanthanomelissa (machos)}

1. Aparato coletor de óleo no basitarso anterior composto por cerdas longas, finas e simples em toda a superfície; placa pigidial com laterais pouco definidas, com ápice esclerotizado e coberta por pelos decumbentes...L. parva (Roig-Alsina, 1997)

- Aparato coletor de óleo no basitarso anterior composto por cerdas curtas foliáceas nas margens laterais e superfície apical com tegumento glabro; placa pigidial bem definida e com superfície lisa, delimitada por cerdas curtas...2

2. Escapo predominantemente preto...3

- Escapo predominantemente amarelo...4

3. Escapo predominantemente preto, podendo apresentar nódoas amarelas nas porções distais e/ou proximais, ou com a superfície face anterior inteiramente amarela; pilosidade do escapo predominantemente curta (menor do que diâmetro de F2); conjunto de 2 a 3 cerdas eretas longas na face ventral dos flagelômeros distribuídas ao longo de todo o segmento antenal; superfície posterior do fêmur posterior com pilosidade irregular, pelos mais longos do que o diâmetro do flagelo mesclados com pelos mais curtos; E2 a E4 com franjas de pelos longos nas laterais e mais curtos medianamente, todos encurvados para o meio (Fig 3c); em E2 pelos mais esparsos na região mediana; E5 com franja de pelos de comprimentos iguais...L.clementis Urban, 1995

- Escapo predominantemente preto geralmente sem nódoas ou estria amarelas; pilosidade do escapo predominantemente longa (maior do que o diâmetro de F2); superfície posterior do fêmur posterior com pilosidade uniforme e mais curta do que o diâmetro do flagelo; conjunto de 2 a 3 cerdas eretas longas na face ventral dos flagelômeros restrita aos segmentos F1 e F2; E2 a E4 com franjas de pelos mais longos nas laterais e mais curtos no disco, sendo todos encurvados para o centro (Fig 3a); E5 com franja em arco rebaixado e com pelos centrais mais curtos do que os laterais, deixando grande parte do tegumento exposto...L. betinae Urban, 1995

4. Flagelômeros lisos na superfície posterior externa; superfície anterior dos flagelômeros inteiramente alaranjada; pilosidade do escapo predominantemente longa (maior do que o diâmetro de F2); esternos alaranjados; E2 a E4 com franjas compostas 
por pelos uniformes, e nas laterais fracamente encurvadas para o meio (Fig 3b); franja de E5 quase reta, com pelos de comprimento uniforme; disco de E6 glabro levemente piloso na base...L. pampicola Urban, 1995

- Flagelômeros crenulados na superfície posterior externa...5

5. Escapo inteiramente amarelo; F1 e F2 geralmente amarelos, enquanto o restante do segmento apresenta uma coloração alaranjada a castanha clara; pilosidade do escapo densa, composta por pelos plumosos e curtos que correspondem a metade do diâmetro de F2; ausência de cerdas eretas longas na face ventral dos flagelômeros; tergos e esternos metassomais amarelados, com presença de nódoas amarelas mais claras nas margens laterais; E2 a E4 com pilosidade densa, pelos muito compridos nas laterais encurvados para o meio (Fig 3e); E2 com pelos laterais muito longos convergindo para o meio, e na área mediana com pelos esparsos; E6 com disco quase glabro e cerdas curtas na margem lateral e inferior...L. discrepans Holmberg, 1903

- Escapo amarelo com estria preta lateral externa; F1 e F2 castanhos; escapo com pelos predominantemente curtos, proporcionais ao diâmetro de F2; conjunto de 2 a 3 cerdas eretas longas na face ventral dos flagelômeros restrita aos segmentos F1 e F2; tergos castanhos com nódoas amarelas nas laterais e esternos castanhos; E2 a E3 com pelos mais longos nas laterais e curtos no centro, sem porção média com pelos esparsos (Fig 3d); E4 e E5 com pelos de tamanho uniformes, E2 com pelos laterais longos arqueados para o meio e na área mediana com pilosidade abundante; E6 com tufo piloso no disco...Lanthanomelissa magaliae Urban, 1995

\section{Chave para as espécies de Lanthanomelissa (fềmeas)}

1. Aparato coletor de óleo no basitarso anterior composto por cerdas longas, finas e simples em toda a superfície; superfície da região interna dos tarsômeros distais da perna anterior com uma ampla área lisa; basitarso da perna posterior com projeção apical truncada; disco do escutelo amarelo; clípeo e labro amarelos; tergos metassomais predominantemente amarelos com manchas castanhas; pelos do metaposnoto tão longos quanto os do propódeo....L. parva (Roig-Alsina, 1997)

- Aparato coletor de óleo no basitarso anterior composto por cerdas curtas foliáceas nas margens laterais e superfície apical com tegumento glabro; superfície da região interna 
dos tarsômeros distais da perna anterior predominantemente coberta por cerdas; basitarso da perna posterior com projeção aguda a levemente arredondada; disco do escutelo preto; cores do clípeo, labro e tergos metassomais variáveis; pelos do metaposnoto mais curtos do que os do propódeo...2

2. Escapo predominantemente preto...3

- Escapo predominantemente amarelo...4

3. Sexto esterno com duas áreas subapicais glabras...L. clementis Urban, 1995

- Sexto esterno sem áreas subapicais, disco amplamente piloso...L. betinae Urban, 1995

4. Clípeo predominantemente preto com mancha amarela na forma de letra "w"; sexto esterno com duas áreas subapicais glabras arredondadas; flagelômeros alaranjados na superfície anterior; área supraclipeal sem nódoa amarela...L. pampicola Urban, 1995

- Clípeo predominantemente amarelo...5

5. Escapo amarelo sem estria escura, com superfície da lateral coberta por pelos predominantemente curtos; superfície da face anterior do escapo quase ou completamente glabra; flagelômeros lisos na superfície posterior externa; pilosidade da cabeça e tórax curta e densa, mais curta do que o diâmetro da antena e de coloração esbranquiçada; clípeo e labro amarelos, tergos amarelos e esternos castanho alaranjados...L. discrepans Holmberg, 1903

- Escapo amarelo com estria preta na lateral externa; flagelômeros inteiramente castanhos em ambas a superfícies, levemente mais claros na superfície anterior; flagelômeros crenulados na superfície posterior externa; tergos e esternos castanhos...L. magaliae Urban, 1995

Lanthanomelissa betinae Urban, 1995

(Figs. 4, 5)

Lanthanomelissa betinae Urban. (1995): 768 (Fig. 1; holótipo macho, Brasil: Rio Grande do Sul, Gramado (DZUP)). 
Lanthanomelissa betinae; Cocucci et al. (2000): 69 (Figs. 9 C, E, G morfologia do aparato coletor de óleo). Melo \& Zanella (2003): 2919 (registro de Parepeolus minutus (Osirini) possivelmente associado como cleptoparasita). Cocucci \& Vogel (2001): 35 (Tabela 4, registros em Sisyrinchium). Silveira et al. (2002): 133 (Brasil: Rio Grande do Sul, Paraná, Santa Catarina). Aguiar et al. (2004): 80 (cit.). Rozen et al. (2006): 2 (Figs. 31-33, 35, 39, 65-73; biologia da nidificação; descrição dos estádios imaturos; associação com Parepeolus minutus (Osirini); registro floral: Sisyrinchium micranthum (Iridaceae); Brasil: Paraná, Santa Catarina). Straka \& Bogusch (2007): 701 (filogenia baseada em caracteres larvais). Alves-dos-Santos et al. (2007): 548, (Fig. 2, visita floral em Sisyrinchium micranthum). Krug \& Alvesdos-Santos (2008): 270 (tabela 1, espécies de abelhas amostradas em Porto União, SC). Alves-dos-Santos et al. (2009): 520 (Fig 2 a-c; visita floral dos machos em flores (Oxalidaceae e Asteraceae). Martins \& Alves-dos-Santos (2013): 78 (cit.). Favretto et al. (2013): 58 (Tabela 1, lista de espécies registradas em Santa Catarina). Alves-dos-Santos et al (2016): 297 (Fig 1, coleta de recurso em S. micranthum).

Lanthanomelissa sp.; Oliveira (1966): 1 (Figs. 1-5; descrição das larvas de primeiro e segundo ínstares e pré-defecante).

Lanthanomelissa (Lanthanomelissa) goeldiana; Sakagami \& Laroca (1988): 347 (identificação errônea; biologia da nidificação).

Chalepogenus (Lanthanomelissa) betinae; Truylio et al. (2002): 11 (registro floral: Sisyrinchium micranthum, Iridaceae). Cappellari \& Harter-Marques (2009): 726 (coleta de óleo em Iridaceae, Scrophulariaceae e Solanaceae).

\section{Comentários e diagnose}

Distingue-se de L. clementis por apresentar pelos laterais do segundo ao quarto esterno mais longos do que os centrais arqueados para o meio; a franja do quinto esterno emarginada, com pelos laterais longos e os centrais mais curtos, deixando o tegumento exposto; pilosidade do fêmur posterior com pelos mais longos do que o diâmetro do flagelo misturados com pelos mais curtos; fêmeas com tufo piloso normal no sexto esterno, sem áreas subapicais glabras (Urban 1995). Outras características que separam L. betinae de L. clementis são: nas fêmeas, presença de amarelo no clípeo, e nos machos escapo inteiramente preto, sem nódoas ou estrias amarelas; pilosidade do escapo abundante, sendo composta por cerdas predominantemente longas, de 2 a 3 vezes mais 
compridas do que o diâmetro de F2; E6 do macho com tegumento do disco com cerdas curtas esparsas, nas margens laterais quase sem cerdas; cerdas da superfície da porção proximal do gonóstilo curtas (ca de 1/2 o diâmetro da porção proximal do gonóstilo); lobo interno ventral de E7 pouco desenvolvido. Além de todas essas características, essa espécie é facilmente destacada das restantes do grupo por apresentar um lobo parapenial quase tão longo quanto o próprio gonóstilo.

Variação: Disco de E6 de machos de localidades distintas: Cascavel (UNB) Curitiba (DZUP), Porto União (UNESC) e Leônidas Marques (DZUP) inteiramente amarelo. Três espécimes machos de Cascavel com manchas amarelas nas regiões paroculares inferiores (UNB 064170, UNB 064172 e UNB 064173). Alguns machos desprovidos de mancha amarela na porção apical da tégula e a maioria das fêmeas examinadas com clípeo amarelo formado apenas por áreas latero basais enegrecidas. Outros indivíduos com clípeo inteiramente preto, e um espécime de Porto União (UNESC 7636) com a presença de apenas uma pequena nódoa arredondada na porção mediana superior. Uma fêmea de Cotia (DZUP) com clípeo predominantemente preto e uma mancha amarela na região central. Alguns espécimes desprovidos de estria amarela na região central dorsal do mesoscuto e com colar pronotal inteiramente preto. Três exemplares da cidade de Cascavel com nódoa amarela em E1 e E2 (E1 com nódoa pequena, arredondada e centralizada no disco do tegmento, E2 com uma faixa amarela contínua). Além disso, nestes mesmos exemplares foram observadas manchas pequenas e amarelas na porção ventral da coxa da perna anterior. Também foi observada variação nas nódoas dos tergos metassomais e na coloração das pernas de três exemplares (UNB 064170, UNB 064172, UNB 064173), todos da cidade de Cascavel. Algumas fêmeas de Curitiba (DZUP) e Santa Rosa (UNESC) com asas levemente mais enfumaçadas do que a observada em outros espécimes. Poucos machos com a superfície anterior dos flagelômeros inteiramente alaranjadas (São Francisco de Paula (MCTP) e Leônidas Marques (DZUP). O único espécime macho examinado da região de Leônidas Marques apresentou o segmento F11 com recorte apical e leve achatamento.

Registros florais: Plantaginaceae, Solanaceae (Cappellari et al. 2009), Iridaceae, Sisyrinchium sp. (Cocucci \& Vogel 2001), Sisyrinchium micranthum Cav. (Alves-dosSantos et. al. 2016), Calibrachoa sellowiana Sendth (Solanaceae). 
Distribuição Geográfica: Brasil (São Paulo, Paraná, Santa Catarina e Rio Grande do Sul).

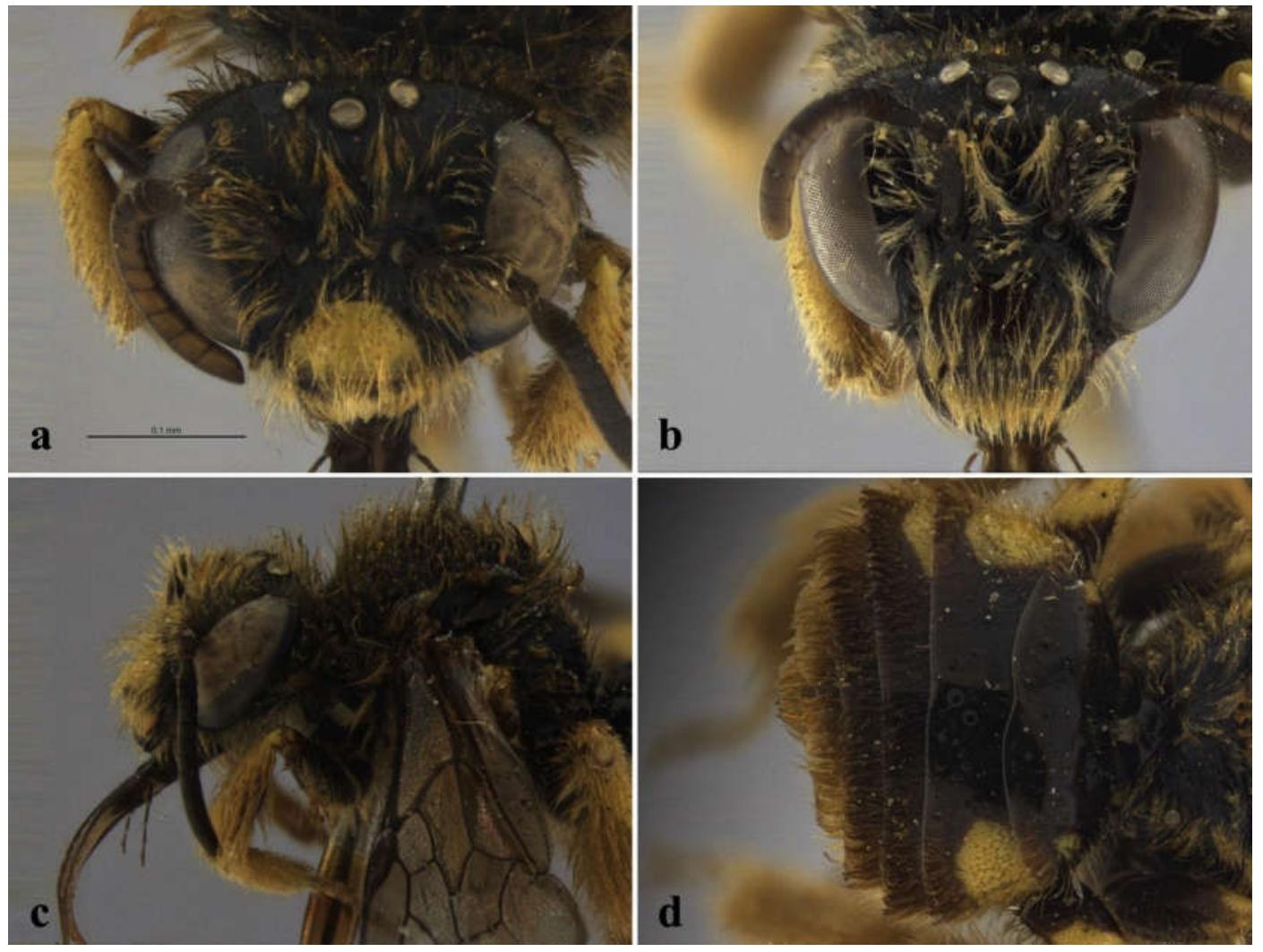

Figura 4. Lanthanomelissa betinae Urban; a. face, macho (holótipo); b. face, fêmea (parátipo, Brasil, Rio Grande do Sul, Gramado); c. cabeça e metassoma lateral (holótipo); d. metassoma dorsal (holótipo). 

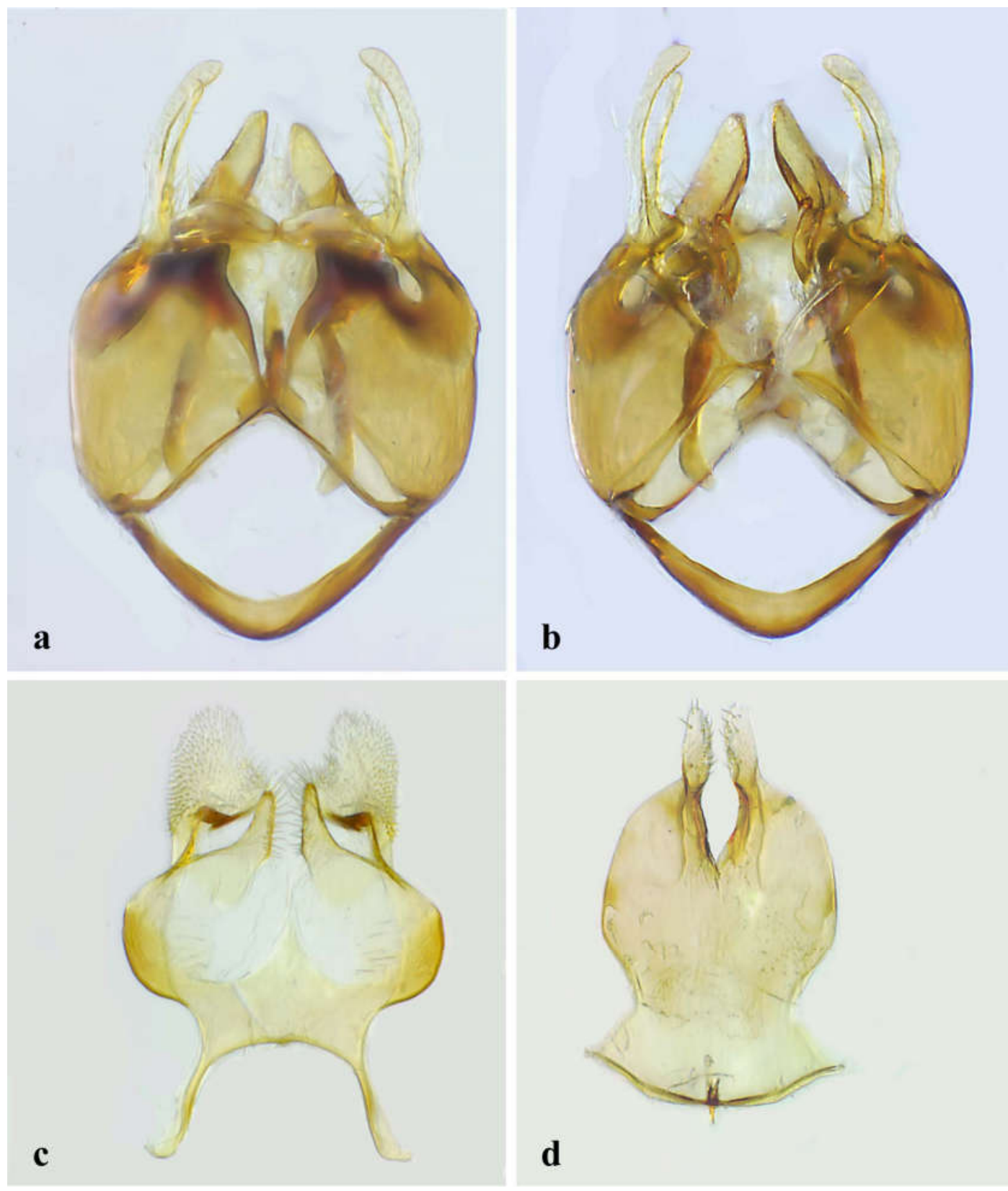

Figura 5. Terminália interna do macho de Lanthanomelissa betinae; a. visão dorsal da cápsula genital; b. visão ventral da cápsula genital; c. visão dorsal de E7; d. visão dorsal de E8. 
Lanthanomelissa clementis Urban, 1995

(Figs. 6, 7)

Lanthanomelissa clementis Urban (1995): 770 (Figs. 5-7; esternos 7-8 e cápsula genital); holótipo macho, Brasil: Rio Grande do Sul, Guaíba (DZUP).

Lanthanomelissa clementis; Schlindwein (1998): 49 (cit. registro floral: Hypochoeris brasiliensis, Histerionica filiformis (Asteraceae), Wahlembergia linarioides (Campanulaceae), Opuntia viridirubra (Cactaceae), Sisyrinchium fasciculatum, S. micranthum (Iridaceae), Oxalis brasiliensis, O. floribunda, O. niedreleinii (Oxalidaceae), Petuniao valifolia (Solanaceae), Verbena montevidensis (Verbenaceae); Brasil: Rio Grande do Sul). Silveira et al. (2002): 133 (Brasil: Rio Grande do Sul, Santa Catarina). Truylio \& Harter-Marques (2007): 395 (Tabela 1; inventário de abelhas do Rio Grande do Sul). Favretto et al. (2013): 59 (Tabela 1; lista de espécies amostradas no oeste do estado de Santa Catarina).

Lanthanomelissa aff. clementis Urban, 1995; Gonçalves et al. (2009): 176 (Apêndice 1; inventário de espécies do Parque Estadual de Vila Velha, PR).

\section{Comentários e diagnose}

Espécie muito semelhante a L. betinae, no entanto, pode apresentar nódoas ou estria amarelas no escapo, assim como a superfície da porção anterior do mesmo inteiramente amarela; cerdas longas presentes ao longo de todo o segmento da antena; pilosidade do escapo predominantemente longa, mesclada com pelos mais curtos iguais ao diâmetro de F2; tufo piloso na zona inferior de E6, com cerdas curtas plumosas nas margens laterais e inferiores; ápice do bordo posterior do basitarso posterior levemente mais pronunciado e mais agudo do que o de L. betinae. Na fêmea, como descrito por Urban (1995), o sexto esterno apresenta um tufo piloso composto por duas áreas subapicais glabras.

Variação: Presença de nódoas ou estria amarela na superfície anterior do escapo de vários espécimes machos de Caçapava do Sul, Pelotas e Pinheiro Machado (Rio Grande do Sul). A ocorrência dessas nódoas ou estrias podem se manifestar de maneiras distintas: apenas em uma das porções do escapo (inferior ou posterior) ou em ambas, no 
formato de pequenas manchas arredondadas e na forma de estria, ocupando toda a superfície anterior do escapo ou apenas metade. Muitos indivíduos possuíam área supraclipeal manchada de amarelo, com variação em relação a sua forma: retangular, triangular e levemente arredondada. Foi observado um macho de Pinheiro Machado (RPSP 124036) com nódoas alaranjadas nos tergos metassomais. Duas fêmeas da região de Canguçu com clípeo bicolor. Todas as fêmeas dessa cidade com tégula marrom e porção apical amarela, diferentemente da condição das fêmeas de outras localidades. Em Cotia, macho com faixa contínua amarela na superfície de T5 (DZUP). Um macho de Caçapava do Sul com a perna posterior amarela da metade do fêmur até os tarsômeros (RPSP 122874), outro com F11 recortado apicalmente (RPSP 122877), e um terceiro macho com flagelômeros alaranjados na superfície a partir de F5 (RSPS 122871). Foi observada variação nas nódoas dos tergos metassomais, que podem estar presentes em todos os tergos, ou ausentes de T4-T6.

Registros florais: Iridaceae, Sisyrinchium sp. (Cocucci \&Vogel 2001).

Distribuição Geográfica: Brasil (São Paulo, Paraná, Santa Catarina e Rio Grande do Sul). 

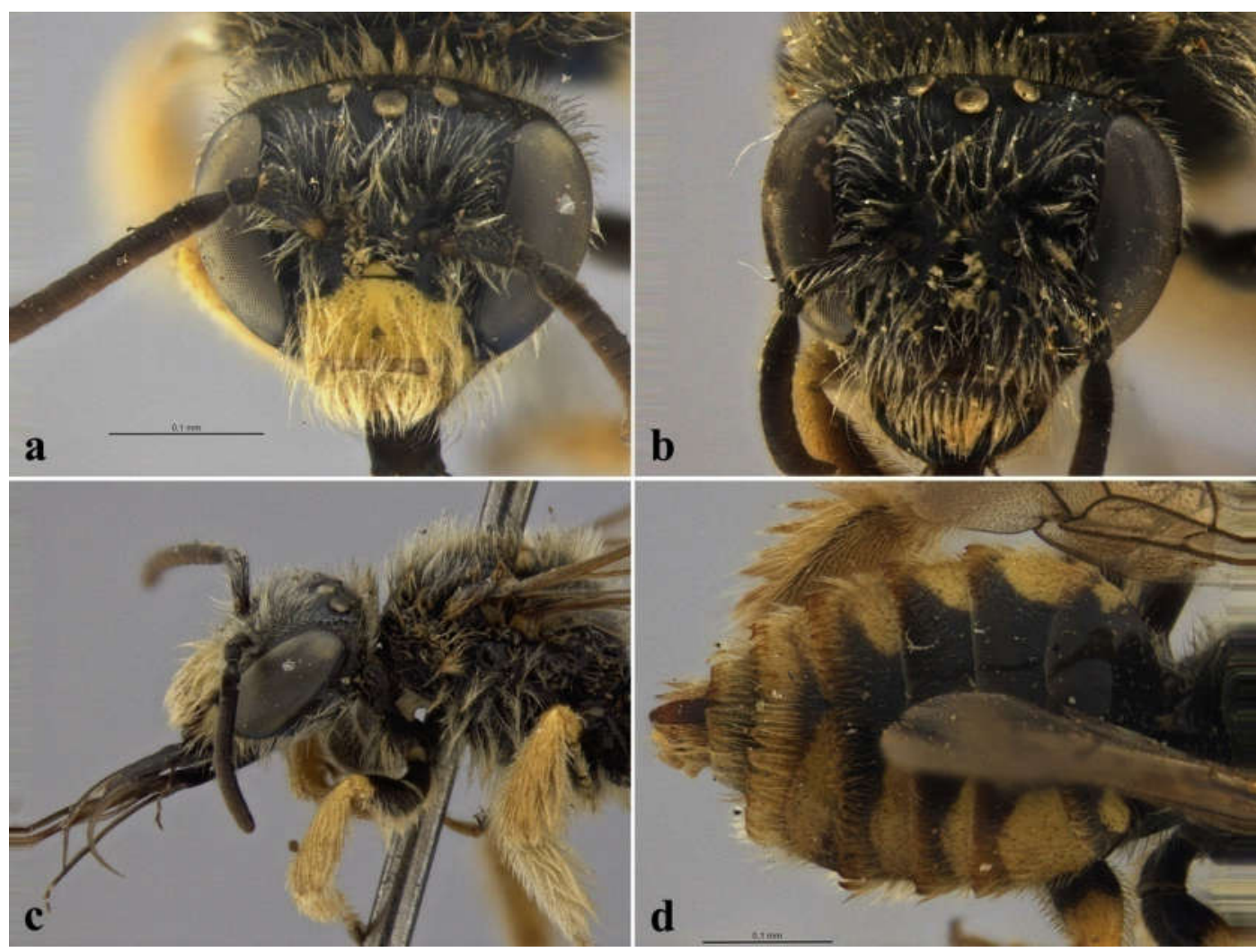

Figura 6. Lanthanomelissa clementis Urban; a. face, macho (holótipo); b. face, fêmea (parátipo, Brasil, Rio Grande do Sul, Guaíba); c. cabeça e metassoma lateral (holótipo); d. metassoma dorsal (holótipo). 

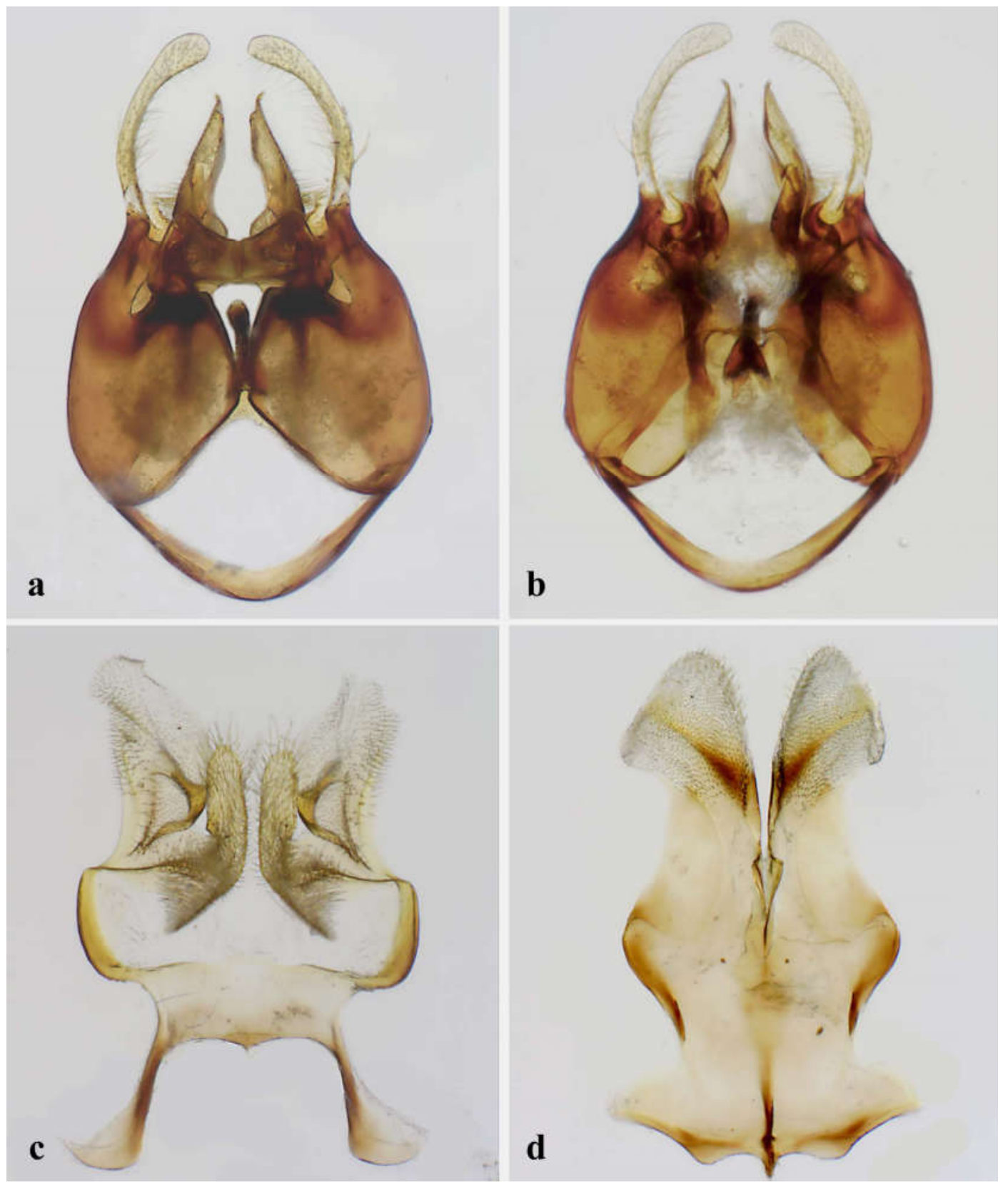

Figura 7. Terminália interna do macho de Lanthanomelissa clementis; a. visão dorsal da cápsula genital; b. visão ventral da cápsula genital; c. visão dorsal de E7; d. visão dorsal de E8. 
Lanthanomelissa discrepans Urban, 1995

(Figs. 8, 9)

Lanthanomelissa discrepans Holmberg (1903): 419; lectótipo fêmea, Argentina: Buenos Aires, Chacabuco (MACN), designado por Roig-Alsina (1997): 18 (Figs. 7-9, 24 (morfologia do aparato coletor de óleo; táxon terminal na análise filogenética da tribo; registro floral: Sisyrinchium platense (Iridaceae); Argentina: Buenos Aires).

Tetrapedia (Schrottkya) goeldiana; Friese, 1908: 58 (identificação errônea).

Anthophorula goeldiana; Brèthes (1909): 223 (cit.) (identificação errônea).

Lanthanomelissa discrepans; Brèthes (1909): 223 (cit.). Urban (1995): 775 (Fig. 4; notas taxonômicas). Schlindwein (1998): 49 (registro floral: Sisyrinchium micrathum, S. sp. 2 (Iridaceae), Spilanthes arnicoides (Asteraceae); Brasil: Rio Grande do Sul). Cocucci et al. (2000): 55 (Fig. 9; morfologia do aparato coletor de óleo; registro floral: Sisyrinchium chilense, S. laxum, S. micranthum, S. pachyrhizum, S. platense, S. setaceum (Iridaceae); Argentina: Córdoba). Cocucci \& Vogel (2001): 36 (Fig. 12 c, e, f; comportamento de coleta de óleo; registro floral: Sisyrinchium chilense, S .laxum, S. pachyrhysum, S. plantense, S. pachyryzum, S. setaceum (Iridaceae).

Lanthanomelissa (Lanthanomelissa) discrepans; Wittmann \& Hoffman (1990): 23 (Brasil: Rio Grande do Sul).

Diagnose: Destaca-se facilmente das outras espécies por apresentar o tegumento do metassoma e esternos de castanho claros a amarelados; pernas amarelas até metade do fêmur e pilosidade mais esbranquiçada no clípeo, fronte, escapo, mesepisterno e pernas. Outra característica que separa L. discrepans das outras espécies do gênero é a presença de pilosidade curta concentrada nas superfícies das laterais interna e externa do escapo (ca 0.5 X F2); presença de cerdas mais longas do que o diâmetro da extremidade do gonóstilo na região proximal dorsal das valvas. Diferencia-se de $L$. pampicola e $L$. magaliae por possuir crenulações bem evidentes em todos os flagelômeros, pelo tamanho corporal levemente maior e mais robusto,e ausência de listra preta no escapo. Distingue-se de L. magaliae por apresentar as cerdas curtas plumosas da superfície 
ventral do fêmur da perna posterior mais esparsas. Apresenta E2 composto por uma franja de pelos simples, longos e esparsos na zona central, nas laterais os pelos são mais próximos uns dos outros e mais longos do que os do meio, E3 e E4 com pelos densos e concentrados na porção mediana, uniformes e encurvados para o meio e cercados por pelos mais longos nas laterais, E5 com pelos curtos no meio e longos nas laterais, E6 com cerdas grossas, curtas e plumosas nas margens laterais e inferior. Pela chave proposta por Urban (1995), a fêmea possui sexto esterno composto por um tufo normal de pelos, não constituído por áreas subapicais glabras; a pilosidade do tórax e da cabeça da fêmea mais curta e densa do que a presente nas outras espécies, sendo mais curta do que o diâmetro da antena (Michener \& Moure 1957).

Variação: Uma fêmea de Uruguaiana (RS) da coleção MCTP, com F10 achatado e recortado apicalmente. De duas fêmeas examinadas de Candiota (DZUP), uma com tergos castanho escuros e com nódoas amarelas em T1, T2 e T3 e a segunda com nódoas grandes em $\mathrm{T} 1$, ocupando grande parte da superfície do tegumento, porém não se unindo na porção mediana e não tocando as margens inferiores, em T2, T3 e T4 as nódoas formam uma faixa contínua amarela, sendo esta mais ampla nas porções laterais e afinando próximo à região do disco. Foi examinado um macho da mesma localidade com tergos e esternos castanho escuros e com pilosidade extremamente densa e de coloração creme nas franjas esternais (PUCRS 38024). Um macho de Pinheiro Machado (Rio Grande do Sul) sem estria amarela central dorsal no mesoscuto (UNB 064120). Fêmeas de regiões do Rio Grande do Sul com mancha amarela, pequena e triangular na área supraclipeal. Machos examinados das localidades de Cordoba, Pronunciamento, Pinheiro Machado, Caçapava do Sul e Pedras Altas possuem tanto o tegumento dos tergos quanto dos esternos amarelos, sem variação aparente na coloração dessas estruturas.

Registros florais: Iridaceae, Sisyrinchium L., Sisyrinchium chilense Hook., Sisyrinchium. micranthum Cav., Sisyrinchium pachyrhizum Baker, Sisyrinchium plantenseI. M. Johnste Sisyrinchium setaceum Klatt (Schlindwein 1995, Roig-Alsina 1997 e Cocucci \& Vogel 2001).

Distribuição Geográfica: Argentina, Brasil (Santa Catarina, Rio Grande do Sul) e Paraguai. 

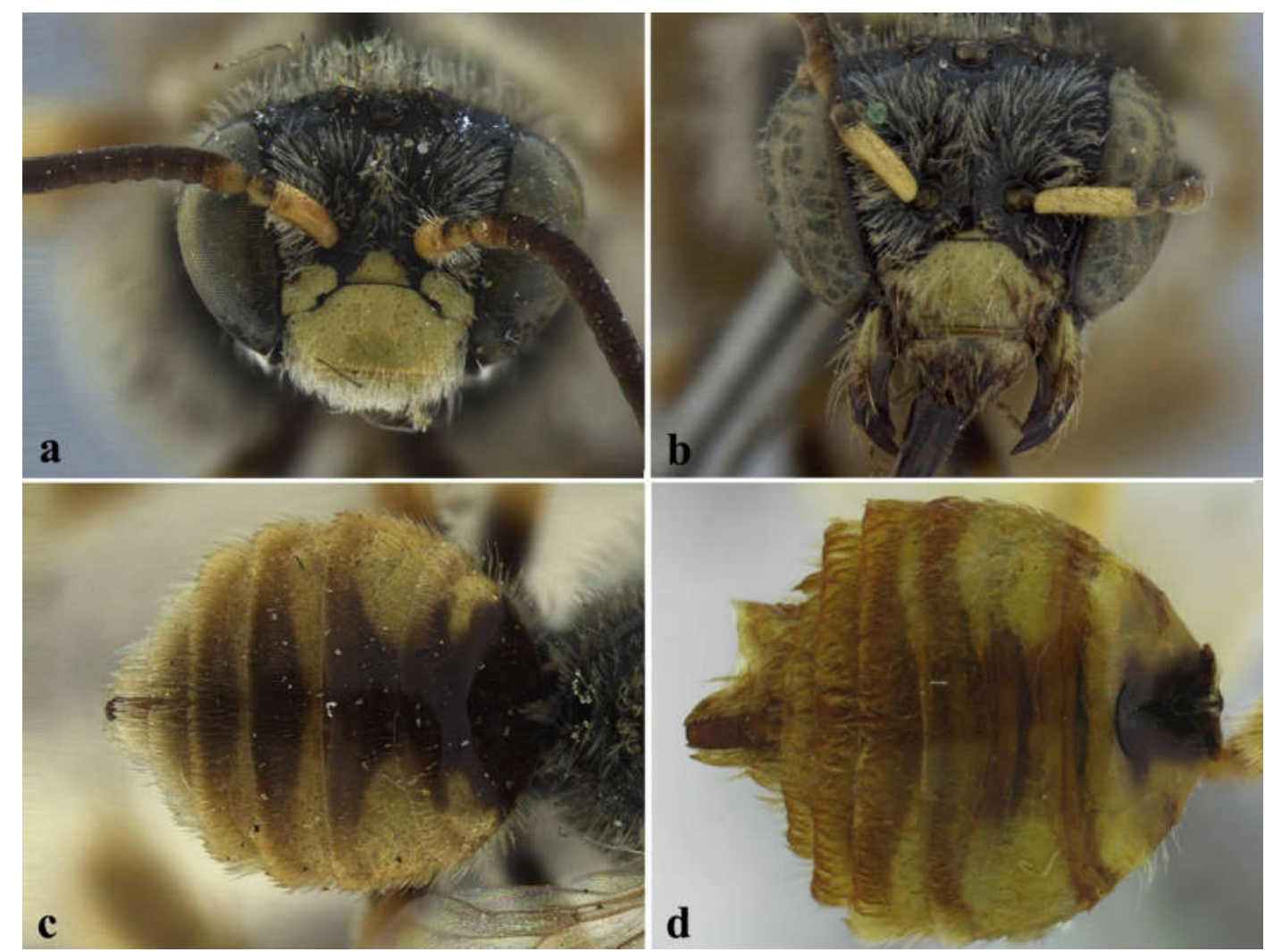

Figura 8. Lanthanomelissa discrepans Holmberg; a. face, macho (DZUP; Argentina, Corrientes, Ituzaingo); b. face, fêmea (DZUP; Argentina, Corrientes, Ituzaingo, Fritz col.; A. Roig-Alsina det., comparado com o lectótipo); c. metassoma, macho, forma escura (DZUP; B rasil, Rio Grande do Sul, Bagé, Casa de Pedra, C. Schlindwein col., D. Urban det.); c. metassoma, macho, forma clara (FSCA; Argentina, Cordoba, Dolores - La Cumbre, C. Porter col.) 

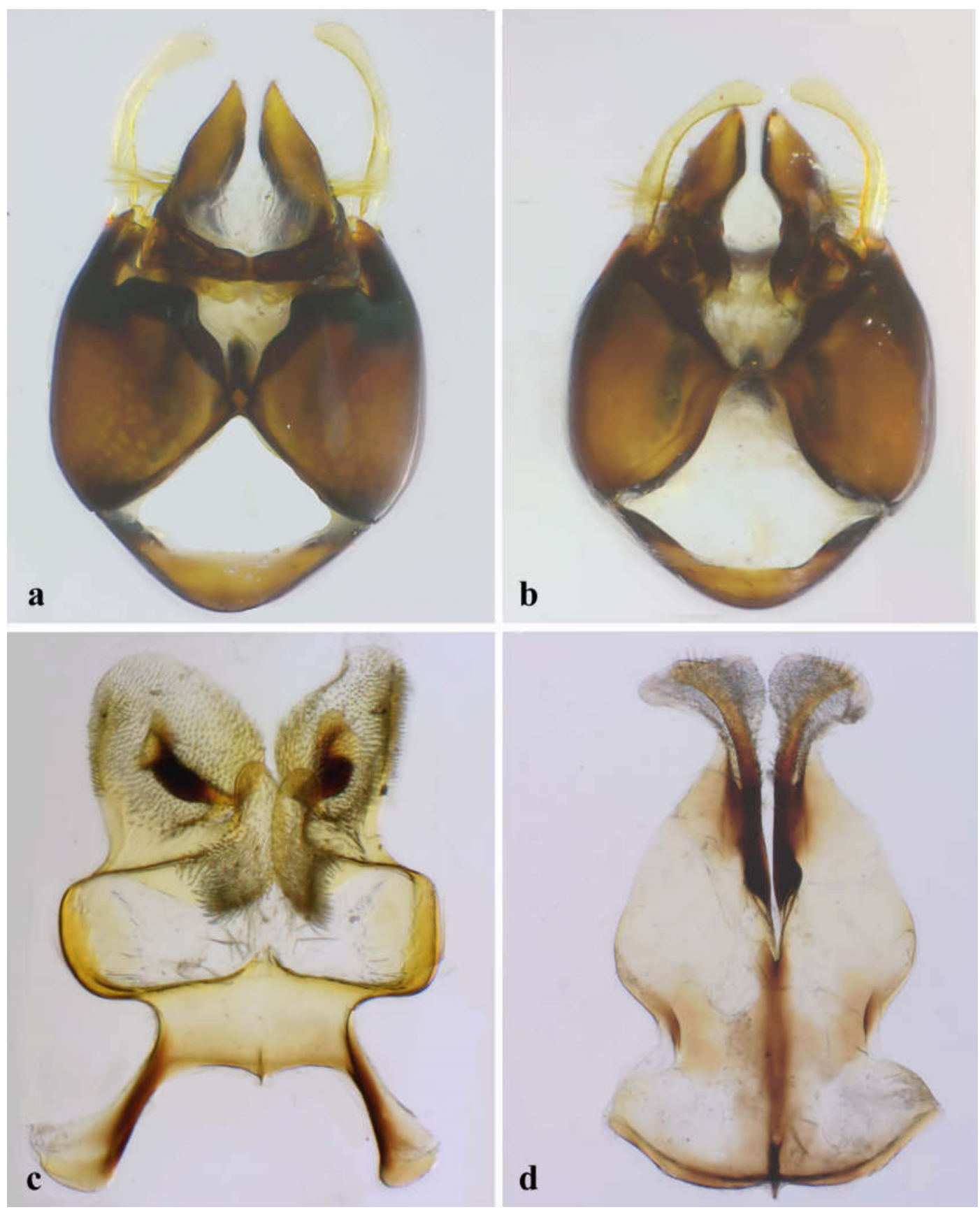

Figura 9. Terminália interna do macho de Lanthanomelissa discrepans; a. visão dorsal da cápsula genital; b. visão ventral da cápsula genital; c. visão dorsal de E7; d. visão dorsal de E8. 
Lanthanomelissa magaliae Urban, 1995

(Figs. 10, 11)

Lanthanomelissa magaliae Urban (1995): 772 (Fig. 2; holótipo macho, Brasil: Rio Grande do Sul, Viamão (DZUP)).

Lanthanomelissa magaliae; Schlindwein (1998): 49 (registro floral: Wahlembergia linarioides (Campanulaceae); Brasil: Rio Grande do Sul). Silveira et al. (2002): 133 (cit.).

Lanthanomelissa mageliae [sic]; Cocucci \& Vogel (2001): 36 (registro floral: Sisyrinchium setaceum (Iridaceae); Brasil: Rio Grande do Sul).

Comentários e diagnose

Assemelha-se a Lanthanomelissa discrepans pela crenulação nos flagelômeros, pela presença de nódoa amarela na área supraclipeal e região da parocular inferior do macho. No macho, a pilosidade da superfície interna do escapo é composta por pelos iguais ao diâmetro de F2; a crenulação da superfície externa dos flagelômeros torna-se mais evidente a partir de F2; presença de tufo distinto de pelos no disco de E6; quinto esterno com pelos laterais voltados para os flancos e na porção mediana os pelos mais curtos (Urban 1995).

Em Urban (1995) não é apresentada a descrição e diagnose referente a fêmea de Lanthanomelissa magaliae, porém, depositado na coleção DZUP encontra-se um parátipo fêmea (Viamão, RS) identificado como L. magaliae. Foram examinadas 23 fêmeas de Lanthanomelissa oriundas dos estados de Santa Catarina e Rio Grande do Sul que foram identificadas aqui como Lanthanomelissa magaliae com base no parátipo da coleção DZUP.

Variação: Na coloração de F1 e F2, dos esternos E1 e E6, no tamanho das nódoas da área supraclipeal e no formato das nódoas na área parocular inferior. Um indivíduo de Caçapava do Sul (UFFS) com F1 e F2 amarelos, E1 com uma pequena nódoa arredondada localizada na porção central do tegumento, E2 com mancha espalhada na superfície e E6 amarelo. Quatro machos com apenas a porção anterior de F1 manchada de amarelo (Criciúma (UNESC 0333), Içara (UNESC 03905), Caçapava do Sul (UFFS) e Viamão (FZB/MCN 93.569). Um macho de Criciúma (UNESC 03874) e outro de 
Viamão (FZB 93.569) com esternos alaranjados. Algumas fêmeas dessa mesma localidade sem mancha amarela na área supraclipeal (UNESC 03875, UNESC 04045 eUNESC 03873) e duas com nódoa amarela na região parocular inferior (UNESC 02938 e UNESC 0336).

Descrição fêmea (LAS-UNESC 03336): comprimento do corpo: 6.4; largura máxima da cabeça: 2.5; altura máxima da cabeça: 2.0; largura máxima de T2: 3.0; comprimento da asa anterior: 5.8; disco do clípeo duas vezes mais largo do que longo; placa labral cerca de 2 vezes mais larga do que longa; primeiro palpômero labial cerca da metade do tamanho do segundo palpômero. Coloração: tegumento predominantemente preto na cabeça, mesossoma e metassoma, com as seguintes áreas amarelas: labro, clípeo, metade basal das mandíbulas, área supraclipeal, região parocular inferior; escapo amarelo com estria lateral preta, colar e lobos pronotais, porção apical da tégula, estria no mesoscuto, nódoas amarelas de T1-T3. T1 com nódoas de formato irregular, T2 com nódoa arredondada grande, cobrindo mais do que $1 / 3$ da região da superfície, porém não se juntando no disco da superfície e nem encostando na margem inferior, T3 com mancha triangular pequena, concentrada apenas na margem superior. Pedicelo castanho; superfície anterior dos flagelômeros castanho claras e posterior castanho escuras; venação alar e pterostigma alaranjados; pernas anteriores e médias pretas até o ápice do fêmur e amarelas até os tarsômeros, pernas posteriores pretas até a metade do fêmur e amarelas até os tarsômeros; unhas amarelas com porção distal marrom; arólios marrons e esternos metassomais castanhos. Pilosidade: esbranquiçada na fronte, gena, clípeo, labro, escapo, escutelo, mesepisterno, metaposnoto e restante do corpo coberto por pilosidade amarelada. Disco do clípeo e labro com pelos predominantemente longos e plumosos, concentrados na margem inferior. Fronte com pelos predominantemente curtos, e outros mais longos na zona central, todos plumosos. Escapo com pilosidade esparsa e plumosa, com pelos curtos mesclados com outros mais longos. Mesoscuto com pilosidade abundante e plumosa, pelos mais longos mesclados com pelos mais curtos, no escutelo pelos predominantemente longos, concentrados na margem lateral e inferior, formando tufos de pelos distintos, no metaposnoto pelos curtos e plumosos cobrindo a superfície central, cercada por pelos mais longos nas laterais. Nos tergos, tufos de cerdas plumosas nas margens laterais, no centro da superfície cerdas curtas simples e esparsas, formando faixas completas a partir de T3, e a partir de T4 com pelos mais longos e plumosos formando franjas densas nas margens inferiores; E2-E4 com 
pilosidade longa, fina e simples no centro, e plumosa nas zonas marginais, E4 e E5 com pelos longos e plumosos das zonas marginais até o centro, sendo mais abundante em E5, E6 composto por um tufo de pelos, desprovido de áreas subapicais glabras. Superfície do integumento:pontuação predominantemente fina. Disco do clípeo com pontuação fina e esparsa na superfície posterior e com pontuação mais grossa e densa no disco e margem inferior da superfície, labro com pontos muito próximos entre si. Mesoscuto, escutelo e metanoto com pontos finos e bastante densos, muito próximos entre si. Metanoto com pontos finos e esparsos entre si na superfície da margem superior e pontos mais próximos nas margens inferiores.

Registros florais: Iridaceae, Sisyrinchium L., Sisyrinchium setaceum Klatt (Cocucci \& Vogel 2001), Asteraceae.

Distribuição Geográfica:Brasil (Santa Catarina e Rio Grande do Sul).
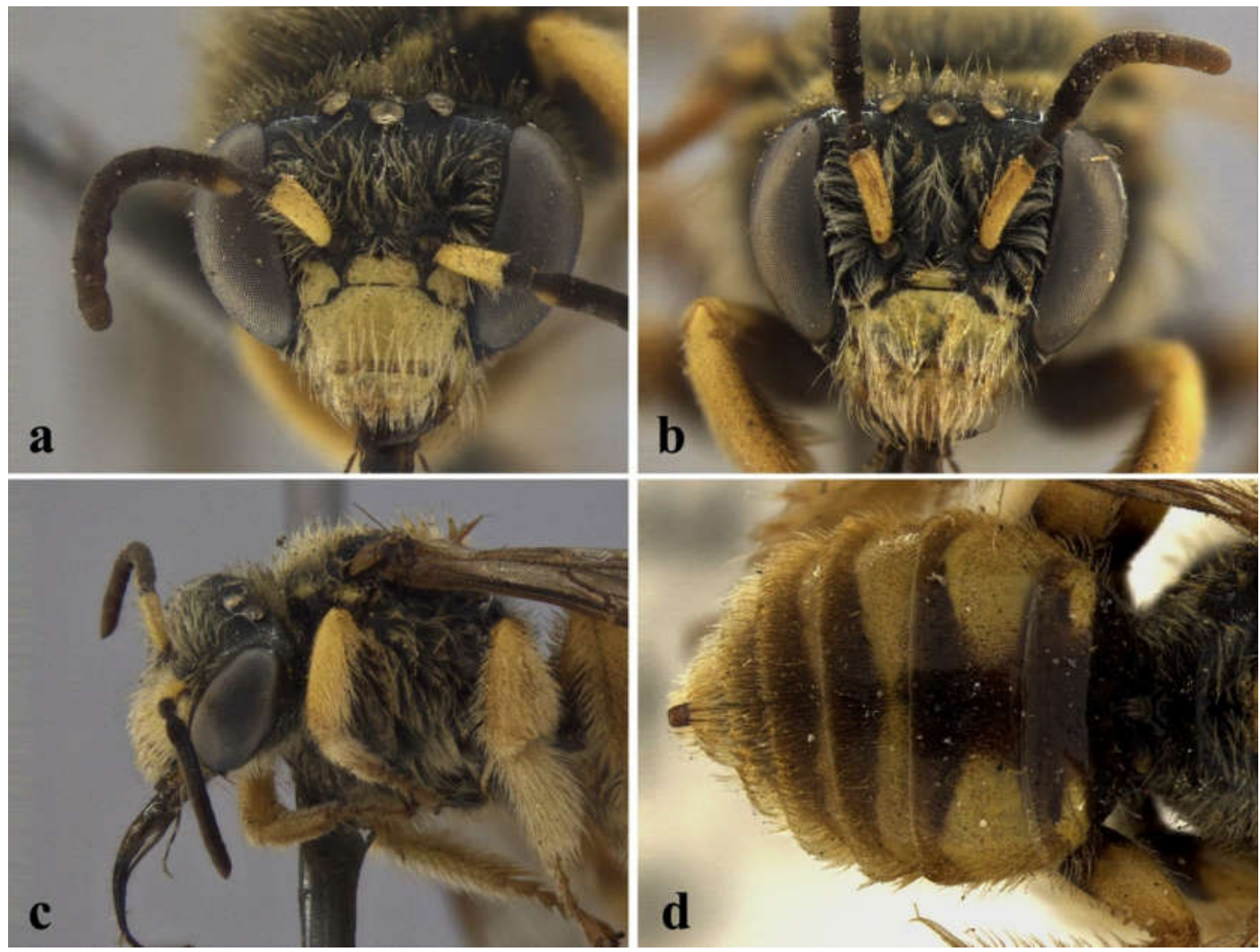

Figura 10. Lanthanomelissa magaliae Urban; a. face, macho (holótipo); b. face, fêmea (DZUP, Brasil, Rio Grande do Sul, Viamão, Morro do Coco); c. cabeça e metassoma lateral (holótipo); d. metassoma dorsal (holótipo). 

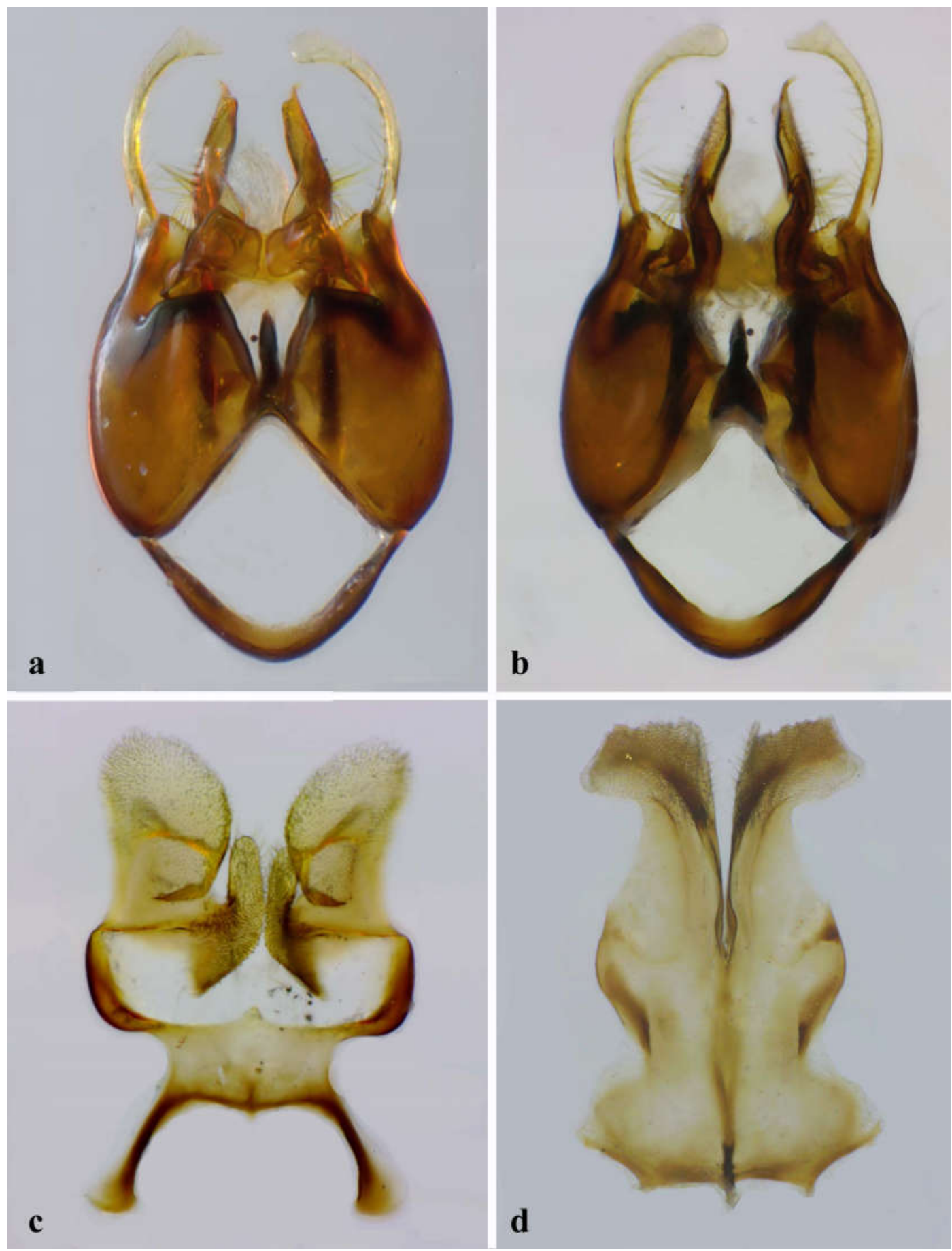

Figura 11. Terminália interna do macho de Lanthanomelissa magaliae; a. visão dorsal da cápsula genital; b. visão ventral da cápsula genital; c. visão dorsal de E7; d. visão dorsal de E8. 
(Figs. 12, 13)

Lanthanomelissa pampicola Urban (1995): 773 (Fig. 3; holótipo macho, Brasil, Rio Grande do Sul, Caçapava do Sul (DZUP)).

Lanthanomelissa pampicola; Schlindwein (1998): 49 (registro floral: Hysterionica filiformis (Asteraceae); Sisyrinchium micranthum (Iridaceae); Brasil: Rio Grande do Sul). Silveira et al. (2002): 133 (cit.).

\section{Comentários e diagnose}

Fêmea com clípeo bicolor, apresentando uma mancha em forma de letra W, circundada por áreas enegrecidas; sexto esterno com duas áreas subapicais glabras. Machos com franjas densas, com pelos de tamanhos uniformes do segundo ao quinto esterno (Urban 1995). No macho cerdas grossas da superfície lateral interna do escapo predominantemente longas (ca. 0.6 X F2); E6 do macho com tegumento praticamente glabro, sem cerdas curtas nas margens laterais e inferiores. Ao contrário das espécies $L$. magaliae e $L$ discrepans, as pernas posteriores de L. pampicola são amarelas a partir do terço apical do fêmur até os tarsômeros. As cerdas localizadas na superfície posterior do fêmur da perna posterior são em sua maioria curtas, intercaladas com outras mais longas.

Variação: Dentre três espécimes de Caçapava do Sul foi observada uma fêmea com pilosidade mais abundante no escapo, superfície anterior dos flagelômeros inteiramente alaranjada (iniciando-se na metade de F1) e T4-T6 inteiramente castanhos (RPSP 12.2879), uma fêmea com a presença de uma pequena nódoa amarela na área supraclipeal e pelos no escapo mais longos do que o diâmetro de F2, além de pedicelo ornado com estria amarela na extremidade superior (UNB 064157) e uma terceira fêmea com nódoa triangular grande em T2, ocupando mais da metade do tegumento, porém não encostando no bordo da margem inferior, nódoas triangulares pequenas e restritas as laterais superiores em T4 e somente F1 e F2 alaranjados (UNB 064158).

Registros florais:.Iridaceae, Sisyrinchium L., Sisyrinchium sp.

Distribuição Geográfica:Argentina, Brasil (Santa Catarina e Rio Grande do Sul). 

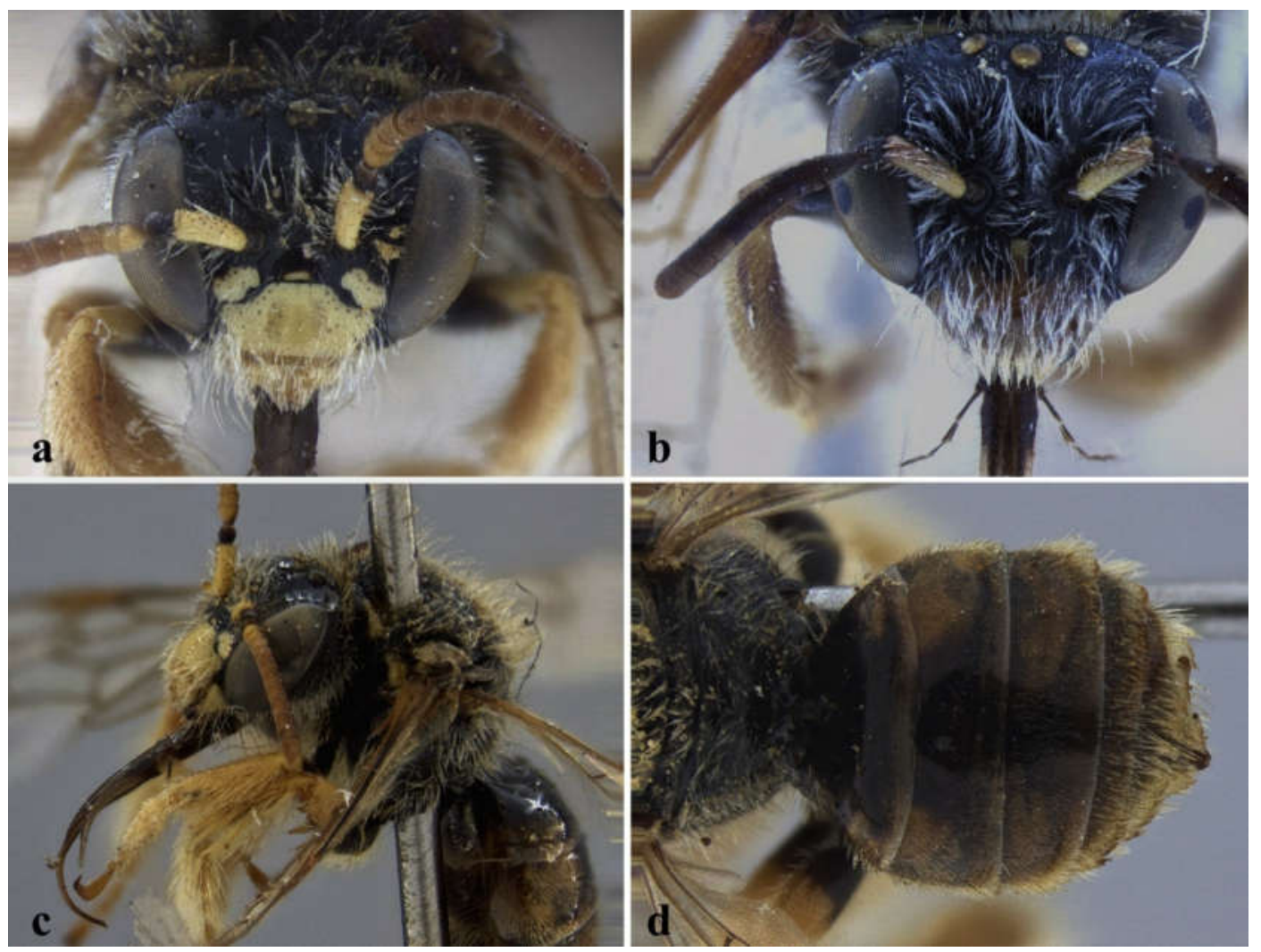

Figura 12. Lanthanomelissa pampicola Urban; a. face, macho (holótipo); b. face, fêmea (parátipo, Brasil, Rio Grande do Sul, Guaritas); c. cabeça e mesossoma lateral (holótipo); d. metassoma dorsal (holótipo). 

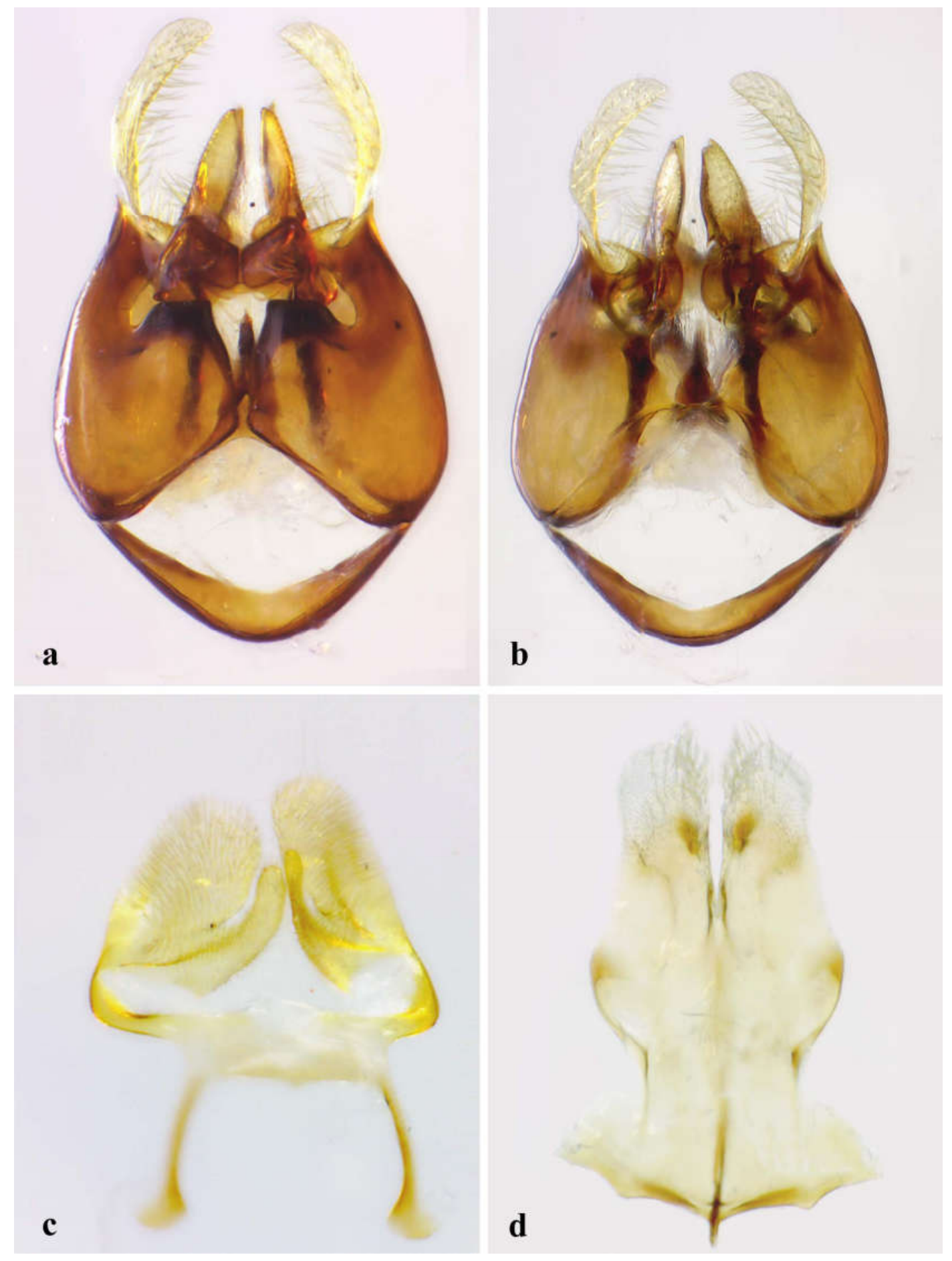

Figura 13. Terminália interna do macho de Lanthanomelissa pampicola; a. visão dorsal da cápsula genital; b. visão ventral da cápsula genital; c. visão dorsal de E7; d. visão dorsal de E8. 
Lanthanomelissa parva (Roig-Alsina, 1999)

(Fig. 14)

Chalepogenus parvus Roig-Alsina (1997): 82 (Figs. 2, 8, 20, 36, 55, 60; holótipo macho (MACN); localidade tipo: Argentina: Tucumán, El Cadillal (registro floral: Nierembergia hippomanica, N. aristata, N. Stricta (Solanaceae)).

Lanthanomelissa goeldiana; Michener \& Moure (1957): 417, (Figs. 22-24, desenhos dos esternos 7-8 e cápsula genital; identificação errônea).

Lanthanomelissa discrepans Holmberg; Cocucci (1984): 38 (identificação errônea; registro floral: Nierembergia hippomanica - Solanaceae).

Lanthanomelissa goeldiana Friese; Cocucci (1991): 27 (identificação errônea; registro floral: Nierembergia aristata - Solanaceae).

Chalepogenus parvus; Cocucci et al.(2000): 54 (Fig. 4; morfologia do aparato coletor de óleo; registro floral: Nierembergia aristata, N. rigida - Solanaceae; Argentina: Córdoba). Silveira et al. (2002): 133 (Brasil: Rio Grande do Sul, localidade não definida). Aguiar (2007): 613 (cit.). Cosacov et al. (2008): 724 (Fig. 2B , coleta de óleo em Nierembergia linariifolia sem a ocorrência de polinização). Nattero et al. (2010): 1960 (Tabela 1 polinização de Nierembergia linariifolia).

Comentários e diagnose

Segundo Roig-Alsina (1999) esta espécie é facilmente identificada pelo tamanho reduzido, com fêmeas medindo de 5.5 a $6 \mathrm{~mm}$ de comprimento e machos de 4.2 a 5 $\mathrm{mm}$. Espécie com corpo bicolor, com as seguintes regiões amarelas: clípeo, labro, pernas, colar e lobo pronotais, base da mandíbula, mancha na porção apical da tégula e escutelo. Assemelha-se a $L$. discrepans por tergos metassomais amarelados e pela pilosidade esbranquiçada na fronte, clípeo, labro, mesepisterno e pernas, sendo esta mais branca do que a observada nas outras espécies de Lanthanomelissa. Outras características que diferenciam L. parva das outras espécies do gênero Lanthanomelissa são a pilosidade na superfície anterior do basitarso anterior composta por cerdas longase finas, e placa basitibial com coloração muito clara, próxima ao amarelo pálido. Como inferido por Roig-Alsina (1999) essa espécie pode ser confundida com L. discrepans, no entanto, difere desta por apresentar um tamanho corporal reduzido, ausência de 
crenulações nos flagelômeros do macho, porção anterior do pedicelo preta, pilosidade no disco do metasponoto curta e decumbente, cobrindo a superfície na forma de um tapete. Nas fêmeas a divergência entre as duas espécies pode ser percebida no escapo predominante preto de L. parva, nas cerdas grossas da superfície lateral interna do escapo que são longas e em um escutelo inteiramente amarelo. Apesar de ter sido descrita dentro do gênero Chalepogenus, L. parva foi erroneamente confundida com $L$. discrepans. A ilustração de terminália interna de um macho de Lanthanomelissa disponível no trabalho de Michener e Moure (1957) pertencia à espécie L. parva.

Registros florais: Solanaceae, Nierembergia, Nierembergia hippomanica Miers (Cocucci 1984, 1991), Nierembergia aristata (Cocucci 1991) e Nierembergia sricta (Cocucci 1991; Roig-Alsina 1999).

Distribuição Geográfica: Argentina (Salta, Tucumán, Catamarca, Córdoba e Entre Rios). Silveira et al. (2002) reportam esta espécie para o Rio Grande do Sul porém sem localidade determinada.
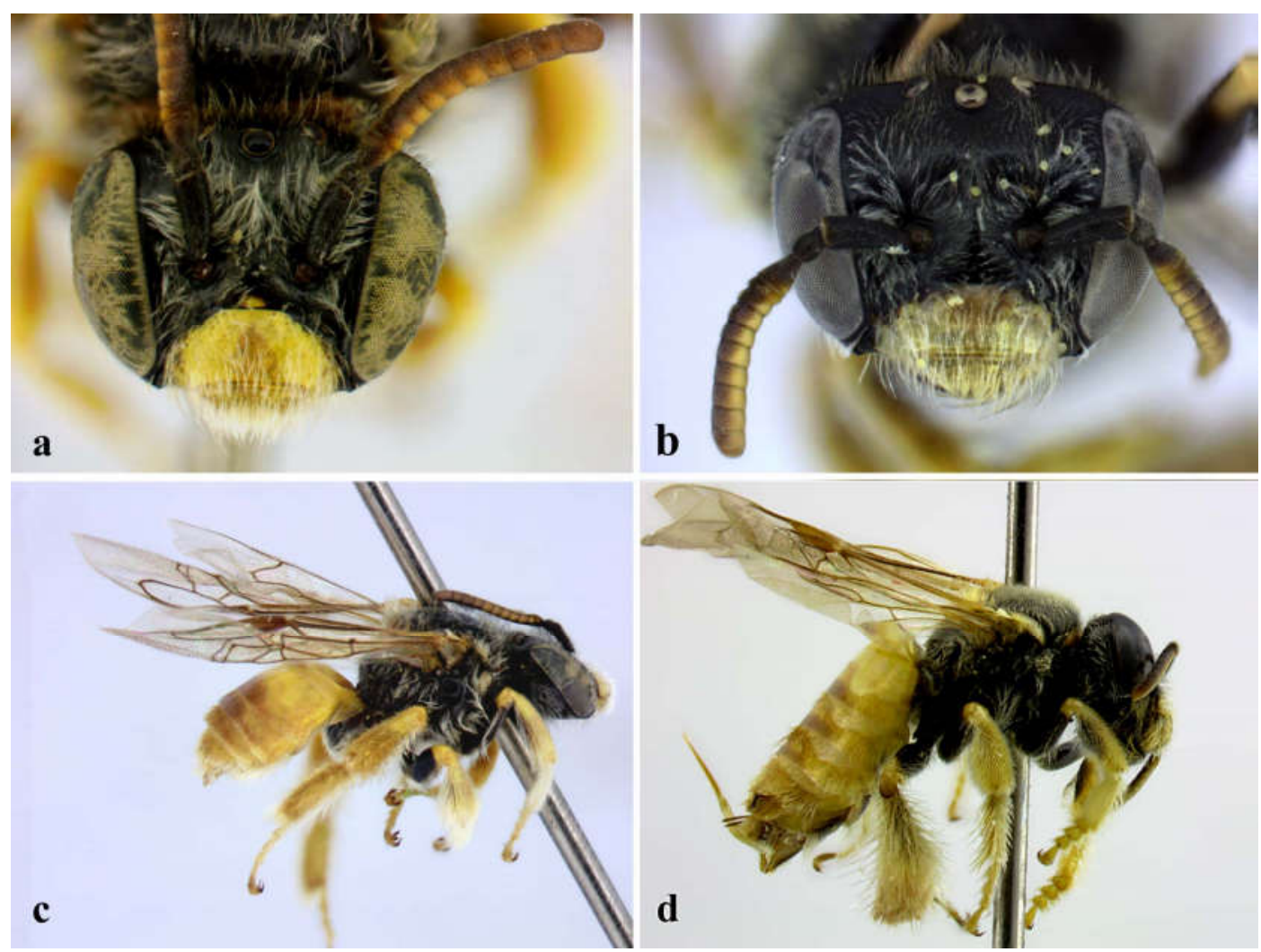

Figura 14. Lanthanomelissa parva (Roig-Alsina); a. face, macho; b. face, fêmea; c. macho, lateral; d. fêmea, lateral (Argentina, Córdoba, Dean Funes). 


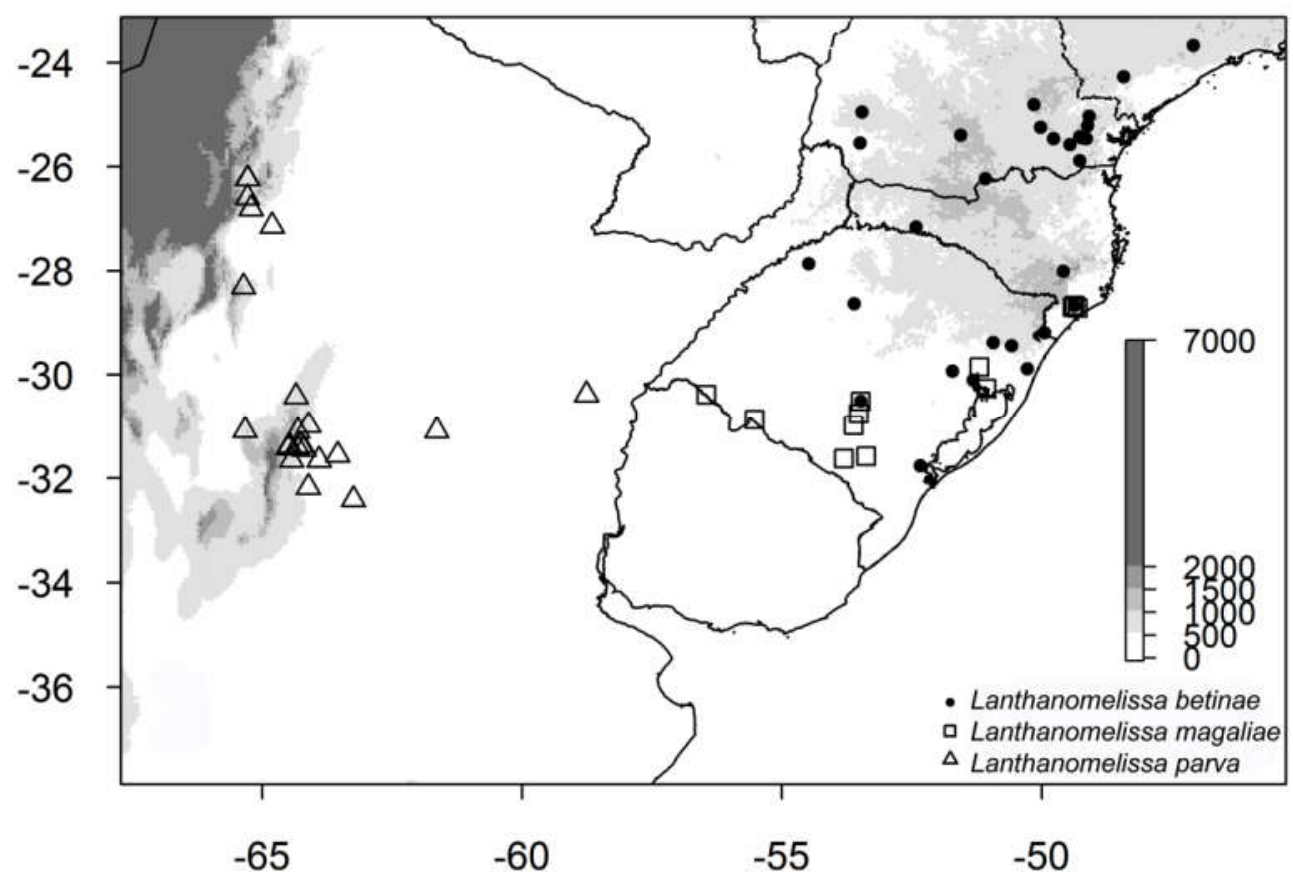

Figura 15. Mapa de distribuição biogeográfica das espécies L. betinae, L. magaliae e L. parva de acordo com o gradiente de altitude.

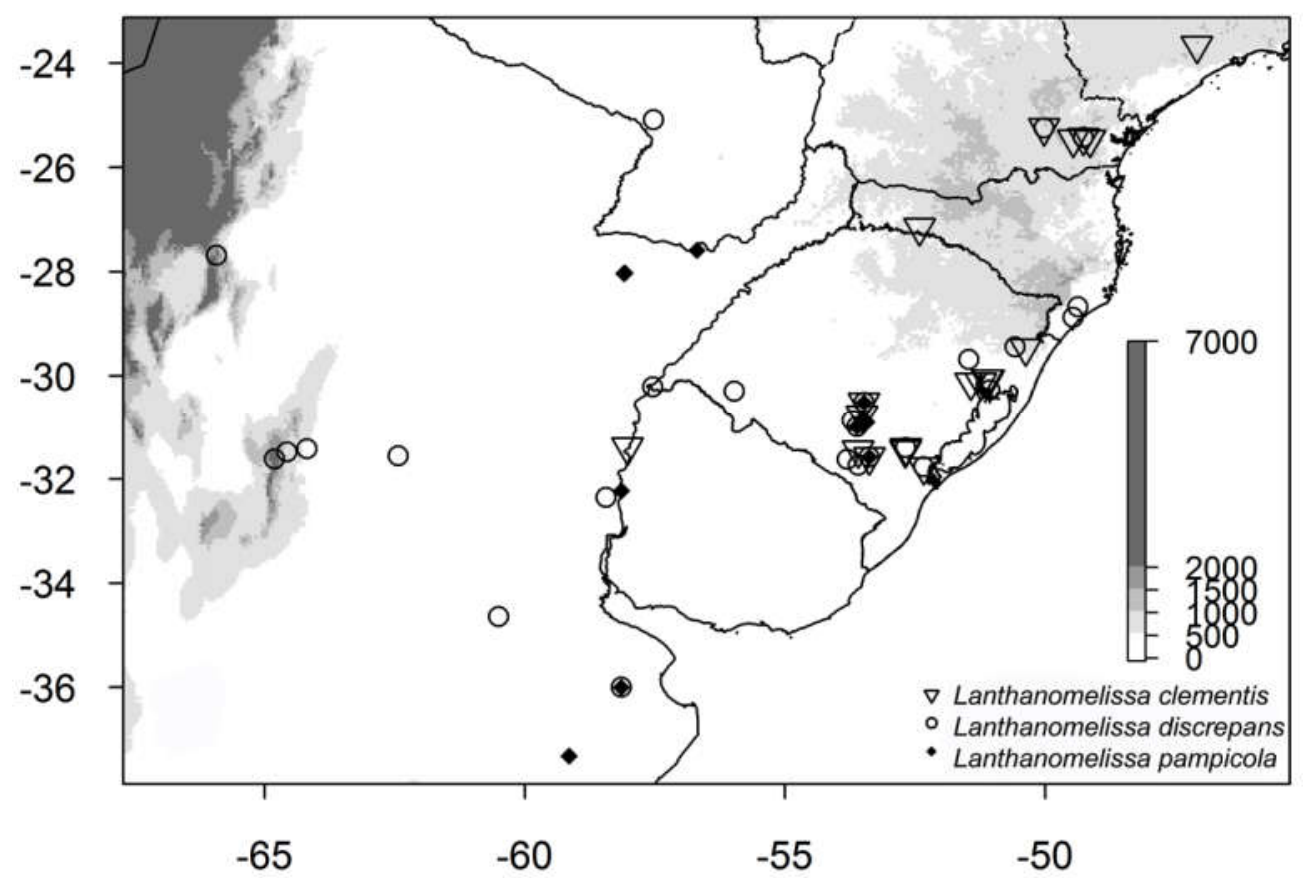

Figura 16. Mapa de distribuição biogeográfica das espécies $L$. clementis, $L$. discrepans e $L$. pampicola de acordo com o gradiente de altitude. 


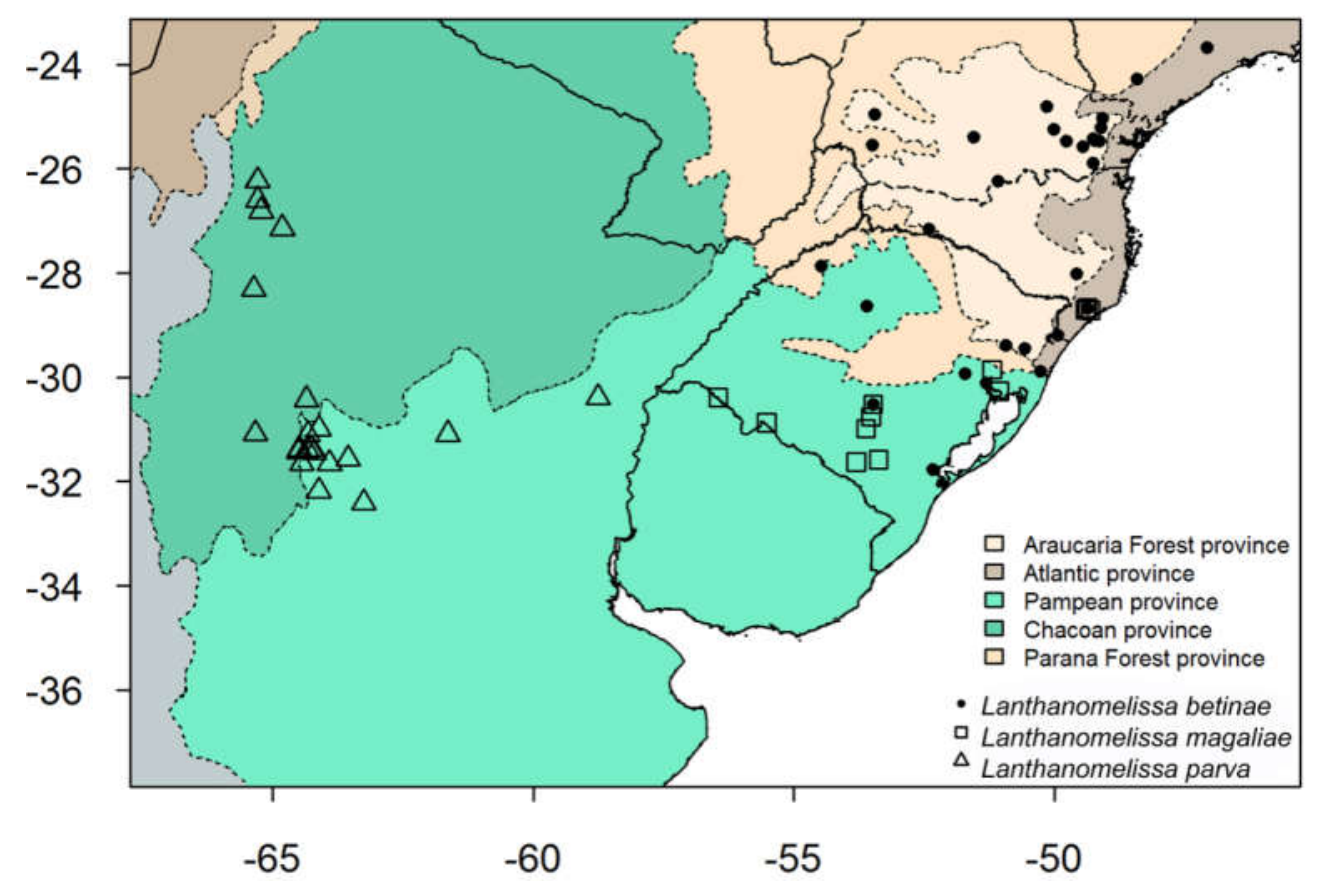

Figura 17. Mapa de distribuição das espécies L. betinae, L. magaliae e $L$. parva de acordo com a regionalização biogeográfica de Morrone (2014).

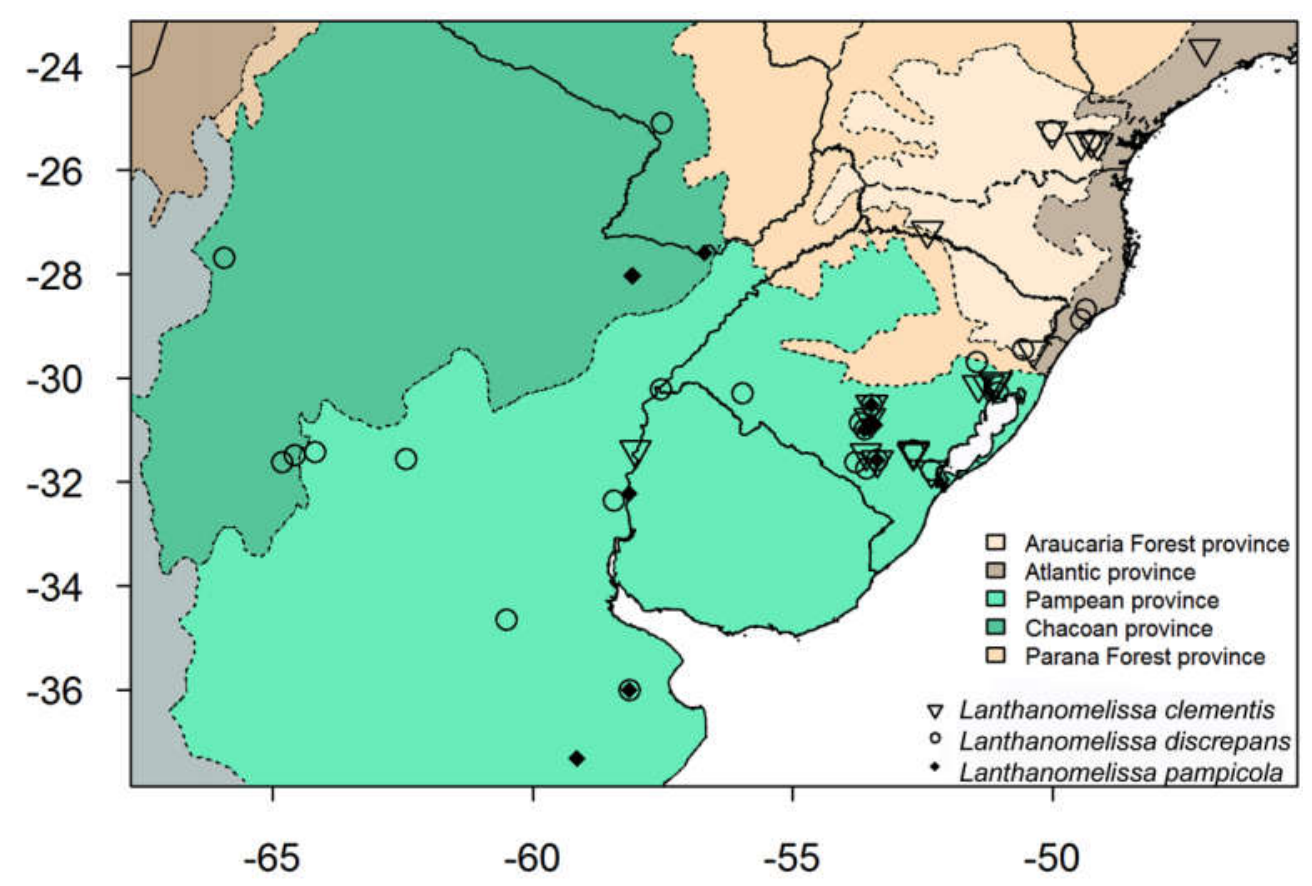

Figura 18. Mapa de distribuição das espécies L. clementis, L. discrepans e L. pampicola de acordo com a regionalização biogeográfica de Morrone (2014). 


\section{DISCUSSÃO}

Os resultados apresentados permitem propor a revalidação do gênero Lanthanella, como proposto inicialmente por Michener e Moure (1957). Em RoigAlsina (1999), o grupo goeldianus apresenta outras duas espécies com forte semelhança morfolófica o que permite propor que também sejam relocadas para dentro de Lanthanella. As três espécies passariam a ser tratadas sob os nomes: Lanthanella goeldiana, Lanthanella luciane e Lanthanella neffi comb.nov.. Quanto a Lanthanomelissa o gênero passa a ser composto por seis espécies, sendo L. parva comb.nov.

A partir desta revisão sistemática, constatou-seque o gênero Lanthanomelissa é fortemente suportado por caracteres discretos que sustentam o monofiletismo do grupo. Suas espécies também são facilmente diagnosticadas por um conjunto de características que incluem principalmente padrão de coloração e pilosidade. A dificuldade do posicionamento de Lanthanomelissa nos trabalhos anteriores foi ressaltada por Michener (1963) que afirmou que as divisões dos grupos Chalepogenus e Lanthanomelissa foram realizadas de forma arbitrária devido a existência de um contínuo de caracteres entre Tapinotaspis e Paratetrapedia. Logo, espera-se que através da filogenia esta nova proposta de classificação do grupo possa ser usada e testada por outros métodos e dados. E que independente do uso das categorias de gêneros e subgêneros estes nomes possam representar um melhor significado biológico, biogeográfico e evolutivo.

O gênero Lanthanomelissa foi registrado nos estados brasileiros de São Paulo, Paraná, Santa Catarina e Rio Grande do Sul, e países como Argentina e Paraguai. Os registros mais ao norte pertencem às espécies Lanthanomelissa betinae e Lanthanomelissa clementis, na cidade de Cotia (SP), e mais ao Sul à espécie Lanthanomelissa pampicola, na cidade de Tandil, província de Buenos Aires (Argentina). Em sua maioria as espécies estão distribuídas em áreas de transição, entre o que seriam áreas mais baixas (até 500 metros) e áreas com altitudes mais elevadas. As espécies L. discrepans e L. parva podem ser encontradas em altitudes de aproximadamente 1.000 metros, nas áreas montanhosas na região oeste da Argentina (Figs. 14 e 15). 
De acordo com a regionalização biogeográfica proposta por Morrone (2014), o gênero está concentrado na subregião Chacoana, dentro dos domínios Chacoano e Paraná, principalmente nas províncias dos Pampas e Floresta de Araucárias (Figs 16, 17). Tendo em vista que o Uruguai encontra-se dentro da região de Pampas era esperado que o gênero estivesse ali presente, contudo, até o momento não há registro da ocorrência de Lanthanomelissa nesse país. Isso pode ser explicado pela falta de coletas na área.

Os registros da espécie Lanthanomelissa parva, obtidos de dados apresentados por Roig-Alsina (1999) concentram-se nas províncias de Córdoba e Tucumán na Argentina. Embora o gênero Nierembergia, visitado por essa espécie para a coleta de óleo seja encontrado nos estados do sul do Brasil, essa espécie apresenta apenas um registro sem localidade definida inferido por Silveira et al. (2002), para o Rio Grande do Sul. A região de Cotia e o Parque Estadual de Intervales onde foram coletadas $L$. clementis e L. betinae está dentro do Domínio do Paraná, na província Atlântica que também está presente no estado do Paraná e em uma parte de Santa Catarina, locais onde também ocorre Lanthanomelissa.

De acordo com dados expostos no trabalho de Fregonezi et al.(2013) observa-se que o gênero Calibrachoa encontra-se distribuído nos estados do Sul do Brasil, e em algumas regiões do Uruguai, Paraguai e Argentina, o mesmo é percebido com as espécies de Lanthanomelissa, exceto pela não ocorrência no Uruguai, o que pode ser explicado apenas pela falta de coletas no país. Os autores ainda enfatizam a diversificação de Petunia em duas linhagens distintas, uma que está concentrada em áreas com altitudes mais baixas e outra em altitudes mais elevadas. Pode ser sugerido que o mesmo ocorra com as espécies de Lanthanomelissa.

Perspectivas futuras no estudo da linhagem Lanthanomelisa poderiam incluir a análise filogenética com as demais espécies de Lanthanella que não foram analisadas neste trabalho, e também análises moleculares a fim de elucidar mais minuciosamente as semelhanças morfológicas e a evolução do grupo como um todo. O presente trabalho abre a possibilidade de futuros estudos acerca da biogeografia e de processos de especiação do gênero Lanthanomelissa. Este representa um dos poucos trabalhos sobre a sistemática de um gênero exclusivamente endêmico dos campos do sul do Brasil e outros países do sul da América do Sul. Estudos mais aprofundados sobre o gênero 
podem permitir reconhecer processos e padrões evolutivos destas formações tão pouco estudadas. 
Tabela 1. Matriz de estados de caracteres para análise cladística de Lanthanomelissa e espécies do grupo externo. Legenda: "?", variável ou inaplicável

Taxa

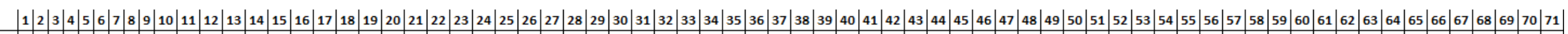
Arhysoceble huberi

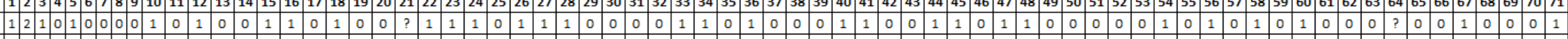

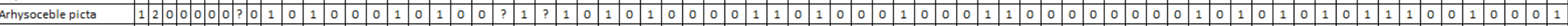

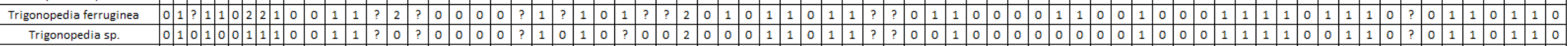

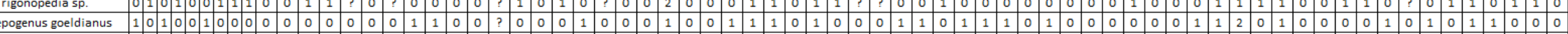

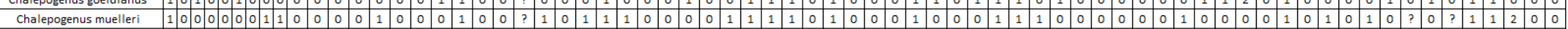

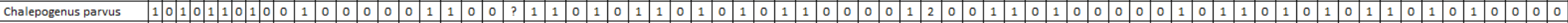

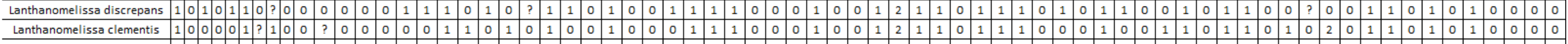

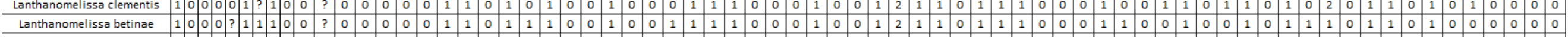

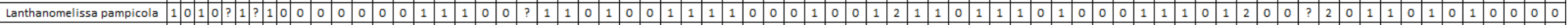

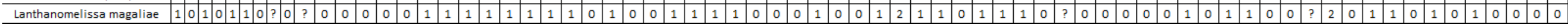




\section{REFERÊNCIAS BIBLIOGRÁFICAS}

Aguiar, A.J.C., Melo, G.A.R., Rozen Jr, J., \& Alves-dos-Santos, I. (2004) Synopsis of Tapinotaspidini nesting biology, p. 80-85. In: K.H. Hartfelder el al. (eds.). Proceedings of the 8th IBRA Conference on Tropical Bees ad VI Encontro sobre Abelhas.Ribeirão Preto, Universidade de São Paulo, Faculdade de Filosofia, Ciências e Letras de Ribeirão Preto.

Aguiar, A.J.C. \& Melo, G.A.R. (2007) Taxonomic revision, phylogenetic analysis, and biogeography of the bee genus Tropidopedia (Hymenoptera, Apidae, Tapinotaspidini). Zoological Journal of the Linnean Society, 151, 511-554.

Aguiar, A.J.C. \& Melo, G.A.R. (2009) Notes on oil sources of the bee genus Caenonomada (Hymenoptera, Apidae, Tapinotaspidini). Revista Brasileira de Entomologia, 53 (1), 154-156.

Aguiar, A.J.C. (2012). New bee species of the genus Monoeca (Hymenoptera, Apidae: Tapinotaspidini) from Brazil. Zootaxa, 3564, 17-32.

Alves-dos-Santos, I., Machado, I.C., \& Gaglianone, C. (2007) História natural das abelhas coletoras de óleo. Oecologia Brasiliensis, 11(4), 544-557.

Alves-dos-Santos, I. (2009) Cleptoparasite bees, with emphasis on the oil bees hosts. Acta Biológica Colombiana, 14(2), 107-114.

Alves-dos-Santos, I., Gaglianone, M.C., Naxara, S.R.C \& Engel, M.S. (2009) Male sleeping aggregations of solitary oil-collecting bees in Brazil (Centridini, Tapinotaspidini, and Tetrapediini; Hymenoptera: Apidae).Genetics and Molecular Research, 8 (2), 515-524.

Alves-dos-Santos, I., da Silva, C.I., Pinheiro, M., \& Kleinert, A., de M, P. (2016) Quando um visitante floral é um polinizador? Rodriguésia, 67(2), 295-307.

Becker, R.A., \& Wilks, A.R. (2016). R version by Ray Brownrigg.Enhancements by Thomas P Minka an Alex Deckmyn.Maps: Draw Geographical Maps. R package version 3.1.1. Disponível em: https://CRAN.R-project.org/package=maps. 
Bengtsson, H. (2016). R. devices: Unifield Handling of Graphics Devices. R package version 2.15.1. Disponível em: https://CRAN.R-project.org/package=R.devices.

Bivand, R., Keitt, T., \& Rowlingson, B. (2016). Rgdal: Bindings for the Geospatial Data Abstraction Library. $\mathrm{R}$ package version 1.2-4. Disponível em: https://CRAN.R-project.org/package=rgdal.

Brèthes, J. (1909) Hymenoptera Paraguayensis. Anales del Museo Nacional Buenos Aires, 20, 210-256.

Brothers, D.J. (1976) Modifications of the metaposnotum and origin of the propodeal triangle' in Hymenoptera Aculeata. Systematic Entomology, 1, 177-182.

Buchmann, S.T. (1987) The ecology of oil flowers and their bees. Annual Review of Ecology and Systematics, 18, 343-369.

Cappellari, S.C., Harter-Marques, B., Aumeier, P., \& Engels, W. (2009) Mecardonia tenella (Plantaginaceae) attracts oil-, perfume-, and pollen-gathering bees in Southern Brazil. Biotropica, 41(6), 721-729.

Chauveau, O., Eggers, L., Raquin, C., Silvério, A., Brown, S., Cououx, A., Cruaud, C., Kaltchuk-Santos, E., Yockteng, R., Souza-Chies, T.T \& Nadot, S. (2011) Evolution of oil-producing trichomes in Sisyrinchium (Iridaceae): insights from the first comprehensive phylogenetic analysis of the genus. Annals of Botany, 126.

Cocucci, A.A. (1984) Polinización en Nierembergia hippomanica (Solanaceae). Kurtziana, 17, 31-47.

Cocucci, A.A. (1991) Pollination biology of Nierembergia (Solanaceae). Plant Systematics and Evolution, 174, 17-35.

Cocucci, A.; A. Sersic.,\&Roig-Alsina, A. (2000) Oil-collecting structures in Tapinotaspidini: their diversity, function and probable origin (Hymenoptera: Apidae). Mitteilungen der Münchner Entomologischen Gesellschaft, 90, 51-74.

Cocucci, A. \& Vogel, S. (2001) Oil-producing flowers of Sisyrinchium species (Iridaceae) and their polinators in southern South America.Flora, 196, 26-46. 
Cosacov, A., Nattero, J.,\& Cocucci, A.A. (2008) Variation of pollinator assemblages and pollen limitation in a locally specialized system: the oil-producing Nierembergia linariifolia (Solanaceae).Annals of Botany, 102, 723-734.

Farris, J.S. (1982) Outgroups and parsimony.Systematic Zoology, 31, 328-334.

Favretto, M.A., dos Santos, E.B., \& Geuster, C.J. (2013) Entomofauna do Oeste do Estado de Santa Catarina, Sul do Brasil. Entomo Brasilis, 6(1), 42-63.

Federal Communications Commission (2016) Degrees Minutes Seconds to/from Decimal Degrees | Federal Communications Comission. Disponível em: http://www.fcc.gov/media/radio/dms-decimal/.

Fregonezi, J. N., Turchetto, C., Bonatto, S.L., \& Freitas, L.B. 2013. Biogeographical history and diversification of Petunia and Calibrachoa (Solanacea) in the Neotropical Pampas grassland. Botanical Journal of the Linnean Society, 171, 140-153.

Friese, H. (1908) Die Apidae (Blumenwespen) von Argentina. Flora og Fauna, 10, 194.

Goloboff P. A., Farris J. S., Nixon K.. (2003) TNT: Tree analysis using New Technology, Version 1.0, version Beta test v. 0.2. Programae documentação disponível em http://www.zmuc.dk/public/phylogeny/TNT

Gonçalves, R.B., Melo, G.A.R., \& Aguiar, A.J.C. (2009) A assembleia de abelhas (Hymenoptera, Apidae) de uma área restrita de campos naturais do Parque Estadual de Vila Velha, Paraná e comparações com áreas de campos e cerrado, 49(14), 163-181.

Hijmans, R.J (2014). Geographic data analysis and modeling. R package version 2.2-12. Disponível em: http://CRAN.R-project.org/package=raster.

Hinojosa-Díaz, I.A.,\& Engel, M.S. (2008) Juxtocellar structures in euglossine bees: a new character for corbiculate studies. Beiträge zur Entomologie, 58(1), 97105.

Holmberg, E.L. (1903) Delectus hymenopterologicus argentinus. Anales del Museo Nacional de Buenos Aires, 2(3), 377-468. 
Krug, C., \& Alves-dos-Santos, I. (2008) O uso de diferentes métodos para amostragem da fauna de abelhas (Hymenoptera: Apoidea), um estudo em floresta ombrófila mista em Santa Catarina. Neotropical Entomology, 37(3), 265-278.

Löwenberg-Neto, P. (2014) Neotropical region: a shapefile of Morrone's (2014) biogeographical regionalisation. Zootaxa, 3802, 300-300.

Martins, A.\& Alves-dos-Santos, I. (2013) Floral-oil-producing Plantaginaceae species: geographical distribution, pollinator rewards and interactions with oil-collecting bees. Biota Neotropica, 13(4), 77-89.

Melo, G.A.R. \& Zanella, F.C.V. (2003) The species of the parasitic bee genus Osirinus (Hymenoptera, Apidae). Journal of Natural History, 20(37), 2919-2929.

Michener, C.D. \&Moure, J.S. (1957) A study of the classification of the more primitive non-parasitic anthophorine bees (Hymenoptera, Apoidea). Bulletin of the American Museum of Natural History, 112, 395-452.

Michener, C.D. (1963) Some future developments in taxonomy. Systematic Zoology, 12(4), 151-172.

Michener, C.D. (1997) Genus-group names of bees and supplemental family-group names. Scientific Papers Natural History Museum The University of Kansas, 1, $1-81$.

Michener, C.D. (2000) The Bees of the World. Baltimore, John Hopkins University Press, 913 pp.

Michener, C.D. (2007) The Bees of the World. Baltimore, John Hopkins University Press, 972 pp.

Morrone, J.J. (2014) Biogeographical regionalization of the Neotropical region. Zootaxa, 3872(1), 001-110.

Moure, J.S. (1944) Lissopedia, gen.n. de Paratetrapediini para a região Neotropical, com as descrições de três espécies novas (Apoidea, Anthophoridae). Revista Brasileira de Zoologia, 9, 305-317. 
Nattero, J., Cocucci, A.A., \& Medel, R. (2010) Pollinator-mediated selection in a specialized pollination system: matches and mismatches across populations. Journal of Evolutionary Biology, 23, 1957-1968.

Neff, J.L. \& Simpson, B. (1981) Oil-collecting Structures in the Anthophoridae (Hymenoptera): Morphology, Function, and Use in Systematics. Journal of the Kansas Entomological Society, 54(1), 95-123.

Nixon, K.C. \& Carpenter, J.M. (1993) On outgroups. Cladistis, 9, 413-426.

Oliveira, B.L. (1966) Descrição de estádios imaturos de Lanthanomelissa sp. (Hymenoptera: Apoidea). Studia Entomologica, 9(1/4), 429-440.

Pebesma, E.J. \& Bivand, R.S. (2005) Classes and methods for spatial data in R. R News 5 (2). Disponível em: http://cran.r-project.org/doc/Rnews/.

R Core Team (2016) R: A language and environment for statistical computing $\mathrm{R}$ foundation for Statistical Computing.Vienna, Austria.Disponível em: http://www.R-project.org/.

RStudio Team (2015) R Studio: Integrated Development for R. RStudio, Inc., Boston, MA. Disponível em: http://www.rstudio.com

Renner, S.S. \& Schaefer, H. (2010) The evolution and loss of oil-offering flowers: new insights from dated phylogenis for angiosperms and bees. Proceedings of the Royal Society B, 365, 423-435.

Roig-Alsina, A. \& Michener, C.D. (1993) Studies of the phylogeny and classification of long-tongued bees (Hymenoptera: Apoidea). TheUniversity of Kansas Science Bulletin, 55, 123-173.

Roig-Alsina, A. (1997) A generic study of the bees of the tribe Tapinotaspidini, with notes on the evolution of their oil-collecting structures (Hymenoptera, Apidae). Mitteilungen der Münchner Entomologischen Gesellschaft, 87, 3-21.

Roig-Alsina, A. (1999) Revision de las abejas colectoras de aceites del genero Chalepogenus Holmberg (Hymenoptera, Apidae, Tapinotaspidini). Revista del Museo Argentino de Ciencias Naturales, 1, 67-101. 
Rozen, J.G., Melo, G.A.R., Aguiar, A.J.C.,\& Alves-dos-Santos, I. (2006) Nesting biologies and immature stages of the tapinotaspidine bee genera Monoeca and Lanthanomelissa and of their osirine cleptoparasites Protosiris and Parepeolus (Hymenoptera: Apidae: Apinae). American Museum Novitates, 3501, 1-60.

Sakagami, S. \& Laroca, S. (1988) Nests of an Exomalopsine Bee Lanthanomelissa goeldiana (Hymenoptera, Anthophoridae). Journal of the Kansas Entomological Society, 61(3), 347-349.

Schlindwein, C. (1998) Frequent oligolecty characterizing a diverse bee-plant community in a xerophytic bushland of subtropical Brazil. Studies on Neotropical Fauna and Environment, 33, 46-59.

Sereno, P. C. (2007) Logical basis for morphological characters in phylogenetics. Cladistics, 23, 565-587.

Silveira, F.A., Melo. G.AR., \&Almeida, E.A.B. (2002) Abelhas Brasileiras: Sistemática e Identificação. Belo Horizonte: Fernando Silveira.

Silvério, A., Nadot, S., \& Souza-Chies, T.T. (2012) Floral rewards in the tribe Sisyrinchieae (Iridaceae): oil as an alternative to pollen and nectar? Sex Plant Reproduction, 25, 267-279.

Simpson, B.B., Neff, L., \& Seigler, D.L. (1977) Krameria, free fatty acids and oilcollecting bees. Nature, 267, 150-151.

Straka, J.\& Bogusch, P. (2007) Phylogeny of the bees of the family Apidae based on larval characters with focus on the origin of cleptoparasitism (Hymenoptera: Apiformes). Systematic Entomology, 32, 700-711.

Torretta, J.P., Gomiz, N.E., Aliscioni, S.S., \& Bello M.E. (2011) Biología reproductiva de Gomesabifolia (Orchidaceae, Cymbidieae, Oncidiinae). Darwiniana, 49(1), $16-24$.

Torretta, J.P \& Roig-Alsina, R. (2016) First report of Monoeca in Argentina, with description of two new species (Hymenoptera: Apidae). Journal of Melittology, 59, 1-12. 
Truylio, B., Harter-Marques, B.,\& Engels, W. (2002) Biologia floral e polinização de Sisyrinchium micranthum (Iridaceae) na região do Planalto das Araucárias do Rio Grande do Sul, Brasil. Biociências, 10, 11-24.

Truylio, B. \& Harter-Marques, B. (2007) A comunidade de abelhas (Hymenoptera, Apoidea) em áreas florestais do Parque Estadual de Itapuã (Viamão, RS): diversidade, abundância relativa e atividade sazonal. Iheringia, Porto Alegre, 97(4), 392-399.

Urban, D. (1967) As espécies do gênero Thygater Holmberg, 1884 (Hymenoptera, Apoidea). Boletim da Universidade do Paraná, 12, 177-309.

Urban, D. (1995) Espécies novas de Lanthanomelissa Holmberg e Lanthanella Michener \& Moure (Hymenoptera, Anthophoridae, Exomalopsinae). Revista Brasileira de Zoologia, 12(4), 767-777.

US Geological Survey (2017) Global 30 Arc-Second Elevation (GTOPO30). Disponível em: https://lta.cr.usgs.gov/GTOPO30/.

Vilhena, A.M.G.F.\& Augusto, S.C. (2007) Polinizadores da aceroleira Malpighia emarginata DC (Malpighiaceae) em área de cerrado no triângulo mineiro. Bioscience Journal, 23, 14-23.

Wickham, H. (2009) Ggplot2: Elegant Graphics for Data Analysis. Springer-Verlag New York. Disponível em: https://CRAN.R-project.org/package=ggplot2

Wittmann, D. \& Hoffman, M. (1990) Bees of Rio Grande do Sul, southern Brazil (Insecta, Hymenoptera, Apoidea). Iheringia, Série Zoologia, 70, 17-43.

Vogel, S. (1974) Ölblumen und ölsammelnde Bienen. Tropische und subtropische Pflanzenwelt, 7, 267. 


\section{APÊNDICE 1}

Lista de material adicional examinado.

\section{Lanthanomelissa betinae}

Parátipos: BRASIL, Santa Catarina: quatro fêmeas e três machos (DZUP), 'Brasilien E\ Nova Teutônia $\backslash 27^{\circ} 11^{\circ} 8$ J2 ${ }^{\circ} 23^{\circ} 1.1$ Fritz Plaumann 'le XI 1951' '300-500m' 'Lanthanomelissa betinae $\backslash$ Urban, 1995' 'PARÁTIPO', mesmos dados. Rio Grande do Sul: dois machos (DZUP), 'Gramado RS $\backslash$ Brasil 17.11.1990\ B. Blochtein col' '3003 H:464' 'Lanthanomelissa $\mathrm{M} \backslash$ (Lanthanomelissa) $\backslash$ (Friese, 1899) \Moure det. 1991' 'Lanthanomelissa betinael Urban, 1995' 'PARÁTIPO'; uma fêmea (DZUP), 'Acasalando \em cima de $\backslash$ flores (compositae)' 'Gramado RS $\backslash$ Brasil 17.11.1980 $\backslash$ B. Blochteub col.' '3009 h:464' 'Lanthanomelissa $\backslash$ (Lanthanomelissa) $\backslash$ goeldiana $\mathrm{F} \backslash$ (Friese, 1899)\Moure det. 1991' 'PARÁTIPO'; dois machos (MCTP), 'Cruz Alta RS $\backslash$ Brasil 3.11.1990\ B. Blochtein col.' '4177 H:356\F:00' 'Lanthanomelissa (Lanthanomelissa) (goeldiana) \(Friese,1899)\Moure det.1991' 'Lanthanomelissa $\backslash$ betinae Urban, 1995' 'PARATIPO', mesmos dados exceto '4178'; duas fêmeas (MCTP), 'OSÓRIO RS $\backslash$ RS.486\Brasil 24.10.1992\I. Alves dos Santos leg' '6386 H:368\F:79 11-12 ${ }^{\text {oo }}$ 'Lanthanomelissa $\backslash$ betinae $\backslash$ Urban,1995' 'PARATIPO', mesmos dados exceto '20.10.1991', '5717 H:368' e 'F:75'.

Material examinado: BRASIL, São Paulo: duas fêmeas (DZUP), 'Brasil, São Paulo,। Cotia 25.x.2009\Ramos \& Kanamura', mesmos dados exceto "20.xi.2011". Paraná: nove machos (DZUP), 'Brasil, Paraná, Araucária $\ 28 . x .2000 \backslash$ G.Melo, dentro da $\backslash$ flor de Petunia', mesmos dados; três machos e três fêmeas (DZUP), 'Brasil, Paraná, Curitiba, Centro\Politécnico 27.x.2001,\G.A.R, Melo', mesmos dados; seis fêmeas e onze machos (DZUP), 'Curitiba, PR, BR \4-5/XI/95\R. Bustos leg' 'Sissyrhynchium sp.। Iridaceae', mesmos dados, exceto '9-xi-95' e '2/XI/95'; um macho (UNB), 'UNB 064144' 'Curitiba\CP.x.2004\Nicole'; cinco fêmeas e dois machos (UNESC), 'Curitiba, PRBrasil/ 03.XI.2002/ leg.Alves dos Santos' 'LAS-UNESC/ 02939', mesmos dados exceto 'LAS-UNESC/ 02940', 'LAS-UNESC/ 02941', 'LAS-UNESC/ 02942'; 'LAS-UNESC/ 02943', 'LAS-UNESC/ 02944' e 'LAS-UNESC/ 02945'; um macho (DZUP), 'Boicaiúva - PR/ Brasil X-1955/ P.J.S. Moure'; dois machos (DZUP), 'Brasil, Paraná, 10km N del 
Bocaiúva do Sul, Santana $\backslash 25^{\circ} 06 ' \mathrm{~S}, 4^{\circ} 06^{\prime} \mathrm{W}, 900 \mathrm{~m}, \backslash 12 . x .2002$, GMelo, LZanette $\ \&$ AJAguiar'; um macho (UNB), 'UNB 064125' 'Brasil, Paraná, 10km N de\ Bocaiúva do Sul, Santana $\backslash 25^{\circ} 06^{\prime} \mathrm{S}, 49^{\circ} 06^{\prime} \mathrm{W}, 900 \mathrm{~m}, \backslash 12 . x .2002$, GMelo, LZanette $\ \&$ AJAguiar'; dois machos (DZUP), 'Brasil, Paraná, Cap.\Leônidas Marques, \Salto Caxias, \6-13.x.2004,\ Soares, am. malaise'; um macho (DZUP), 'Brasil, Paraná,\Guarapuava, 26 G.A.C.। $25^{\circ} 23^{\prime} \mathrm{S} 51^{\circ} 28^{\prime} \mathrm{N}, 1100 \backslash \mathrm{m}, 24 . x .2003$, G. Melo $\ \&$ S. Bazílio'; um macho (DZUP), 'BRASIL: PR:\Curitiba, $\backslash 15 . x i .2007 \backslash$ B. Garcete coll.'; um macho (DZUP), 'DPT ${ }^{\circ}$ ZOOL\UF-PARANÁ' 'CURITIBA - PR\BRASIL 20/3/1944\Pe.J.Moure leg'; três machos (DZUP), 'Brasil, Paraná, 23km $\backslash \mathrm{E}$ de Palmeira, 950m $\backslash 25^{\circ} 28^{\prime} \mathrm{S} 49^{\circ} 46^{\prime} \mathrm{W}$, 2.xi.2009, K. Ramos \\& V. Kanamura', mesmos dados exceto 'G. Melo'; quatro fêmeas (DZUP), 'Brasil, Piraquara, PR, \Mananciais da Serra $\$ 03.xi.2002\AJCAguiar, \G.Melo \& I. Alves-Santos', mesmos dados; dois machos (DZUP), 'Brasil, Paraná, Piraquara,। 2531'00"S 4900'37"W,\920m, 20.x.2001, IG.A.R. Melo', mesmos dados; dois machos e 3 fêmeas (UNB), 'UNB 064122' 'Brasil, Piraquara, PR,\ Mananciais da Serra\ 03.xi.2002 \A.J.C. Aguiar, G.Melo \& I.Alves-Santos', mesmos dados exceto 'UNB 064132', 'UNB 064127', '932m', '25²4'S', '4903', 'AJCAguiar', 'UNB 064168', '25301S', '4859'W', '4.xi.2000' e 'UNB 064164'; cinco fêmeas e dois machos (DZUP), 'DZUP \172260' 'Brasil, PR, Ponta Grossa \Pq. Est. Vila Velha, $\backslash 25.238^{\circ} \mathrm{S} 49.999^{\circ} \mathrm{W}, \backslash$ 900m, 02.xi.2012\ L.P. Amaral-Neto', mesmos dados exceto 'DZUP/ 172261', 'DZUP/ 172262', 'DZUP/ 171982', '1.xi.2012', 'DZUP/ 171202', '21.xi.2011', 'DZUP/ 171133', '7.xi.2011' e 'DZUP/ 171123'; três fêmeas e um macho (DZUP), 'PEVV/ 0165' 'Brasil, Paraná, Parque $\backslash$ Estadual de Vila Velha, $\backslash 25^{\circ} 14 ' S$ 4959'W, $\backslash 09 . x i .2002$, G.A.R.Melo \&l R.B.Gonçalves', mesmos dados exceto 'PEVV/ 0187', 'PEVV $\backslash$ 1878', '15.xi.2003' e 'PEVV/ 1882'; dois fêmeas e um macho (DZUP), 'Curitiba, Paraná,\ Piraquara,। Mananciais da Serra,\05.xi.2002, G.Melo', mesmos dados; cinco fêmeas e um macho (DZUP), 'Brasil, Paraná, Piraquara, $\backslash$ Mananciais da Serra, $\backslash 25^{\circ} 30^{\prime} \mathrm{S} 48^{\circ} 59^{\prime} \mathrm{W}, \backslash 4$.xi.2000, G.A.R. Melo', mesmos dados exceto '04/11/2008', 'L.M.Santos'; três machos e uma fêmea (DZUP), 'PEC/ 103' 'Brasil, Paraná, Parque Estadual de Campinhos, $\backslash 25^{\circ} 02^{\prime} \mathrm{S}$ 4905'W, $23 . x i .2003$, R. Gonçalves $\backslash \&$ F. Fernandes', mesmos dados exceto 'PEC/ 106, 'PEC/ 107', 'PEC/ 125'; um macho (DZUP), 'DPT Z ZOOL\ UF-PARANÁ' 'TIJUCAS DO SUL \ VOSSOROCA - BRASIL\ PR - 3/10/1971\ Moure e Giacomel' 'Lanthanomelissa $\backslash$ betinae $\mathrm{M} \backslash$ Urban. 1996 $\backslash$ A.J.C.Aguiar det 2004'; um macho (DZUP), 'VILA VELHA - PR \Brasil 2-XI-1955\Pe. J. S. Moure'; quatro machos (UNB), 'UNB 064170' 'Brasil, Paraná, Cascavel\2457'21"S 53²7'19"W,\19.x.2015/ tarde \C.M. 
Maia leg', mesmos dados exceto 'UNB 064171', 'UNB 064172' e 'UNB 064173'; seis fêmeas e dois machos (UNB), 'UNB 064112' 'Brasil, PR, Palmeira. Rio dos\ Papagaios, -5.46670"S $\backslash 49.76685 " O, 28 . x .2012 \backslash$ AJCAguiar', mesmos dados exceto 'UNB 064133', 'UNB 064135', 'UNB 064136', 'UNB 064137', 'UNB 064138', 'UNB 064141' e 'UNB 064167'. Santa Catarina: seis machos e quatro (DZUP), 'N. Teutônia - SC \ Brasil 26.X.1955 A. Maller leg', mesmos dados exceto 'II/V.1948' e 'Fritz Plaumann'; dois machos (AMNH), 'Brasilien\Nova Teutonia $\backslash 27^{\circ} 11^{\prime}$ B. $52^{\circ} 23 ' \mathrm{~L} \backslash$ Fritz Plaumann' 'X.28.1963' '300 - 500 m'; um macho (MCTP), 'SC, Urubici 07/12/95 Leg.: J.R.Stehmann 9512-41\Em Calibrachoa sellowiana $\backslash$ (Solanaceae)' 'Lanthanomelissa betinae M $\backslash$ Urban, 1995\Schlindwein det. 1996' 'LPB MCT/ PUCRS \19296'; uma fêmea (DZUP), 'Criciúma, SC \Unesc 22.X.2002\leg. I. Alves dos Santos'; uma fêmea (UNESC), 'SATC, Criciúma, SC, \Brasil./05/11/2008/Leg. Maiara Bez' '6522 H: 202/L:81' 'Lanthanomelisa $\backslash$ betinae $\backslash$ Urban, 1995 $\backslash$ Det. B. Harter-Marques'; três fêmeas (UNESC), 'St a Rosa, SC-Brasil 09.XI.2002\leg. L. C. Minussi' 'LAS-UNESC/02001', mesmos dados exceto 'LAS-UNESC/02003' e 'LAS-UNESC/02004'; duas fêmeas e três machos (UNESC), 'Porto União, SC-Brasil\ Lança 14.X.2006\leg. Cristiane Krug' '815' 'Lanthanomelissa $\backslash$ betinae $\backslash$ Urban det.06' 'Unesc - Liap/7638', mesmos dados exceto '816', 'Liap/7637', '805', 'UNESC-Liap/7636', '824', 'UNESC-Liap/7633', '828', 'UNESCLiap/7635', '13.X.2006', '863' e 'UNESC-Liap/7634'; um macho (UNESC), 'Praia Grande, SC Brasil \Guarita Pedra Branca $\backslash 18$ XII 2002\Leg. G.C.N.Figueiredo' 'LASUNESC/02946'. Rio Grande do Sul: uma fêmea (DZUP), 'Brasil, Rio Grande` do Sul, Porto \Alegre, Campus $\backslash$ UFRGS, Agronomia $\backslash 30^{\circ} 04^{\prime} \mathrm{S} 51^{\circ} 07^{\prime} \mathrm{W}, \backslash 60 \mathrm{~m}, 19 . x i .2007$, A. $\backslash$ Martins'; um macho (FZB), 'Porto Alegre RS $\backslash$ Vila Hanneza $\backslash 27 . x i .1985 \backslash$ B. Blochtein leg.' 'Col. MCN./93.014' 'Lanthanomelissa $\backslash$ goeldiana $\backslash$ (Friese) $\backslash$ Pe. J. S. Moure det. 1987'; dois machos (MCTP), 'PORTO ALEGRE RS \Morro Santana $\backslash$ Brasil 03.10.1991\ O. Tschoepke leg.' '10012 H:147/F:23 13 $3^{30 \prime}$ 'Lanthanomelissa aff. $\backslash$ betinae Urban 1995 Schlindwein det.1997', mesmos dados exceto '27.10.1993', '10309', 'H:147' e 'F:23'; uma fêmea (DZUP), 'Brasil, Rio Grande \do Sul, $35 \mathrm{~km} \mathrm{~S} \mathrm{de} \mathrm{\ Caçapava} \mathrm{do} \mathrm{Sul, \backslash Guaritas,}$ $30^{\circ} 50^{\prime} \mathrm{S} \backslash 53^{\circ} 30 \mathrm{~W}, 270 \mathrm{~m}, \backslash 16 . x i .2007$, A. $\backslash$ Martins'; quatro machos (FZB), 'Triunfo, RS $\backslash$ Capesul 24/x/1988\M.A.L. Marques leg.' 'Col. MCN.194979', mesmos dados exceto 'MCN.94980', 'MCN.95221', '8.x.1988', 'M.Hoffman col.' e 'MCN.94981'; uma fêmea (FZB), 'Santo Amor $\backslash$ Pelotas $\backslash$ Brasil 7.12.1986 D.Wittman col' 'Col. MCN\93.910'; um macho (MCTP), 'Gramado RS $\backslash$ Brasil 16.11.1990\B. Blochtein col.' '3007 H: 464' 'Lanthanomelissa $\mathrm{M} \backslash$ (Lanthanomelissa) $\backslash$ goeldiana $\backslash$ (Friese, 1899)\ Moure det. 1991' 
'Lanthanomelissa $\mathrm{M} \backslash$ betinae $\backslash$ Urban, 1995\Schlindwein det. 1996'; onze machos (MCTP), 'BRA-RS-POA\São $F^{\text {oo }}$ de $\backslash$ Paula, Pró-Mata $\backslash$ Koehler 3.12.97' '633/31', mesmos dados exceto '1406/116', 'MCP/114111', '1407', 'MCP/114110', '1436/31', '1438', '7.11.97', '631/51', '11.11.97', '760/116', '26.12.97', '2115/98', 'MCP/114112'; quatorze machos e cinco fêmeas (MCTP), 'São Francisco de \Paula, Pró-Mata, RS $\backslash$ Brasil 14.11.1997\ leg. Birgit Harter' '17580 H:906 F:86 $14^{\circ 0} 23^{\circ} \mathrm{C}^{\prime}$ 'Lanthanomelissa betinae \Urban, 1995\ B.Harter det. 1999', mesmos dados exceto '17581', '18.11.1996', '1704', 'H:862', '11:30', '1708', '22.11.1997', '15382', 'H:864', '13:00', '15384', '29.12.1998', 'leg. Betânia Truylio', '17114', '17107', 'H:368', 'F:85', 'leg. Liége Candido', '17162', 'H:368', 'F:86', '28.11.1998', '17163'; '17116', '17917', 'F:84', '17175', 'H:770', '17581', 'H:906', '17206', 'H:862', '17173', 'H:770', '15380' e 'Harter det. 1999'.

\section{Lanthanomelissa clementis}

Parátipos: Santa Catarina: uma fêmea (DZUP), 'Brasilien \Nova Teutonia $\backslash\left(27^{\circ} 11 \mathrm{~B}\right.$ $\left.52^{\circ} 23^{\prime} \mathrm{L}\right) \backslash$ Fritz Plaumann' 'X/1951' '300 - 500 m'\'PARÁTIPO' 'Lanthanomelissa clementis \Urban, 1995'. Rio Grande do Sul: uma fêmea (MCTP), 'CAÇAPAVA\DO SUL RS $\backslash$ Guaritas $\backslash$ Brasil 11.10.1991 $\backslash$ C.Schlindwein leg. $\backslash 5875$ H:368 $\backslash$ F:40 14-15 'Lanthanomelissa $\backslash$ goeldiana(Friese, 1899)\Moure det.1992' '89' 'PARATIPO'; uma fêmea (DZUP), 'Guaíba RS $\backslash$ Br. 116, km 307\ Brasil 3.11.1990\C. Schlindwein leg' 'PUC/RS - Univ. Tubingen $\backslash$ Lab. Pesq. Biológica 2213 F:16 H:60' '8 'Lanthanomelissa $\backslash$ (Lanthanomelissa) \goeldiana $\backslash$ (Friese, 1899) F\Moure det. 1981' 'PARÁTIPO' 'Lanthanomelissa clementis $\backslash$ Urban, 1995'; uma fêmea (MCTP), 'Guaíba\ Faz.Matzebache RS $\backslash$ Brasil 23.11.1990\B.Blochtein col.' 'PUCRS - Univ. Tubingn\ Lab. Pesq. Biológicas $\backslash 2440$ H:60\ F.16' 'Lanthanomelissa $\backslash$ (Lanthanomelissa) $\backslash$ goeldiana $\backslash$ (Friese,1899)\ Moure det.1999' 'PARATIPO'; dois machos (MCTP), 'Guaíba $\mathrm{RS} \backslash$ BR.116 Km 307\ Brasil 13.10.1990 C.Schlindwein leg' '1079 F:16 $\mathrm{H}: 147$ ' 'Lanthanomelissa (Lanthanomelissa)\goeldiana (Friese,1899)\ Moure det.1991' 'PARATIPO' 'Lanthanomelissa $\backslash$ clementis $\backslash$ Urban', mesmos dados exceto '1177 F:16/ H:234'; um macho (MCTP), 'Canguçu RS \ Morro Redondo\ Brasil 16.11.1989\C. Schlindwein leg.' 'PUCRS - Univ. Tubingen\Lab. Pesq. Biológicas $\backslash 599-\mathrm{H}$ 234' 'Lanthanomelissa (Lanthanomelissa) $\backslash$ goeldiana $\backslash$ (Friese,1899)\ Moure det.1991' 'PARATIPO' 'Lanthanomelissa $\backslash$ clementis $\backslash$ Urban, 1995'. 
Material examinado: ARGENTINA, Concordia: uma fêmea (MLP), 'Arg. Entre Rios $\backslash$ Concordia $\backslash 13-X-2009 \backslash$ Della pé col.' 'Lanthanomelissa $\backslash$ clementis $\backslash$ Urban det. 10'. BRASIL, São Paulo: dois machos (DZUP), 'Brasil, São Paulo,\Cotia 25.x.2009\ Ramos \& Kanamura', mesmos dados exceto '20.xi.2011'. Paraná: 6 machos e 1 fêmea (DZUP), 'DZUP/ 172011' 'Brasil, PR, Ponta Grossa\ Pq. Est. Vila Velha, $\backslash 25.238^{\circ} \mathrm{S}$ 49.999 $\mathrm{W}, \backslash 900 \mathrm{~m}, 30.1 x .2012 \backslash$ L.P. Amaral-Neto', mesmos dados exceto '21.X.2004', '4.X.2002', '5.X.2002', 'PEVV/ 3049', 'PEVV/ 3050', 'PEVV/ 0005', 'PEVV/ 0030', 'PEVV/ 0089', 'PEVV/ 1630' e 'A. Aguiar, R. Gonçalves e G. Melo'; uma fêmea (DZUP), '3' 'R. dos Papagaios $\backslash$ PR-Brasil-I-X5g $\backslash$ P.D.HURD leg'; um macho (UNESC), 'Curitiba, PR-Brasil \03.XI.2002\leg.Alves dos Santos' 'LAS-UNESC/ 02945'; um macho (DZUP), '5' 'PALMEIRA-PR\ Brasil x.59\P.D.HURD leg'. Santa Catarina: uma fêmea (DZUP), 'DPTo ZOOL\UF-PARANÁ' 'Nova Teutônia\ S.C. 3/XII/1955'. Rio Grande do Sul: cinco fêmeas (RPSP), 'RPSP 122878' 'Brasil, Rio Grande do Sul,। $35 \mathrm{~km}$ S de Caçapava do $\backslash$ Sul, Guaritas $30^{\circ} 50^{\prime} \mathrm{S} \backslash 53^{\circ} 30^{\prime} \mathrm{W}, 270 \mathrm{~m}, 16 . x i .2007 \backslash$ E. A. B. \& J. Almeida', mesmos dados exceto 'UNB 064147', '31.x.2012', '3045'36"S', '53³1'26"W', '351m', 'A.J.C.Aguiar', 'UNB 064152', '(RS265)', '01.xi.2012', '350m', 'DZUP'; três fêmeas (MCTP), 'CAÇAPAVA DO SUL\Guaritas\ Brasil, RS 26.10.1996\ Clemens Schlindwein' '12217 H:584\F:45' 'Lanthanomelissa clementis Urban,1995 Schlindwein det.1996', mesmos dados exceto '12219' e '12221'; quatro fêmeas e dois machos (RPSP), 'RPSP 122882' 'Brasil, Rio Grande \do Sul, 35km S de $\backslash$ Caçapava do Sul, $\backslash$ Guaritas, $30^{\circ} 50^{\prime} \mathrm{S} \backslash 53^{\circ} 30^{\prime} \mathrm{W}, 270 \mathrm{~m} \backslash 16 . x i .2007$, A. $\backslash$ Martins', mesmos dados exceto 'RPSP 122883', 'RPSP 122884', 'UNB 64151', 'DZUP'; oito machos (RPSP), 'RPSP 122876' 'Brasil, Rio Grande do sul, $\backslash 7 \mathrm{~km}$ SW de Caçapava do $\backslash$ Sul, Pedra do Segredo,\ $30^{\circ} 32^{\prime} \mathrm{S} 53^{\circ} 33^{\prime} \mathrm{W}, \backslash 220 \mathrm{~m}, 16 . x i .2007, \backslash$ E. A. B. \& J. Almeida', mesmos dados exceto 'RPSP 122871', 'RPSP 122872', 'RPSP 122873', 'RPSP 122874', 'RPSP 122875', 'RPSP 122877' e 'UNB 064130'; duas fêmeas (UNB), 'UNB 064183' 'Brasil, RS, 12 km NNE Pedras Altas $\backslash(\mathrm{RS}-608), 3^{\circ} 39^{\prime} 24^{\prime \prime S} \backslash 53^{\circ} 32^{\prime} 16^{\prime \prime W} \backslash 430 \mathrm{~m}, 02 . x i .2012 \backslash$ E.A.B.Almeida \& A.J.C.Aguiar', mesmos dados exceto 'UNB 064184'; duas fêmeas e vinte e um machos (UNB), 'UNB 064145' 'Brasil, RS, 10.5 km SW Pinheiro\ Machado linha de trem (RS-

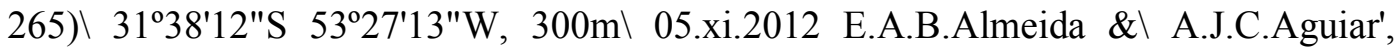
mesmos dados exceto 'UNB 064146', 'UNB 064121', 'UNB 064123', 'UNB 064124', 'UNB 064126', 'UNB 064128', 'UNB 064129', 'UNB 064131', 'UNB 064134', '415m', 'UNB 064117', 'RPSP 124036', 'RPSP 124034', 'RPSP 124037', 'RPSP 124035', 'RPSP 124033', 'Rod.RS-265', 'linha férra', '5.xi.2012', 'Lanthanomelissa $\backslash$ clementis $\backslash$ Aguiar 
det. 2013', '370m', 'em Nierembergia'; um macho (FZB), 'Santo Amor $\backslash$ Pelotas RS $\backslash$ Brasil 7.12.1986\ R. Radtke col.' 'Col. MCN./ 93.909'; um macho e uma fêmea (UNESC), 'Parque Natural do \Morro do Osso, Porto \Alegre, RS, Brasil.\28.X.2009\ Leg. Q. Cardozo' '6841 H:333/L:85' 'Lanthanomelissa sp. 1\ Det. B. Harter-Marques' 'Lanthanomelissa $\backslash$ cf. Clementis $\backslash$ det. GAR Melo 2010', mesmos dados exceto '19.XI.2009', '6842 H:209' e 'L:87'; uma fêmea (UNB), 'UNB 064143' 'Brasil, Rio Grande $\backslash$ do Sul, Porto $\backslash$ Alegre, Campus $\backslash$ UFRGS, Agronomia $\backslash 30^{\circ} 04^{\prime} \mathrm{S} 51^{\circ} 07 \mathrm{~W}, \backslash 80 \mathrm{~m}$, 19.xi.2007, A.\Martins'; uma fêmea (FZB), 'Brasilen\ Rio Grande do Sul $\backslash$ S.Franc. D. Paula \Rincão de Kroeff $\ 3.11 .1984 \backslash$ Lanthanomelissa $\backslash$ spec.usv. $\backslash$ det.19 $\backslash$ Col.MCN./ 90.995'; uma fêmea (FZB), 'VIAMÃO, RS \ Brasil 15.XI.1981\B. Blochtein col.' 'Col. MCN./ 93.568' 'Lanthanomelissa $\backslash$ discrepans $\backslash$ ? Holmberg, 1903\Pe.J. S. Moure det. 1987'; dois machos (UFFS), 'Petunia sp.\21.10.09\ Caçapava' 'A7', mesmos dados exceto ' 11.08 ' e '125'.

\section{Lanthanomelissa discrepans}

Material examinado: ARGENTINA, Buenos Aires: uma fêmea (JPT), '13069 Hymenoptera\Argentina Buenos Aires Pila\Ex. Las Chicas, sobre Sisyrinchium platense I.M \Johnst leg. H. J. Marrero\10/11/2009'. Cordoba: um macho (Flórida), 'ARGENTINA: Cordoba \rov., Dolores nr. La \Cumbre, 1000m. Chaco \Scrub, 12-20XI-1998\C. Porter' 'Lanthanomelissa $\backslash$ discrepans $\backslash$ A.J.C. Aguiar det 2015'; 3 machos e fêmeas (CCS), 'ARGENTINA\Córdoba \Santa Maria \XI.2006\A. A. Cocucci' 'sobre\ Sisyrinchium $\backslash$ chilensis'; duas fêmeas (CCS), 'ARGENTINA\Cordoba\Agua de Ovo\ XI.2006\A.A. Cocucci' 'sobre\Sisyrinchium $\backslash$ valdivianum'. Pampa de Achala: uma fêmea (CCS), 'Lantera em $\backslash S$. chi^ Achala $\backslash 29 / 01 / 09 '$. Catamarca: uma fêmea (Flórida), 'ARGENTINA\Catamarca, Las \Chacritas, 160m, 12-\XII-2002, L.A Stange \Alnus Forest' 'Chalepogenus $\backslash$ (Lanthanomelissa)\ det. Wiley 2002' 'Lanthanomelissa discrepans $\backslash$ A.J.C.Aguiar det. 2015'; Pronunciamento: um macho (DZUP), 'COLEÇÃO $\backslash$ CAMPOS SEABRA' 'PRONUNCIAMENTO $\backslash$ Entre Rios Argentina I1961 J. Foerster'. BRASIL, Paraná: seis fêmeas e 3 machos (DZUP), 'Curitiba, PR, BR $\ 31 . X .96 \backslash$ R. Bustos leg'; 1 fêmea (DZUP), 'Vila Velha, PR II. 1970\V. Graf leg'. Santa Catarina: quatro fêmeas e dois machos (UNESC), 'Criciúma, SC-Brasil $\backslash$ Unesc 08.XI.04\Leg. Thiago Souza' 'LAS-UNESC/03872', mesmos dados exceto 'LAS- 
UNESC/0373', '05.XI.04', 'leg. Morgana Sazan', 'LAS-UNESC/04045', '10.XI.04', 'legl. Múcio Bratti Jr, 'LAS-UNESC/03336', '28.X.04', 'leg. L.N. Essinger', 'LASUNESC/03147' e 'LAS-UNEC/03151'; duas fêmeas (UNESC), 'SATC, Criciúma,SC,। Brasil.\05/11/2008\leg.Maiara Bez' '6523 H:202/ L:81' 'Lanthanomelissa $\backslash$ discrepans $\backslash$ Holmberg, 1903\ Det. B.Harter-Marques', mesmos dados exceto '6525'; uma fêmea (DZUP), 'Criciúma, SC $\backslash$ Unesc 22.X.2002\ leg. I. Alves dos Santos'; uma fêmea (UNESC), 'Maracajá, SC-Brasil Pq.Ecológ 28/XI/03/ leg T.Souza' 'Iridaceae' 'LASUNESC/02938'. Rio Grande do Sul: 1 fêmea (DZUP), 'Brasil, Rio Grande $\backslash$ do Sul, $60 \mathrm{~km} \mathrm{Ne} \backslash$ de Bagé, Palmas, $\backslash 30^{\circ} 59^{\prime} \mathrm{S} 53^{\circ} 37 \mathrm{~W} \backslash 270 \mathrm{~m}, 17 . x i .2007 \backslash$ A. Martins'; três fêmeas e um macho (UNB), 'UNB 064110' 'Brasil, RS, Caçapava do Sul, Estrada \para Bage (BR-153, 39km NE $\quad$ Bagé),3052'15"S 53³6'59"W $\backslash 189 \mathrm{~m}$, 01.xi.2012 E.A.B.Almeida \& A.J.C.Aguiar', mesmos dados exceto 'UNB 064118', 'UNB 064162' e 'UNB 064166' ; cinco machos e uma fêmea (UFFS), 'Notoscordum $\backslash 26.10 .09 \backslash$ Caçapava' 'AA8', mesmos dados exceto '21.10.09', '25.10.09', '21.10.08', 'S. micran', 'A6', 'S. osteananum', 'AA13', 'AA12', '98', 'S. scarios' e '18'; dois machos e uma fêmea (DZUP), 'Candiota - RS $\backslash$ Chácara da HORTEC $\backslash$ 13.XI.1998\Lopes, L. Col' 'Oxalis articulata Savigny $\backslash$ Área 1 Hora: 10:00' 'LPB MCT/PUCRS $\backslash$ 38.023', mesmos dados exceto 'Anthemis cotula L', '15:15', '38024', '7.XI.1998', 'Aspilia motevidensis', 'Spreng', '14:45' e '38.100'; dois machos (UNB), 'UNB 064154', 'Brasil, RS, 12 km NNE Pedras Altas (RS-608)31 39'24"S 5332'16"W,\430m,05.xi.2012 E.A.B.Almeida \& A.J.C.Aguiar', mesmos dados exceto 'UNB 064182' e '2.XII.2012'; um macho (MCTP), 'Uruguaiana, RS $\backslash$ Barra do Quaraí \Brasil,29.11.1993\leg.C.Schlindwein' '8708 H:60 F:61 15-16 'Lanthanomelissa $\backslash$ discrepans $\backslash$ Holmberg 1903\Schlindwein det. 1996'; uma fêmea (FZB), 'Brasilien \ Rio Grande do Sul $\backslash$ Quaraí-Passo $\backslash$ da Guarda\23.XI.1985' 'Col.MCN \92.581' 'Lanthanomelissa $\backslash$ goeldiana $\backslash$ (Friese) \Pe.J.S.Moure det.1917'; uma fêmea (FZB), 'Santo Amor \ Pelotas $\backslash$ Brasil 7.12.1986\ D.Wittman col' 'Col. MCN \93.908'; duas fêmeas e um macho (UNB), 'UNB 064116', 'Brasil, RS, 10.5 km

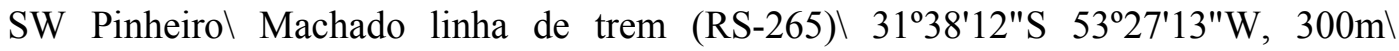
05.xi.2012 E.A.Almeida \&\ A.J.C.Aguiar', mesmos dados exceto ' 2.XI.2012', 'UNB 064120' e 'UNB 064156'; um macho (RPSP), 'RPSP 124220', 'Brasil, RS, Rod.RS-265,

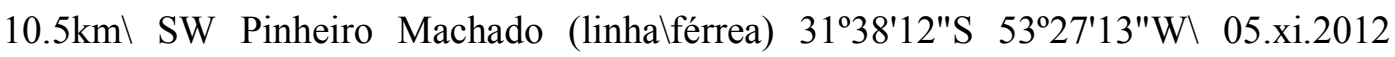
E.Almeida \& A.Aguiar'; um macho (MCTP), 'São Franciso de Paula\ Pró-Mata RS $\backslash$ Brasil 15.11.1995\ leg. C. Schlindwein' '1226|H:748/F:57 930' 'Lanthanomelissa discrepans $\backslash$ Holmberg 1903\Schlindwein det. 1996'; um macho (MCTP), 'M. Coco 
Viamão\ Brasil 03.12.1992 $\quad$ I.Alves dos Santos leg.' '7098 H: 132/F:25' 'Lanthanomelissa $\backslash$ discrepans Holm $\backslash$ Ubran det. 1995'; um macho (FZB), 'Montenegro, RS $\backslash 3 / x i / 1977 \backslash$ M. H. Galileo leg.' 'Col. MCN\40785'; um macho (MCTP), 'Lavras do Sul $\backslash$ Rincão do $\backslash$ Inferno $\backslash$ Brasil 10.12.1991 $\backslash$ C. Schlindwein leg.' '5871 H:481 $\backslash$ F:54 $15^{\text {oor }}$ 'Lanthanomelisa goeldiana (Friese, 1899)\Moure det. 1992' '90M' 'Lanthanomelissa discrepans Holm \Urban, det.1995'; um macho (DZUP), 'Canguçu RS $\backslash$ Posto branco $\backslash$ Brasil 17.XI.1989\ C. Schilindwein leg' 'PUC/RS - Univ. Tubingen\ Lab.Pesq.Biológicas $\backslash$ 662-H. 190' 'Lanthanomelissa $\mathrm{M} \backslash$ (Lanthanomelissa) $\backslash$ goeldiana $\backslash$ (Friese, 1989)\Moure det. 1991' 'Lanthanomelissa $\backslash$ discrepans Holm \Urban det. 1995'; um macho (UNB), 'UNB 064111', 'Brasil, Rio Grande do Sul, \35km NW de Canguçu,। Faz. Sobrado Branco, $\backslash 31^{\circ} 06$ 'S 52 $52^{\prime} \mathrm{W}, \backslash 230 \mathrm{~m}, 15 . x i .2007 \backslash$ E. A. B \& J. Almeida'. PARAGUAI: uma fêmea (CAS), 'PARAGUAY $\backslash$ D.P.HAYES $\backslash$ Villa Hayes $\backslash X-13-$ 1968 ' 'at night $\backslash$ C.W.O' Brien'.

\section{Lanthanomelissa magaliae}

Parátipos: Rio Grande do Sul: um macho (DZUP), 'Esteio $\backslash$ R. 99.\ XI -1943' 'Lanthanomelissa magaliae Urban, 1995' 'PARÁTIPO'; um macho (MCTP), 'Bagé Casa de Pedra RS $\backslash$ Brasil 1.11.1992 $\backslash$ C.Schlindwein leg.' '6347 H:190\ F:27 15 'Lanthanomelissa magaliae \Urban,1995' 'PARATIPO'; um macho (MCTP), 'Viamão Morro do Osso RS $\backslash$ Brasil 13.02.1991 $\backslash$ C.Schlindwein leg.' 'Lanthanomelissa $\backslash$ goeldiana (Friese, 1899)\ Moure det.1992' '90' 'Lanthanomelissa magaliae Urban, 1995' 'PARATIPO'.

Material examinado: BRASIL, Santa Catarina: dois machos e uma fêmea (UNESC), 'Içara, SC \ Brasil 19.X.04\ leg.Thiago Souza' 'LAS-UNESC/ 03905', mesmos dados exceto 'Em Iridaceae', 'LAS-UNESC/ 03908', '30.X.2004', 'L.N.Essinger' e 'LASUNESC/ 03131' ; um macho (DZUP), 'Brasil, Santa Catarina,\Criciúma, Campus da\ UNESC, 16.xi.2002,\G.A.R. Melo' 'Lanthanomelissa aff. magaliae'; 9 machos e 4 fêmeas (UNESC), 'Criciúma, SC \Brasil 10.XI.04\leg. Múcio Bratti Jr' 'LAS-UNESC/ 03334', mesmos dados exceto 'LAS-UNESC/ 0337', 'LAS-UNESC/ 0338', '9.XI.04', 'Em Asteraceae', 'LAS-UNESC/ 03335', '08.XI.04', 'Thiago Souza', 'Em Iridaecae', 'LASUNESC/ 03874', '28.X.04', 'L. N. Essinger', 'LAS-UNESC/ 03146', 'LAS-UNESC/ 03336', 'LAS-UNESC/06523', 'LAS-UNESC/ 03148', 'LAS-UNESC/ 03151', 'LAS- 
UNESC/ 03873', 'LAS-UNESC/ 03874', 'LAS-UNESC/ 04045' e 'LAS-UNESC/ 03333'.

Rio Grande do Sul: dois machos e uma fêmea (UNB), 'UNB 064115' 'Brasil, Rio Grande $\backslash$ do Sul, 60km NE de $\backslash$ Bagé, Palmas, $\backslash 30^{\circ} 59^{\prime} \mathrm{S} 53^{\circ} 37^{\prime} \mathrm{W}, \backslash 270 \mathrm{~m}, 17 . x i .2007, \mathrm{~A} \backslash$ Martins', mesmos dados exceto 'UNB 064119', 'UNB 064155' e 'UNB 064161'; 2 fêmeas (RPSP), 'RPSP 122864' 'Brasil, Rio Grande do $\backslash$ Sul, 60km NE de Bagé,\Palmas, $30^{\circ} 69^{\prime} \mathrm{S} 53^{\circ} 37^{\prime} \mathrm{W}, \backslash 270 \mathrm{~m}, 17 . x i .2007, \backslash$ E.A.B \& J. Almeida', mesmos dados exceto 'RPSP 122870'; dois machos (DZUP), 'Brasil, Rio Grande \do Sul, 60km Ne\ de Bagé, Palmas. $\backslash 30^{\circ} 59^{\prime} \mathrm{S} 53^{\circ} 37 \mathrm{~W} \backslash 270 \mathrm{~m}, 17 . x i .2007 \backslash$ A. Martins'; um macho (RPSP), 'RPSP 123939' 'Brasil, RS, Santana do $\backslash$ Livramento 3052'23"S $\backslash 55^{\circ} 31^{\prime} 42^{\prime \prime W}, 200 \mathrm{~m}$, 03.xi.2012 $\backslash$ E.Almeida \& A.Aguiar, cols'; dois machos (MCTP), 'VIAMÃO \Morro do

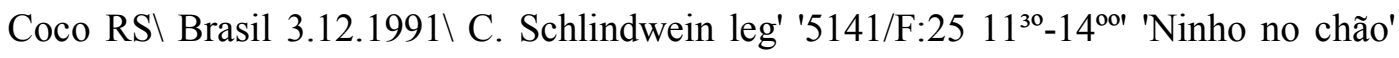
$\begin{array}{llllllll}\text { Lanthanomelissa } & F \backslash \text { goeldiana (Friese, 1899) } \backslash \text { Moure } & \text { det. } & 1992 ' & \text { '90 } & \text { F' }\end{array}$ 'Lanthanomelissa $\backslash$ magaliae $\backslash$ Urban, 1995', mesmos dados exceto '5881 H:517', '13 ${ }^{\text {ool }}$ e 'Schilindwein det. 1996'; um macho (FZB), 'Viamão, RS \ Brasil 07.xi.1986 B.Blochtein col.' 'II.13' 'Col.MCN.\ 93.572'; duas fêmeas (DZUP), 'CAÇAPAVA DO SUL RS $\backslash$ Guaritas/ Brasil 14.10.1992\ C. Schlindwein leg' 'Lanthanomelissa $\backslash$ discrepans $\backslash$ Holmberg 1903\Schlindwein det 1996' '6324 / F:45 16 '26.X.1991'; dois machos (UNB), 'UNB 064153' 'Brasil, RS, Caçapava do Sul,।

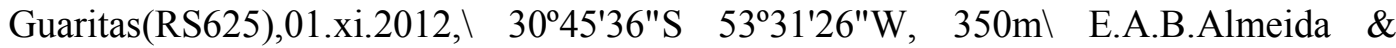
A.J.C.Aguiar', mesmos dados exceto 'UNB 064169', '31.X.2012' e '351m'; um macho (UFFS) 'S. setaceum $\backslash$ Caçapava $\backslash$ out. 2007' '19'; um macho (UFFS) 'S. micrant. Grande Caçapava 21.10.09' 'A4'; um macho (UFFS) 'Notoscordum $\backslash 26.10 .09 \backslash$ Caçapava' 'AA9'; um macho (UFFS) 'S. setaceum $\backslash$ Caçapava\ Out. 2007' '24'; um macho (UFFS) 'S.micrantum $\backslash$ grande $\backslash$ Caçapava $\backslash 21.10 .09$ ' 'A2'; um macho (UFFS) 'S. micr tip.। 26.10.09\ Caçapava' 'A5'; um macho (DZUP), 'Candiota - RS/Chácara da HORTEC 07.XII.1999\Lunardi, M. Col' 'Aspilia montevidens (Spreng.) \Área 6 Hora: 15:15' 'LPB MCT $\backslash$ PUCRS/38.102', 2 fêmeas (RPSP), 'RPSP 124070' 'Brasil, RS, Rd. RS 608, 6 $\mathrm{km} \backslash \mathrm{SSW}$ Pinheiro Machado $3^{\circ} 36^{\prime} 50^{\prime \prime} \mathrm{S} 53^{\circ} 25^{\prime} 29^{\prime \prime} \mathrm{W} 415 \mathrm{~m} \backslash$ 02.xi.2012 E.Almeida \& A.Aguiar', mesmos dados exceto 'RPSP 0124219' e '5.xi.2012'; 1 fêmea (UNB), 'UNB 064163' 'Brasil, RS, Quaraí $\backslash 30^{\circ} 24^{\prime} 03 " S$ 56²6'29"W, 150m\04.xi.2012 $\backslash$ E.A.B.Almeida \& A.J.C.Aguiar'. 
Lanthanomelissa pampicola

Parátipos: Rio Grande do Sul: um macho (MCTP), 'Caçapava RS $\backslash$ Minas Cama\ Brasil 27.10.1990\B.Hiller leg.\PUC/RS - Univ. Tubingen\Lab. Pesq. Biológicas' '2273 H:417\F:44' 'Lanthanomelissa (Lanthanomelissa)goeldiana (Friese,1899)\ Lanthanomelissa $\backslash$ pampicola $\backslash$ Urban' 'PARATIPO'; um macho (DZUP), 'Caçapava RS $\backslash$ Min. Camaguá \Brail 27.10.1990\S. W. Freitas leg' 'PUC/RS - Univ. Tubingen em\ Lab. Pesq. Biológicas $\backslash 2299$ H.407/F43' 'Lanthanomelissa M $\backslash$ (Lanthanomelissa) $\backslash$ goeldiana $\backslash$ (Friese, 1899)\Moure det. 1991' 'Lanthanomelissa $\backslash$ pampicola $\backslash$ Urban, 1995' 'PARÁTIPO'; duas fêmeas (DZUP), 'CAÇAPAVA\DO SUL RS Guaritas \Brasil 26.10.1991\C. Schlindwein leg' 'H:68' '91F' '595/26.10.91\:40/12 ${ }^{\circ 01}$ 'Lanthanomelissa pampicola $\backslash$ Urban, 1995' 'PARÁTIPO', mesmos dados exceto '17.10.1992', 'leg.6338 H:368' e 'F:40 14 ${ }^{\text {oor }}$; uma fêmea (DZUP), 'Caçapava do Sul RS $\backslash$ Guaritas $\backslash$ Brasil 17.10.1992 \C.Schlindwein leg. $\backslash 6339$ H:368\F:40 14 ${ }^{\text {oo }}$ 'Lanthanomelissa $\backslash$ pampicola $\backslash$ Urban,1995' 'PARATIPO'; uma fêmea (DZUP), 'Caçapava/RS\Gruta de Camacuã $\$ Brasil 25.10.1990\ B.Hiller leg.' '5335 H:368/F:40' 'Lanthanomelissa $($ Lanthanomelissa $) \backslash$ goeldiana $) \backslash$ (Friese, 1899)\ Moure det.1991' 'Lanthanomelissa pampicola $\backslash$ Urban,1995' 'PARATIPO'.

Material examinado: ARGENTINA, Buenos Aires: uma fêmea (JPT), '13070 Hymenoptera $\backslash$ Argentina: Buenos Aires Pila $\backslash$ En las Chicas sobre linum $\backslash$ usitatissimum L. leg. H.J Marrero 10/02/2009'. Corrientes: um macho (MLP), 'ARGENTINA: Corrientes, $\backslash$ Sta. Tella, Iuzaringá, xi. 1995', um macho (CAS), 'ARGENTINA: Corrientes $\backslash$ P. N. Mburucuva, Potrero $6 \backslash \mathrm{S} 28^{\circ} 01.466$ WO5804. 424\ 5.x.2009 malaise N. Veiga $\backslash$ OCYU-NSV:02892' 'Lanthanomelissa $\backslash$ pampicola Urban $\backslash$ det. Roig-Alsina'. Entre Ríos: duas fêmeas'ARGENTINA Entre Rios $\backslash$ Colón \15.X.2006 \A.A. Cocucci' ' sobre \Sisyrinchium $\backslash$ platense'. Tendil: uma fêmea (CCS) 'Lantera 4\ Tandil 21/11/08\ F5'. BRASIL, Rio Grande do Sul: uma fêmea (RPSP), 'RPSP 124218' 'Brasil, RS, Rod. RS-265, $10.5 \mathrm{~km} \backslash \mathrm{SW}$ Pinheiro Machado (linha $\backslash$ férrea) 31 $38^{\prime} 12^{\prime \prime S} 53^{\circ} 27^{\prime} 13^{\prime \prime} \mathrm{W} \backslash$ 05.xi.2012 $\backslash$ E.Almeida \& A.Aguiar'; uma fêmea (UNB), 'UNB 064157' 'Brasil, RS, Caçapava do Sul,\ Estrada para Bagé(BR-153, 39km\ NE Bagé),3052'15"S 53³6'59"W $\backslash 189 m, 01 . x i .2012 \backslash$ E.A.B.Almeida \& A.J.C.Aguiar'; uma fêmea e um macho (UNB), 'UNB 064158' 'Brasil, RS, Caçapava do Sul, Guaritas(BR625),01.xi.2012, $\quad 30^{\circ} 45^{\prime} 36^{\prime \prime} \mathrm{S} \quad$ 5331'26"W， 350m\ E.A.B.Almeida \& A.J.C.Aguiar', mesmos dados exceto 'UNB 064109', '31.x.2012' e '351m'; uma fêmea 
(RPSP), 'RPSP 122879', 'Brasil, Rio Grande do Sul, 35 km S de Caçapava do $\backslash$ Sul, Guaritas 3050'S $\backslash 53^{\circ} 30^{\prime} \mathrm{W}, 270 \mathrm{~m}, 16 . x i .2007 \backslash$ E. A. B. \& J. Almeida".

\section{Lanthanomelissa parva}

Material examinado: ARGENTINA, Santa Fe, Castellanos: uma fêmea (JPT), '4949

'Hymenoptera $\backslash$ Argentina Santa Fe Castellanos $\backslash$ Sunchales sobre Nierembergia $\backslash$ aristata leg. J. P. Torretta de N.H. $\backslash$ Montaldo 17/12/2005'. 


\section{APÊNDICE 2}

Dados de distribuição geográfica das espécies de Lanthanomelissa.

Os dados se referem à latitude e à longitude respectivamente.

\section{Lanthanomelissa betinae}

BRASIL: São Paulo, Ribeirão Grande (-24. 2732222, -48.4227222), Cotia (23.6703059, -47.0870193); Paraná, Araucária (-25.5757263, -49.4556535), Bocaiúva do Sul, Santana (-25.2116181, -49.1191412), Cascavél (-24.955350,-53.457592), Castro (-24.8058555, -50.1527436), Curitiba (-25.429371, -49.266128), Curitiba, Centro Politécnico (-25.4517181, -49.2320914), Guarapuava (-25.3927901, -51.5558719), Leônidas Marques, Salto Caxias (-25.5433281, -53.4988557), Palmeira, Rio dos Papagaios (-25.465108, -49.7698504), Parque Estadual de Campinhos (-25.0372292, 49.0913082), Piraquara, Mananciais da Serra (-25.4674252, -49.1429178), Ponta Grossa, Parque Estadual de Vila Velha (-25.246354, -50.021272), Tijucas do Sul, Vossoroca (-25.8856093, -49.2699514); Santa Catarina, Criciúma (-28.670384, 49.370252), Nova Teutônia (-27.160938, -52.416679), Porto União (-26.235592, 51.080818), Praia Grande (-29.1888381,-49.961028), Santa Rosa (-27.870999, 54.482781), Urubici (-28.0046091, -49.6023925); Rio Grande do Sul, Caçapava do Sul (-30.512781, -53.483451), Cruz Alta (-28.639474, -53.605986), Gramado (29.3795583, -50.9365089), Osório (-29.885392, -50.281648), Pelotas, Santo Amor (31.764788, -52.337722), Porto Alegre, Vila Hanneza (-30.1084987, -51.3169911), Porto Alegre, Morro Santana (-30.1084987, -51.3169911), São Francisco de Paula, PróMata (-29.444088, -50.580609), Triunfo, Capesul (-29.935156, -51.713560).

\section{Lanthanomelissa clementis}

ARGENTINA: Entre Rios, Concordia (-31.386937, -58.026688). BRASIL: São Paulo, Cotia (-23.6703059, -47.0870193); Paraná, Curitiba (-25.429371, -49.266128), Palmeira (-25.465108, -49.7698504), Piraquara, Mananciais da Serra (-25.4674252, - 
49.1429178), Ponta Grossa, Parque estadual de Vila Velha (-25.246354, -50.021272); Santa Catarina, Nova Teutônia (-27.160938, -52.416679); Rio Grande do Sul,

Caçapava do Sul, Pedra do Segredo (-30.512781, -53.483451), Caçapava do Sul, Guaritas (-30.76, -53.523889), Canguçu, Fazenda Sobrado Branco (-31.396459, 52.679347), Canguçu, Morro Redondo (-31.441442, -52.687470), Guaíba (30.1259199, -51.4336669), Pedras Altas (-31.729488, -53.594567), Pelotas, Santo Amor (-31.764788, -52.337722), Pinheiro Machado (-31.575113, -53.380573), Porto Alegre, Campus UFRGS Agronomia (-30.066667, -51.116667), Porto Alegre, Parque Nacional do Morro do Osso (-30.1222175, -51.2369109), São Francisco de Paula, Rincão de Kroeff (-29.4723344, -50.3772709), Viamão (-30.068943, -51.085076).

\section{Lanthanomelissa discrepans}

ARGENTINA: Buenos Aires (-35.998633, -58.145813), Catamarca, Las Chacritas (35.066837, -67.697395), Cordoba, Agua de Ovo (-31.474024, -64.572500), Província Dolores la Cumbre (-31.419855, -64.186802), Buenos Aires, Chacabuco (-34.6384855, -60.5009906), Pampa de Achala (-31.6094444, -64.80946111), Santa Maria (31.553680, -62.428778). Pronunciamento, Campos Seabra, Entre Rios Argentina (32.349702, -58.440937). BRASIL: Paraná, Curitiba (-25.429371, -49.266128), Ponta Grossa, Parque Estadual de Vila Velha (-25.246354, -50.021272); Santa Catarina, Criciúma (-28.670384, -49.370252), Maracajá, Parque Ecológico (-28.879637, 49.466983); Rio Grande do Sul, Bagé, Palmas (-30.983333, -53.616667), Bagé, Rincão do Inferno (-30.868046, -53.708925), Caçapava do Sul (-30.512781, -53. 483451), Candiota, Chácara da Hortec (-31.621729, -53.806010), Canguçu (31.396459, 52.679347), Montenegro (-29.682464, -51.466859), Pedras Altas (31.729488, -53.594567), Pelotas, Santo Amor (-31.764788, -52.337722), Pinheiro Machado (-31.575113, -53.380573), São Francisco de Paula, Pró-Mata (-29.444088, 50.580609), Uruguaiana, Barra do Quaraí (-30.207029, -57.543749), Viamão, Morro do Coco (-30.269872, -51.063294), Quaraí, Passo da Guarda (-30.294211, -55.974990), PARAGUAI: Hayes, Vila Hayes (-25.090984, -57.528440). 
Lanthanomelissa magaliae

BRASIL: Santa Catarina, Criciúma (-28.670384, 49.370252), Criciúma, Campus da UNESC (-28.701298, -49.408306), Içara (-28.713883, -49.309405); Rio Grande do Sul, Bagé, Palmas (-30.983333, -53.616667), Caçapava do Sul (-30.512781, -53. 483451), Caçapava do Sul, Guaritas (-30.76, -53.523889), Candiota, Chácara da Hortec (-31.621729, -53.806010), Esteio (-29.8508813, -51.2014493), Pinheiro Machado (31.575113, -53.380573), Santana do Livramento (-30.873056, -55.528333), Viamão, Morro do Coco (-30.269872, -51.063294), Quaraí (-30.3845087, -56.4509973).

Lanthanomelissa pampicola

ARGENTINA: Buenos Aires (-35.998633, -58.145813), Corrientes, Parque Nacional Mburucuya (-28.035259, -58.098536), Sta. Tella (-27.589734, -56.691641). Entre

Ríos, Colón (-32.222347, -58.141675), Tandil (-37.3162472, -59.149452777).

BRASIL: Rio Grande do Sul, Bagé, Palmas (-30.983333, -53.616667), Caçapava do Sul (-30.512781, -53.483451), Caçapava do Sul, Guaritas (-30.833333, -53.5), Caçapava do Sul, Minas de Camaquã (-30.8997766, -53.4310791), Pinheiro Machado ($31.575113,-53.380573)$.

\section{Lanthanomelissa parva}

ARGENTINA: Catamarca: El Alto (-28.3122859, -65.3709523). Córdoba: Barrio Chateau Cerrera (?), Ciudad Universitaria (-31.4374121, -64.1911629), Carlos Paz (31.4120474, -64.569772), Villa del Rosario (-31.5587481, -63.5490552), San Roque (?), El Sauce (?), Jesús Maria (-30.984361, -64.1097211), Villa María (-32.4191364, 63.2742394), Alta Gracia (-31.6560451, -64.4770212), Córdoba (-31.3990508, 64.3344304), Dean Funes (-30.425145, -64.3742836), Río Segundo (-31.6486602, 63.9221428), Río Tercero (-32.1705334, -64.1583661). Salta: Rosario de la Frontera (25.7943816, -64.9880872), Santa Fe: Castellanos (-31.087007, -61.638816). Tucumán: Tacanas (-27.1369382, -64.8134214), Trancas (-26.230363, -65.289668), 
Tucumán (-26.8326885, -65.2926343), Tapia (-26.5943399, -65.288174). Entre Ríos:

Feliciano (-31.3668723, -58.0310435). 